\title{
ॠUSGS
}

science for a changing world

\section{Response Plan for Volcano Hazards in the Long Valley Caldera and Mono Craters Region, California}

Bulletin 2185

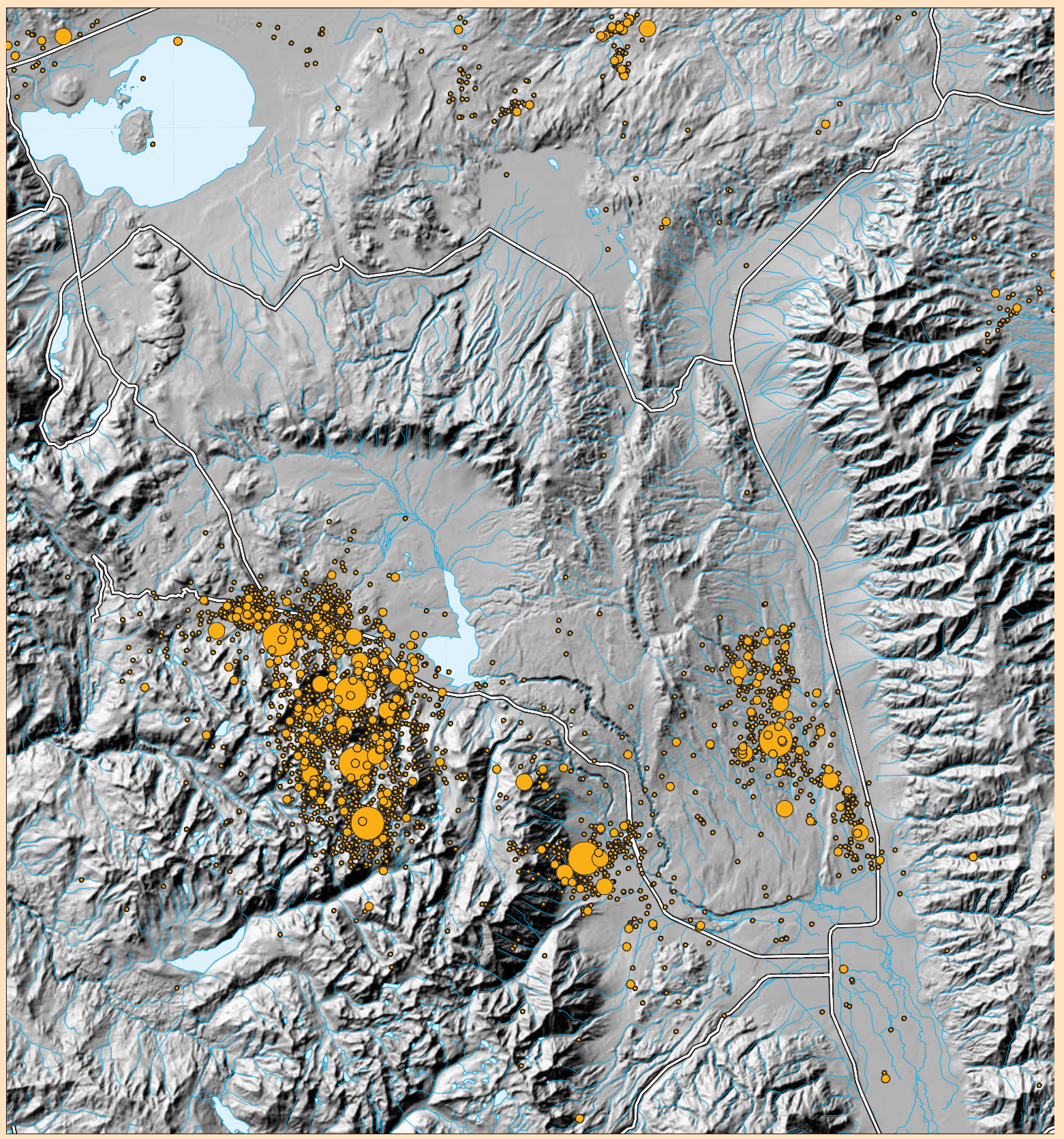

U.S. Department of the Interior

U.S. Geological Survey 


\section{Response Plan for Volcano Hazards in the Long Valley Caldera and Mono Craters Region California}

By David P. Hill, Dan Dzurisin, William L. Ellsworth, Elliot T. Endo, D.L. Galloway, Terry M. Gerlach, Malcolm J.S.. Johnston, John Langbein, Ken A. McGee, C. Dan Miller, David Oppenheimer, and Michael L. Sorey

Bulletin 2185

Prepared in cooperation with:

California Department of Conservation, Division of Mines and Geology

Mono County Office of Emergency Services

Mammoth Mountain Ski Area

Mammoth Community Water District

Town of Mammoth Lakes

U.S. Forest Service 


\title{
U.S. Department of the Interior \\ Gale A. Norton, Secretary
}

\author{
U.S. Geological Survey \\ Charles G. Groat, Director
}

\begin{abstract}
Any use of trade, product, or firm names in this publication is for descriptive purposes only and does not imply endorsement by the U.S. Government.
\end{abstract}

United States Government Printing Office: 2002

For additional copies please contact:

USGS Information Services

Box 25286

Denver, CO 80225

This report and any updates to it are available online at http://geopubs.wr.usgs.gov/bulletin/b2185/

Additional USGS publications can be found online at http://geology.usgs.gov/products.html

For more information about the USGS and its products:

Telephone: 1-888-ASK-USGS

World Wide Web: http://www.usgs.gov/

ISBN 0-607-98488-0

Cataloging-in-Publication data

is on file with the Library of Congress

Text edited by James W. Hendley II Layout and design by Stephen L. Scott Published in the Western Region, Menlo Park, California Manuscript approved for publication, September 24, 2001 


\section{CONTENTS}

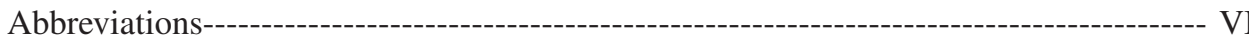

Summary--------------------------- 1

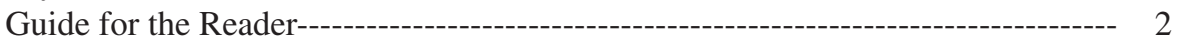

I. Introduction------------------------------------------------------------------------------ 2

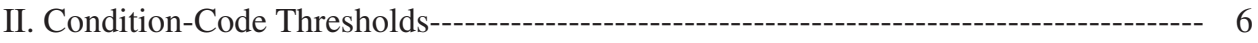

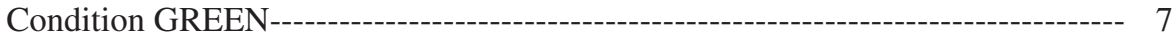

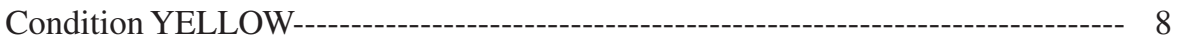

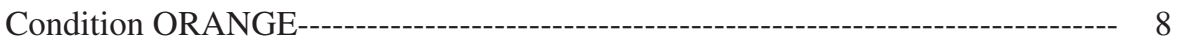

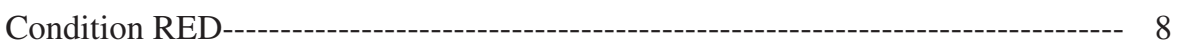

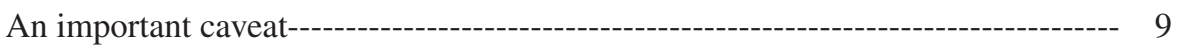

Standdown criteria--

III. Organization and Response--- 10

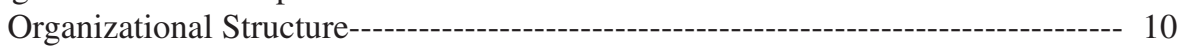

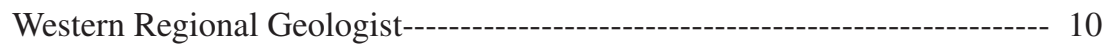

Chief Scientist, Volcano Hazards Team---_---o 10

Scientist-in-Charge, Long Valley Observatory--------------------------- 11

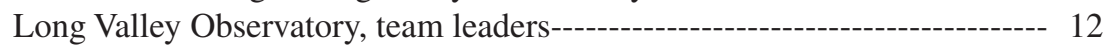

Monitoring Team Leader----on 12

Hazards Assessment Team Leader----------------------------------- 13

Support Team Leader----------------------------------------------- 13

Scientific Advisory Team-------------------------------------- 13

Associate Scientist-in-Charge------------------------------------- 13

Response and General Operational Procedures----------------------------- 13

(1) Condition GREEN Advisory Calls---_- 13

(2) Condition YELLOW: Declaration of EVENT RESPONSE------------ 14

(3) Condition ORANGE: Declaration of GEOLOGIC HAZARD WARNING------ 14

(4) Condition RED: Continuation of EVENT RESPONSE and update of GEOLOGIC HAZARD WARNING--- 15

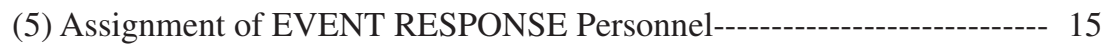

(6) Establishment of a Field Center---_- 15

(7) Field Operations and Communications------------------------------ 15

(8) Change of Field Centers---- 16

(9) Deactivation----on 16

Coordination Among USGS Disciplines---------------------------------------- 16

References Cited----------------- 16

Appendix A. History of Volcanism in the Long Valley Region---------------------- 21

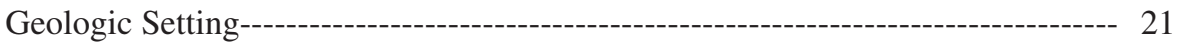

Recent Unrest: 1978-2000--- 24

Increasing Unrest: 1978-83---------- 27

Slowing Caldera Unrest and Regional Earthquake Activity: 1984-88------- 28

The 1989 Mammoth Mountain Swarm, Long-Period (LP) Earthquakes, and $\mathrm{CO}_{2}$ Emissions-------------------------------------------- 28

Unrest Returns to the Caldera: 1990-95------on 28

The March-April 1996 South-Moat Earthquake Swarm------------------ 29

Strong Caldera Unrest: 1997 to Mid-1998---------------------------- 29

Caldera Quiescence and M>5 Earthquakes in the Sierra Nevada Block: Mid-1998 to 1999----------- 31

Sources of 1989-99 Unrest----on 31

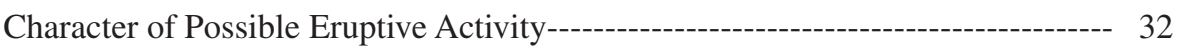

Eruptions of Rhyolitic (Silicic) Magma---_- 32

Eruptions of Basaltic (Mafic) Magma---_--- 33 


\section{CONTENTS}

Appendix B. USGS Terminology for Geologic Hazard Warnings------------------------ 33

Current Hazard Warnings-------------------------------------------------- 33

Hazard Warnings Prior to 1983----------------------------------------- 33

Appendix C. Scientific Rationale for Activity Criteria Under Color Codes--------------- 33

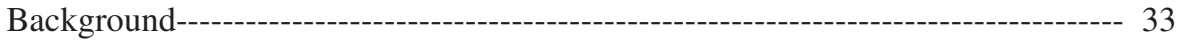

Seismic Criteria-------------- 34

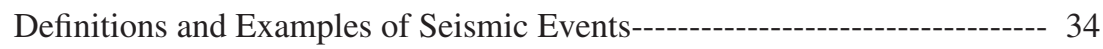

High-frequency Earthquakes and Spasmodic Bursts------------------- 34

Earthquakes Generated by Fluid-Dynamic Processes (Volcanic

Earthquakes)------- 35

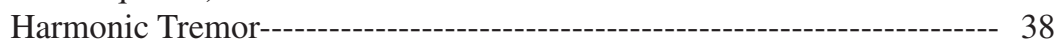

Earthquakes Intermediate in Character---------------------- 38

Using spectrograms to distinguish earthquake types--------------------- 39

Application to Seismic Status---------------------------------------- 41

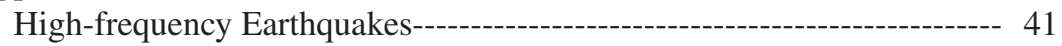

Volcanic Earthquakes------------------------------------------------ 41

Deformation Criteria---------------------------------------------------- 42

Gases and Geochemical criteria--------- 43

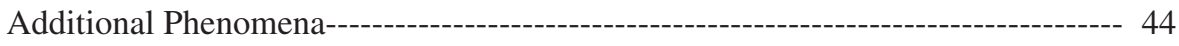

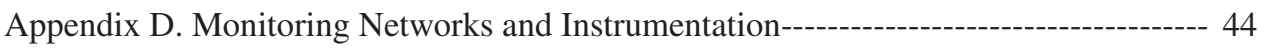

Seismic Network---- 44

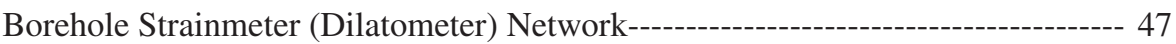

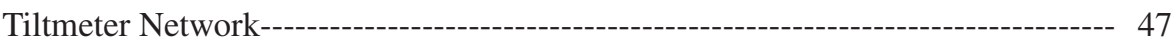

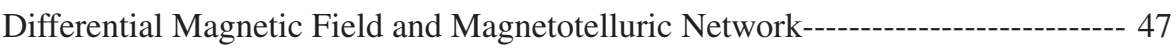

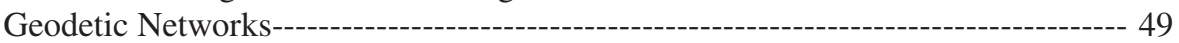

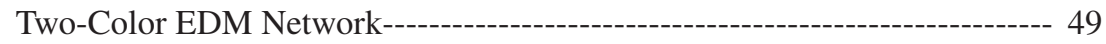

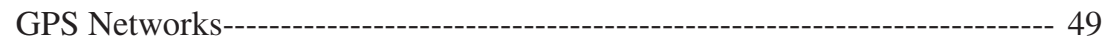

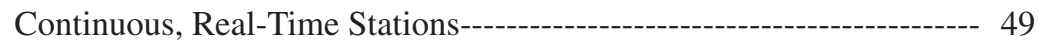

Regional Geodetic Networks---------------------------------- 49

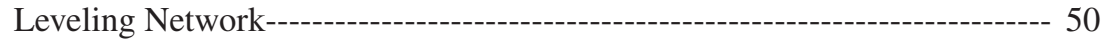

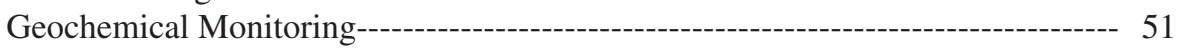

$\mathrm{CO}_{2}$-Soil-Gas Concentrations---------------------------------------------- 51

$\mathrm{CO}_{2}$-Flux Monitoring--------------------------------------------------- 54

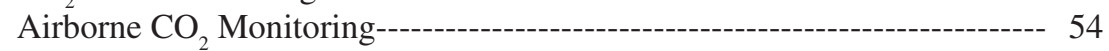

Helium Isotopic Ration in Fumarole Gas-----_--- 54

Hydrologic Monitoring--- 54

Appendix E. Sample Messages Accompanying Change in Color Code----------------- 55

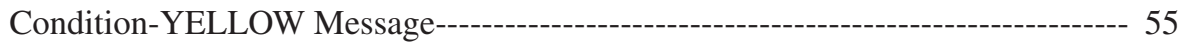

Condition-ORANGE Message---_---_-_- 55

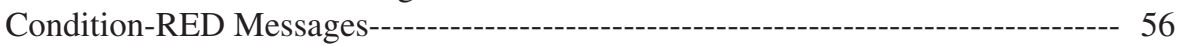

Example for Eruption Onset------------------------------------------------- 56

Example for Ongoing Eruption----------------------------- 56

Appendix F. Memo Defining the Role of the Long Valley Observatory

Scientist-in-Charge Under an EVENT RESPONSE--------------------------- 57

\section{FIGURES}

1. Shaded relief map of the Long Valley Caldera-Mono Craters region showing epicenters of magnitude $(\mathrm{M}) \geq 3$ earthquakes for 1978 through 1999

3. Organizational structure for the Long Valley Observatory under normal (noncrisis) operation (condition GREEN)-

4. Organizational structure for the Long Valley Observatory under an EVENT RESPONSE

(conditions YELLOW, ORANGE, or RED)- 


\section{CONTENTS}

\section{FIGURES}

5. U.S. Geological Survey calldown structure for an EVENT RESPONSE------ 14

A1. Simplified geologic map for Long Valley Caldera and the Mono-Inyo volcanic chain--------- 21

A2. Eruptive history for the Mono-Inyo Craters volcanic chain for the past 5,000 years------------------ 22

A3. Seismicity map for magnitude $\geq 2.0$ earthquakes in the Long Valley Caldera and Mono-Inyo Craters region for period 1978 through 1999

A4. History of earthquake activity and swelling of Long Valley's resurgent dome from 1978 through 19991

A5. A, Seismicity patterns in Long Valley Caldera and the adjacent Sierra Nevada block defined by magnitude $\geq 1.5$ earthquakes from 1978 through 1999. B, Dominant seismicity clusters for the same period along with selected landmarks in the area---

A6. Seismicity patterns in the Long Valley region for the six time intervals identified in figure A4----------------- 26

A7. Map showing locations of recognized sources contributing to the 1978-99 unrest in Long Valley Caldera and vicinity-

C1. Examples of seismograms recorded on Mammoth Mountain station MMPM for a typical high-frequency (volcano-tectonic earthquake with a magnitude 1.1 and the onset of a spasmodic burst -

C2. Seismograms of deep, long-period earthquakes beneath Mammoth Mountain as recorded on the station MDCM-

C3. Seismograms of the August 13, 2000 very-long-period earthquake beneath Mammoth Mountain--------------

C4. Example of seismogram showing weak harmonic tremor along with long-period and high-frequency earthquakes recorded on Nevada del Ruiz Volcano, Colombia--

C5. Examples of spectrograms illustrating the distinctive signatures of high-frequency (volcano-tectonic) earthquakes and harmonic tremor in the time-frequency domain-26

C6. Theoretical deformation profiles for an intruding dike in an elastic half space-

D1. Chaotic breccia developed between two basalt flows along road to repeater station----

D2. View of Wildhorse Lake from overlook---

D3. View to the south into Big Indian Gorge---

D4. View to the west looking down the Steens Mountain Loop Road at east (upper) end of The Rooster Comb-

D6. Itregup of weathered Steens Basalt at the east end of The Rooster Comb--- 51

D7. View to the northeast up Little Blitzen Gorge from vicinity of the west end of The Rooster Comb--- 53

\section{TABLES}

1. Summary of Color-Code conditions and associated U.S. Geological Survey responses for volcanic unrest in Long Valley Caldera and the Mono-Inyo Craters region-

2. Color-Code conditions for increasing levels of volcanic unrest in Long Valley Caldera and the Mono-Inyo Craters region and the attendant U.S. Geological Survey response--

3. Standdown rules for Color-Code conditions under declining activity levels---

C1. Criteria for deformation and stain rates for Color-Code conditions under table- 


\section{ABBREVIATIONS}

ASIC, Associate Scientist in Charge

$\mathrm{BB}$, broadband

Caltech, California Institute of Technology

CDMG, California Division of Mines and Geology

CEPEC, California Earthquake Prediction and Evaluation Council

CL-MM, Convict Lake-Mount Morrison

$\mathrm{CO}_{2}$, carbon dioxide

COSPEC, correlation spectrometer

CVO, Cascades Volcano Observatory

DLP, deep long-period

DOI OAS, Department of Interior Office of Aircraft Services

DSIC, Deputy Scientist in Charge

EDM, electronic distance meter

EHZ, Earthquake Hazards Team

FAA, Federal Aviation Administration

FTP, file transfer protocol

$\mathrm{f}$, frequency

fc, corner frequency

GIS, geographical information system

GOES, Geostationary Operational Environmental Satellite

GPS, Global Positioning System

HC-DR, Hot Creek-Doe Ridge

HCF, Hilton Creek Fault

${ }^{3} \mathrm{He} /{ }^{4} \mathrm{He}$, helium-3/helium-4 isotopic ratio

HF, high-frequency

Hqrts, headquarters

HSF, Hartley Springs Fault

IPG, Institut de Physique du Globe, Paris

LC, Laurel Creek

LP, long period

LVC, Long Valley Caldera

LVC/MC, Long Valley Caldera-Mono Craters

LVO, Long Valley Observatory

$\mathrm{M}$, magnitude
MC, McGee Creek

ML, Mammoth Lakes

MM, Mammoth Mountain

NCSN, Northern California Seismic Network

NDIR, nondispersive infrared

nT, nanotesla

OES, Office of Emergency Services

PC, Program Coordinator

PDT, Pacific Daylight Time

PIO, Public Information Officer

ppm, parts per million

PST, Pacific Standard Time

RSAM, real-time seismic amplitude measurement system

RTK, real-time kinematic

RTP, real-time processing system

SE-RD, southeast resurgent dome

SIC, Scientist in Charge

SMSZ, south-moat seismic zone

$\mathrm{SO} 2$, sulfur dioxide

SW-RD, southwest resurgent dome

TCS, Team Chief Scientist

TF, Tobacco Flat

TL, Team Leader

TP, Tom's Place

UNR, University of Nevada, Reno

USFS, U.S. Forest Service

USGS, U.S. Geological Survey

WC-RVF, Wheeler Crest-Round Valley Fault

WRG, Western Regional Geologist

VCO, voltage-controlled oscillator

VEI, Volcanic Explosivity Index

VHZ, Volcano Hazards Team

VLP, very long period

VT, volcano tectonic 


\title{
Response Plan for Volcano Hazards in the Long Valley Caldera and Mono Craters Region, California
}

\author{
By David P. Hill, Dan Dzurisin, William L. Ellsworth, Elliot T. Endo, D.L. Galloway, Terry M. Gerlach, \\ Malcolm J.S. Johnston, John Langbein, Ken A. McGee, C. Dan Miller, David Oppenheimer, and \\ Michael L. Sorey
}

\section{Summary}

Persistent unrest in Long Valley Caldera-characterized by recurring earthquake swarms, inflation of the resurgent dome in the central sections of the caldera, and emissions of magmatic carbon dioxide around Mammoth Mountain-during the last two decades and continuing into the 21 st century emphasize that this geologically youthful volcanic system is capable of further volcanic activity. This document describes the U.S. Geological Survey's (USGS) response plan for future episodes of unrest that might augur the onset of renewed volcanism in the caldera or along the Inyo-Mono Craters chain to the north. Central to this response plan is a four-level color code with successive conditions, GREEN (no immediate risk) through RED (eruption under way), reflecting progressively more intense activity levels as summarized in table 1 and 2 and described in detail in section II.

Key response activities specified under this plan include:

- Condition GREEN (background activity through strong unrest) involves informal information calls to scientists and officials within the USGS and to the California Office of Emergency Services (OES), the U.S. Forest Service (USFS), county, and city authorities regarding the nature of the activity and the associated condition as the level of activity increases through the four sub-categories under condition GREEN.

- Conditions YELLOW (intense unrest) and higher require the additional commitment of USGS resources and personnel. A condition YELLOW will trigger an EVENT RESPONSE (WATCH), which includes the following: (1) a formal notification (calldown) to all agencies affected, (2) activation of the USGS Long Valley Observatory (LVO) field office, which is located in the Mammoth Community Water District facility in Mammoth Lakes, as a base for intensified on-site monitoring and observation, and (3) assignment of authority to the USGS Scientist-in-Charge (SIC) for LVO to direct all USGS personnel engaged in the response. Section III describes the organization of LVO within the USGS and the LVO operational procedures for LVO.

- Condition ORANGE (WARNING) will be initiated when the geophysical data suggest that an eruption may break out within a few hours to days. Notification procedures are the same as those for condition YELLOW. A condition ORANGE will initiate the process for a formal GEOLOGIC HAZARD WARNING issued by the Director of the USGS.
- Condition RED will be triggered by the onset of eruptive activity, either in the form of phreatic (steamblast) or magmatic eruptions. Notification procedures for condition RED will be the same as those for condition ORANGE.

- STANDDOWN criteria specify a schedule for terminating a given condition after activity has fallen below the threshold for that condition level (see table 3 in section II).

(Draft templates for messages to announce transition to Conditions YELLOW, ORANGE, and RED appear in Appendix E.)

The nature and intensity of activity determining a condition level (color code) are based on recent activity within Long Valley Caldera since 1978, as summarized in Appendix A, plus well-documented case histories of precursory activity to volcanic eruptions elsewhere in the world. Although such information provides an invaluable basis for judging whether activity may lead to an eruption, it is not sufficient in itself to support robust probabilistic calculations that activity associated with a given color-code will culminate in an eruption. Thus, lacking a record of precursory activity to earlier eruptions from the Long Valley Caldera-Mono Craters (LVC/MC) system (the most recent of which occurred about 250 years ago), we do not attempt to assign numerical probabilities that the activity associated with a given color code will lead to an eruption. In this regard, it is important to recognize that the criteria governing the transition between the above Conditions as spelled out in section II serve as guidelines only. Personal judgment and experience will inevitably play a critical role in decisions on the transition from one color-code to the next. Final decisions on color-code transitions rest solely with the LVO SIC in consultation with other scientists involved in the response, the LVO Science Advisory Team, and the USGS Volcano Hazards Team Chief Scientist (see section III).

The data that provide the basis for monitoring activity levels in Long Valley Caldera and vicinity derive from a system of geophysical, geochemical, and hydrological instrumentation networks that first became operational in mid-1982. As described in appendix D, the data from most of the installed instrumentation in these networks are telemetered to computers in USGS offices in Menlo Park, California, the LVO field office in Mammoth Lakes, California, and the USGS Cascades Volcano Observatory (CVO) in Vancouver, Washington, for automatic, real-time processing and immedi- 
Table 1.-Summary of Color-Code Conditions and associated U.S. Geological Survey (USGS) responses for volcanic unrest in Long Valley Caldera and the Mono-Inyo Craters region. See table 2 for details; see figure 5 for calldown structure.

\begin{tabular}{|c|c|c|c|}
\hline CONDITION & USGS RESPONSE $^{1}$ & ACTIVITY LEVEL & RECURRENCE INTERVALS $^{2}$ \\
\hline \multirow{4}{*}{$\begin{array}{l}\text { GREEN - No } \\
\text { immediate risk }\end{array}$} & \multirow{4}{*}{$\begin{array}{l}\text { Normal operations plus } \\
\text { information calls to } \\
\text { local and other } \\
\text { authorities for weak } \\
\text { through strong unrest as } \\
\text { appropriate }\end{array}$} & Background or quiescence & Most of the time \\
\hline & & Weak Unrest & Days to weeks \\
\hline & & Minor Unrest & Weeks to months \\
\hline & & Moderate-to-Strong Unrest & Months to years \\
\hline $\begin{array}{l}\text { YELLOW } \\
\text { (WATCH) }\end{array}$ & $\begin{array}{l}\text { Full calldown and } \\
\text { EVENT RESPONSE }\end{array}$ & Intense Unrest & Years to decades \\
\hline $\begin{array}{l}\text { ORANGE } \\
\text { (WARNING) }\end{array}$ & $\begin{array}{l}\text { Full calldown and } \\
\text { EVENT RESPONSE } \\
\text { (if not already in place } \\
\text { under YELLOW) }\end{array}$ & $\begin{array}{l}\text { Accelerating intense unrest: } \\
\text { eruption likely within hours } \\
\text { to days }\end{array}$ & Decades to centuries \\
\hline \multirow[t]{4}{*}{$\begin{array}{l}\text { RED (ERUPTION } \\
\text { IN PROGRESS) }\end{array}$} & \multirow{4}{*}{$\begin{array}{l}\text { Full calldown and } \\
\text { EVENT RESPONSE } \\
\text { (if not already in place } \\
\text { under YELLOW or } \\
\text { ORANGE) } \\
\text { Daily or more frequent } \\
\text { updates on eruption } \\
\text { levels }\end{array}$} & LEVEL 1: Minor eruption & Centuries \\
\hline & & $\begin{array}{l}\text { LEVEL 2: Moderate } \\
\text { explosive eruption }\end{array}$ & Centuries \\
\hline & & $\begin{array}{l}\text { LEVEL 3: Strong explosive } \\
\text { eruption }\end{array}$ & Centuries \\
\hline & & $\begin{array}{l}\text { LEVEL 4: Massive } \\
\text { explosive eruption }\end{array}$ & Centuries to millennia \\
\hline
\end{tabular}

1 USGS response for a given condition will include the responses specified for all lower conditions.

${ }^{2}$ Estimated recurrence intervals for a given condition are based primarily on the recurrence of episodes of unrest in Long Valley Caldera since 1980 , the record of $M>4$ earthquake activity in the region since the 1930's, and the geologic record of volcanic eruptions in the region over the past 5,000 years.

ate analysis. Thresholds for specific activity levels are programmed into these computers to send round-the-clock pages to the LVO Scientist-in-Charge and others with monitoring responsibilities.

\section{Guide for the Reader}

- Those wishing to skip the technical and scientific details in this document should focus on the Introduction (section I), the first six headings under Condition code thresholds (section II), and the section on Organization and response (section III). For a description of the type of activity to expect if an eruption does occur, see the heading "Character of Possible Eruptive Activity" under Appendix A.

- Those interested in the scientific and technical background may wish to read appendix A for a summary of the geologic setting and the activity in the area since 1978. The Appendices contain discussions of additional technical issues, including the scientific rationale behind the color-code transition criteria and descriptions and examples of various types of earthquakes commonly recorded in volcanic areas (appendix $\mathrm{C}$ ).

- Additional information on the Long Valley Caldera and the Mono-Inyo Craters volcanic system and its current activity is available through the LVO web page at http://lvo.wr.usgs.gov.

\section{Introduction}

Long Valley Caldera and the Mono-Inyo volcanic chain in eastern California form one of several geologically youthful volcanic systems in California that pose potential hazards to nearby population centers from future volcanic eruptions 
Table 2.-Color-Code conditions for increasing levels of volcanic unrest in Long Valley Caldera and the Mono-Inyo Craters region and the attendant U.S. Geological Survey (USGS) response. See figure 5 for calldown structure. LP, long period; VLP very long period; RSAM real-time seismic amplitude measurement; M, magnitude; LVO, Long Valley Observatory.

\section{CONDITION GREEN — No Immediate Risk}

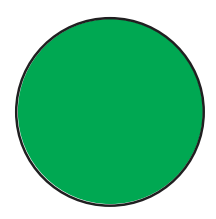

\begin{tabular}{|c|c|c|}
\hline $\begin{array}{l}\text { ACTIVITY } \\
\text { LEVEL }\end{array}$ & GEOLOGIC BEHAVIOR & USGS RESPONSE \\
\hline $\begin{array}{l}\text { Background or } \\
\text { Quiescence }\end{array}$ & $\begin{array}{l}\text { Background typically includes several } \mathrm{M} \sim 2 \\
\text { earthquakes/day with } 10-20 \text { smaller events and } \\
\mathrm{CO}_{2} \text { emissons at Mammoth } \mathrm{Mtn}<500 \text { t/day }\end{array}$ & Normal operations \\
\hline Weak Unrest & $\begin{array}{l}\text { Any of the following with strain rates }<0.1 \mathrm{ppm} / \text { day or } \\
\text { displacements }<1 \mathrm{~mm} / \text { week and } \mathrm{CO}_{2} \text { emissions }<500 \\
\text { t/day } \\
\text { - At least } 1 \mathrm{M} \geq 3 \text { earthquake/day (may be locally felt), } 5 \\
\mathrm{M} \geq 2 \text { earthquakes/day, or } 30 \mathrm{M} \geq 1 \text { earthquakes/day. } \\
\text { - A swarm with }>20 \mathrm{M} \geq 1 \text { earthquakes/hr } \\
\text { - Sudden onset of seismicity in a new area }\end{array}$ & $\begin{array}{l}\text { Discretionary information calls to } \\
\text { project scientists and or local } \\
\text { authorities as appropriate }\end{array}$ \\
\hline Minor Unrest & $\begin{array}{l}\text { Any of the following with strain rates }<0.1 \mathrm{ppm} / \text { day or } \\
\text { disiplacements }<1 \mathrm{~mm} / \text { week and } \mathrm{CO}_{2} \text { emissions }<500 \\
\text { tons/day } \\
\text { - A swarm and at least } 1 \mathrm{M} \geq 3.5 \text { earthquake/day, } 5 \mathrm{M} \geq 2.5 \\
\text { earthquakes/day, or } 30 \mathrm{M} \geq 1.5 \text { earthquakes/day } \\
\text { - More than } 20 \mathrm{M} \geq 1 \text { earthquakes/hr for }>3 \mathrm{hrs} \\
\text { - More than } 100 \mathrm{M} \geq 1 \text { earthquakes/day }\end{array}$ & $\begin{array}{l}\text { Information calls to project } \\
\text { scientists and discretionary } \\
\text { information calls to local } \\
\text { authorities as appropriate. }\end{array}$ \\
\hline $\begin{array}{l}\text { Moderate-to-Strong } \\
\text { Unrest }\end{array}$ & $\begin{array}{l}\text { Any combination of the following: } \\
\text { - A swarm and at least } 1 \mathrm{M} \geq 4 \text { earthquake/day, } 5 \\
\mathrm{M} \geq 3 \text { earthquakes/day, or } 30 \mathrm{M} \geq 2 \text { earthquakes/day } \\
\text { - } 500 \mathrm{M} \geq 1 \text { earthquakes /day (avg. }>20 \mathrm{M} \geq 1 \\
\text { earthquakes } / \mathrm{hr} \text { for } 24 \text { hrs) } \\
\text { - } 5 \text { shallow }(<5 \mathrm{~km}) \text { LP earthquakes /day } \\
\text { - } 5 \text { shallow }(<5 \mathrm{~km}) \mathrm{VLP} \text { earthquakes /day } \\
\text { - } 5 \text { minutes of shallow }(<5 \mathrm{~km}) \text { harmonic tremor } \\
\text { with RSAM amplitudes }>50 \text { on }>2 \text { stations } \\
\text { - Strains }>0.1 \mathrm{ppm} / \text { day or displacements }>5 \\
\text { mm/week } \\
\text { - } \mathrm{CO}_{2} \text { emissons }>500 \text { tons/day }\end{array}$ & $\begin{array}{l}\text { Information calls to project } \\
\text { scientists, California Office of } \\
\text { Emergency Services (OES) and } \\
\text { local authorities. } \\
\text { A heads-up calldown if } \\
\text { increasing activity rates approach } \\
\text { the criteria for condition } \\
\text { YELLOW (see below). }\end{array}$ \\
\hline
\end{tabular}

(Miller, 1989). The recurring earthquake swarms and episodes of ground uplift (particularly the uplift centered on Long Valley Caldera's resurgent dome) that dominated the geologic unrest in Long Valley Caldera through the 1980's and 1990's (see figs. 1, 2 and appendix A) emphasize that this large silicic magmatic system is still active and capable of producing volcanic eruptions (Bailey and Hill, 1990; Farrar and others, 1995; Hill, 1996; Hill, Bailey, and Ryall, 1985a; Hill, Wallace, and Cockerham, 1985b; Langbein and others, 1993; McGee and Gerlach, 1998; Rundle and Hill, 1988; Sorey and others, 1998). This document outlines USGS plans for responding to future episodes of unrest and onset of possible volcanic activity in the vicinity of the caldera and the Mono-Inyo volcanic chain. It updates and supersedes Open-File Reports 84-500
(U.S. Geological Survey, 1984) and 91-270 (Hill and others, 1991).

Sections II and III form the core of this document. Section II defines a four-level condition-code tied to successively more intense levels of geologic unrest detected on networks that monitor seismic activity, ground deformation, and stress-induced variations in the magnetic field intensity. Section III outlines the USGS's response to various levels of unrest and the corresponding color-code condition.

The four-level color-code conditions (tables 1 and 2) were developed in collaboration with Mono County, the Town of Mammoth Lakes, the California Earthquake Prediction Evaluation Council (CEPEC) and the California Division of Mines and Geology (CDMG). It was formally adopted in 
Table 2.-Coontinued.

\begin{tabular}{|c|c|c|}
\hline \multicolumn{3}{|c|}{ CONDITION YELLOW (WATCH) } \\
\hline $\begin{array}{l}\text { ACTIVITY } \\
\text { LEVEL }\end{array}$ & GEOLOGIC BEHAVIOR & USGS RESPONSE \\
\hline Intense Unrest & $\begin{array}{l}\text { A swarm and } \geq 1 \mathrm{M} \geq 5,>5 \mathrm{M} \geq 4 \text {, or }>30 \mathrm{M} \geq 3 \text { events/day } \\
\text { OR } \\
\text { Average strain rates of }>1 \mathrm{ppm} / \text { day or displacements of } \\
>5 \mathrm{~mm} / \text { day on } 3 \text { or more instruments sustained for }>48 \\
\text { hrs } \\
\text { AND any of the following: } \\
\text { - A swarm with }>60 \mathrm{M} \geq 1 \text { earthquakes } / \mathrm{hr} \text { for }>8 \mathrm{hrs} \text { or } \\
\quad>500 \text { earthquakes } / 8 \mathrm{hrs} \\
\text { - A swarm with }>1000 \mathrm{M} \geq 1 \text { earthquakes } / \text { day (avg }>40 \\
\quad \text { earthquakes } / \mathrm{hr} \text { for } 24 \mathrm{hrs)} \\
\text { - Shallow }(<5 \mathrm{~km}) \text { harmonic tremor with duration }> \\
\quad 10 \text { minutes and } \mathrm{RSAM} \text { amplitudes }>50 \text { on }>2 \\
\text { stations } \\
\text { - }>5 \text { shallow }(<5 \mathrm{~km}) \mathrm{M} \geq 1 \mathrm{LP} \text { earthquakes } / \mathrm{hr} \text { for }> \\
\quad 4 \text { hrs. } \\
\text { - }>5-10 \text { shallow }(<5 \mathrm{~km}) \mathrm{VLP} \text { earthquakes } / \text { day } \\
\text { - Sustained } \mathrm{CO}_{2} \text { emission rates }>1,000 \mathrm{t} / \text { day } \\
\text { AND } / \mathrm{OR} \mathrm{SO}_{2} \text { emission rates }>100 \mathrm{t} / \text { day }\end{array}$ & $\begin{array}{l}\text { Calldown notification of change to } \\
\text { condition YELLOW } \\
\text { EVENT RESPONSE } \\
\text { - Implement LVO EVENT } \\
\text { RESPONSE structure } \\
\text { (Figure 10) } \\
\text { - Establish LVO field office } \\
\text { in Mammoth Lakes } \\
\text { - Establish LVO backup field } \\
\text { office in Bridgeport } \\
\text { A heads-up calldown if activity } \\
\text { looks as though it is rapidly evolving } \\
\text { toward a condition ORANGE }\end{array}$ \\
\hline \multicolumn{3}{|c|}{ CONDITION ORANGE (WARNING) } \\
\hline $\begin{array}{l}\text { ACTIVITY } \\
\text { LEVEL }\end{array}$ & GEOLOGIC BEHAVIOR & USGS RESPONSE \\
\hline $\begin{array}{l}\text { Accelerating } \\
\text { Intense Unrest: } \\
\text { ERUPTION } \\
\text { LIKELY within } \\
\text { hours to days }\end{array}$ & $\begin{array}{l}\text { Average strain rates of }>10 \mathrm{ppm} / \text { day or displacements of } \\
>50 \mathrm{~mm} / \text { day on } 3 \text { or more sustained for } 24 \text { hours } \\
\text { AND any of the following: } \\
\text { - }>10 \text { shallow }(<5 \mathrm{~km}) \mathrm{LP} \text { earthquakes } / \mathrm{hr} \text { for }> \\
3 \text { hrs. } \\
\text { - Tens of shallow }(<5 \mathrm{~km}) \text { VLP earthquakes per day } \\
\text { - Shallow }(<5 \mathrm{~km}) \text { harmonic tremor with duration } \\
>1 \mathrm{hr} \text { and RSAM amplitudes }>100 \text { on }>2 \\
\text { stations } \\
\text { - A swarm with }>15 \mathrm{M}>2.5 \text { earthquakes } / \mathrm{hr} \\
\text { sustained for }>6 \mathrm{hrs}(\text { locally felt earthquakes } \\
\text { every } 4 \text { to } 5 \text { minutes }) \\
\text { - Sustained } \mathrm{CO}_{2} \text { emission rates }>10,000 \mathrm{t} / \text { day } \\
\text { AND } / \mathrm{OR} \mathrm{SO}_{2} \text { emission rates }>1,000 \mathrm{t} / \text { day }\end{array}$ & $\begin{array}{l}\text { Calldown notification of change to } \\
\text { condition ORANGE. } \\
\text { EVENT RESPONSE (If not already } \\
\text { in effect under condition YELLOW) } \\
\text { - Implement LVO EVENT } \\
\text { RESPONSE structure } \\
\text { (Figure 10) } \\
\text { - Establish LVO field office } \\
\text { in Mammoth Lakes } \\
\text { - Establish LVO backup field } \\
\text { office in Bridgeport }\end{array}$ \\
\hline
\end{tabular}

June 1997 in an effort to simplify and clarify the five-level, alphabetic (E through A), status system initially adopted in 1991 and described in Open File Report 91-270 (Hill and others, 1991). The alphabetic system, which was based on a similar scheme developed for the Parkfield earthquake prediction experiment (Bakun, and others, 1987), was abandoned after experience showed that it was prone to misinterpretation by both the media and the public when applied to volcanic unrest in Long Valley Caldera (Hill, 1998).

The color-code system through condition ORANGE is based on activity levels and rates for premonitory activity commonly observed prior to the onset of a volcanic eruption. Once underway, however, volcanic eruptions commonly show a wide range of behavior involving multiple eruptive phases that may 


\section{CONDITION RED (ERUPTION IN PROGRESS)}

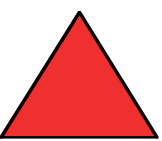

\begin{tabular}{|c|c|c|}
\hline $\begin{array}{l}\text { ACTIVITY } \\
\text { LEVEL }\end{array}$ & GEOLOGIC BEHAVIOR & USGS RESPONSE \\
\hline $\begin{array}{l}\text { LEVEL 1: } \\
\text { Minor eruption } \\
\text { underway }\end{array}$ & $\begin{array}{l}\text { Eruptive activity characterized by any of the following: } \\
\text { - Small explosive blasts (either phreatic or } \\
\text { magmatic) } \\
\text { - Effusive lava fountains feeding fluid lava flows } \\
\text { - Dome growth } \\
\text { - Eruption column, if present, may reach } 1 \mathrm{~km} \\
\text { above vent elevation } \\
\text { - Hazardous zone subject to ballistic ejecta or } \\
\text { small pyroclastic flows generally limited to } 1 \text { to } \\
2 \mathrm{~km} \text { from eruption vent(s). Minor downwind } \\
\text { ash fall possible }\end{array}$ & \multirow{4}{*}{$\begin{array}{l}\text { Calldown notification of change to } \\
\text { condition RED } \\
\text { EVENT RESPONSE (if not already } \\
\text { in effect under conditions YELLOW } \\
\text { or ORANGE). } \\
\text { - Implement LVO EVENT } \\
\text { RESPONSE structure } \\
\text { (Figure 10) } \\
\text { - Establish LVO field office } \\
\text { in Mammoth Lakes } \\
\text { - Establish LVO backup field } \\
\text { office in Bridgeport } \\
\\
\text { Communicate changes in eruption } \\
\text { levels and associated hazard zone to } \\
\text { civil authorities through daily to } \\
\text { hourly updates. }\end{array}$} \\
\hline $\begin{array}{l}\text { LEVEL 2: } \\
\text { Moderate } \\
\text { eruption } \\
\text { underway }\end{array}$ & $\begin{array}{l}\text { Explosive eruptive activity characterized by } \\
\text { - Eruption column } 2 \text { to } 5 \mathrm{~km} \text { above vent(s) } \\
\text { - Hazardous zone subject to pyroclastic flows or } \\
\text { surges as far as } 5 \mathrm{~km} \text { from eruption vent(s). } \\
\text { - Light to moderate downwind ash fall }\end{array}$ & \\
\hline $\begin{array}{l}\text { LEVEL 3: } \\
\text { Strong eruption } \\
\text { underway }\end{array}$ & $\begin{array}{l}\text { Explosive eruption characterized by } \\
\text { - Eruption column } 5 \text { to } 15 \mathrm{~km} \text { above vent(s) } \\
\text { - Hazardous zone subject to pyroclastic flows or } \\
\text { surges as far as } 10 \mathrm{~km} \text { from eruption vent(s). } \\
\text { - Ash cloud may intersect some commercial } \\
\text { aircraft flight paths over region } \\
\text { - Moderate to heavy downwind ash fall }\end{array}$ & \\
\hline $\begin{array}{l}\text { LEVEL 4: } \\
\text { Massive eruption } \\
\text { underway }\end{array}$ & $\begin{array}{l}\text { Explosive eruption characterized by } \\
\text { - Eruption column reaching or exceeding } 25 \mathrm{~km} \\
\text { above eruption vent(s) } \\
\text { - Hazardous zone subject to pyroclastic flows or } \\
\text { surges may extend } 20 \mathrm{~km} \text { or more from eruption } \\
\text { vent(s). } \\
\text { - Ash cloud pervades most aircraft flight paths } \\
\text { over the region } \\
\text { - Heavy downwind ash fall. }\end{array}$ & \\
\hline
\end{tabular}

play out over months to years and even decades. The four levels under condition RED (eruption underway) corresponds to varying intensities of eruptive activity and their likely impacts.

A principal objective of this document is to facilitate communication of the significance of scientific information derived from monitoring measurements to local, state, and Federal officials. Specifically, the color codes described in section II provide a graded measure of our concern about how a given level of unrest might threaten local communities with a possible volcanic eruption. The use of a color-code scheme for volcano status or activity levels, which is becoming widely adopted for many volcanoes, offers civil authorities and the general public an intuitive, easily understandable framework for gauging and coordinating a response to developing vol- 
cano crisis. Worldwide experience in recent decades demonstrates that effective communication among scientists, civil authorities, and the population affected is a prerequisiteindeed, perhaps the single most important element- to mitigate the risk from potentially hazardous volcanoes.

\section{Condition-Code Thresholds}

The guidelines for relating activity levels to the color-code conditions in table 1 are summarized in table 2 . In this section, we expand on and describe the basis for the specific choices

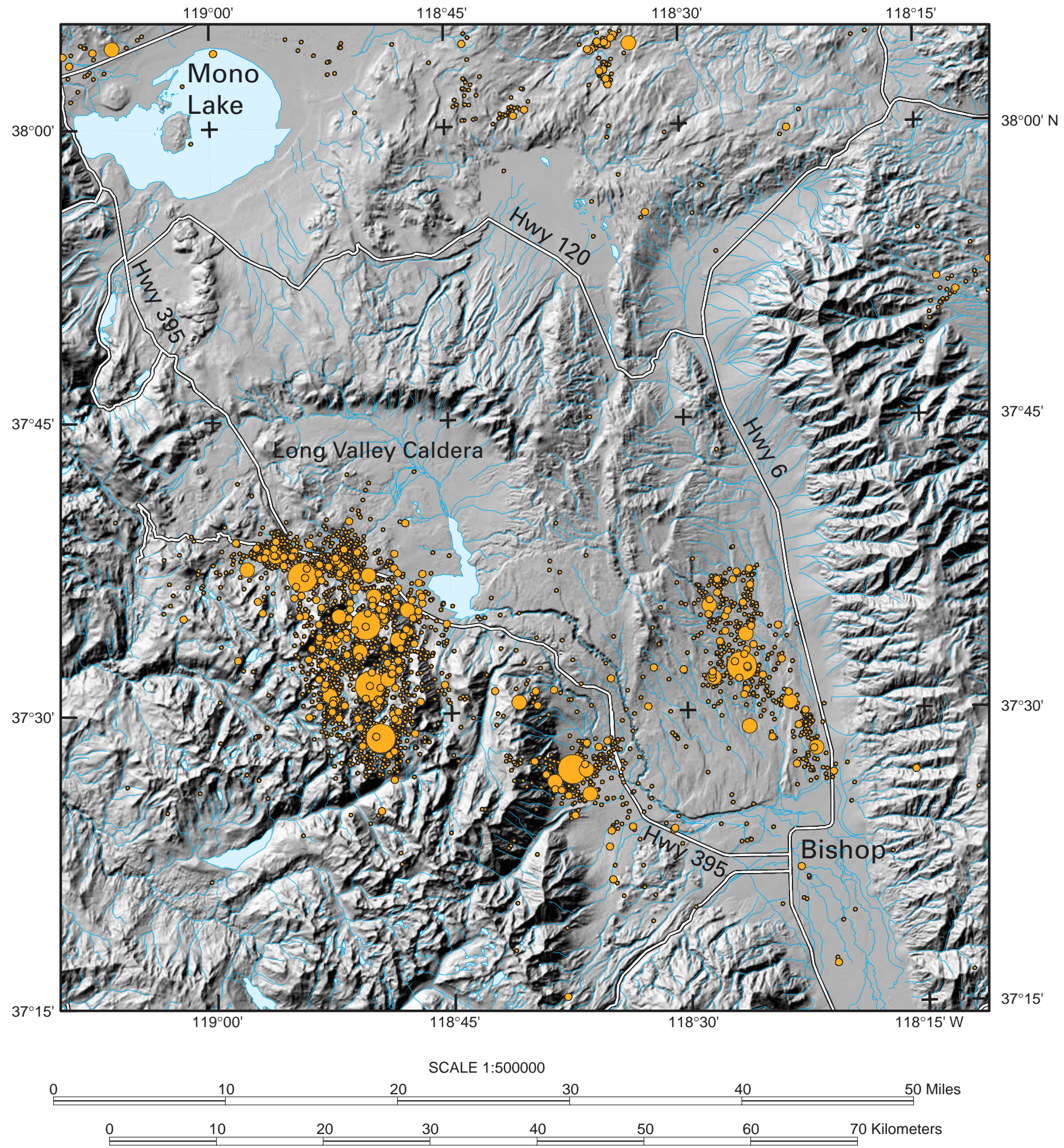

Figure 1.-Shaded relief map of the Long Valley Caldera-Mono Craters region showing the epicenters of magnitude (M) $\geq 3$ earthquakes for 1978 through 1999 (see fig. 2 for selected place names). Circle sizes represent earthquake magnitude in four steps from $M=3.0$ to $M=6.0$. 
in the types and levels of activity that serve as these transition criteria. These criteria apply only to activity within the confines of the caldera, beneath Mammoth Mountain, and along the Mono-Inyo volcanic chain. In particular, they do not apply to seismic activity in adjacent areas, such as the Sierra Nevada block south of the caldera, the upper Owens Valley, or the Chalfant Valley that, based on the geologic record, are unlikely sites for the onset of volcanic activity in the near future.

\section{Condition GREEN}

Activity under condition GREEN includes a range of unrest levels that, based on the history of unrest in Long Valley Caldera since 1980 and case histories from other calderas and volcanic systems, pose no immediate risk in terms of a volcanic eruption developing in the short term (days to weeks). The four activity levels under condition GREEN (table

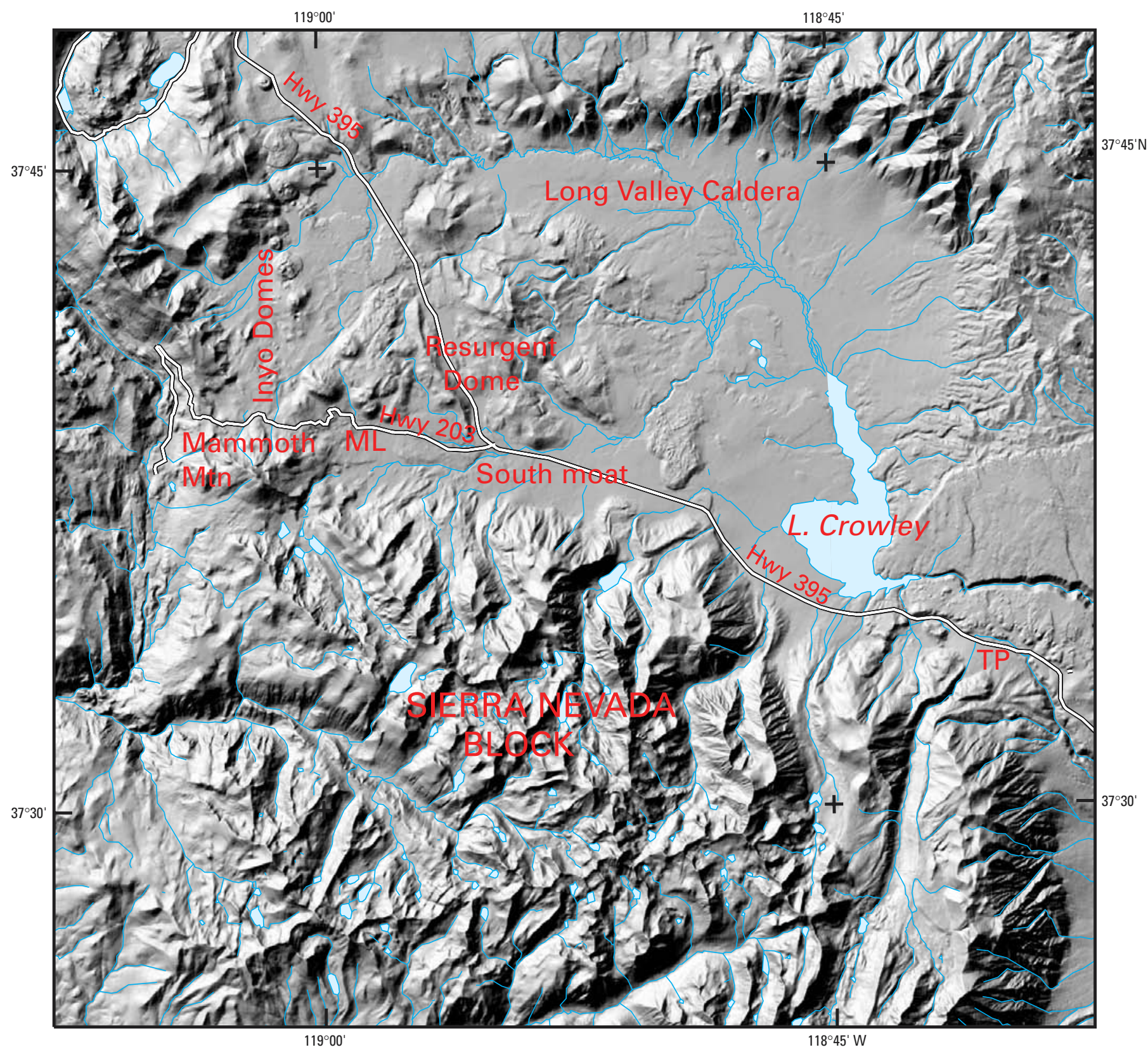

\begin{tabular}{|c|c|c|c|c|c|c|c|}
\hline \multicolumn{8}{|c|}{ SCALE 1:250000 } \\
\hline 0 & 5 & & 10 & 15 & & 20 & 25 Miles \\
\hline 0 & 5 & 10 & 15 & 20 & 25 & 30 & 35 Kilometers \\
\hline
\end{tabular}

Figure 2.-Shaded relief map of Long Valley Caldera and the Sierra Nevada block to the south with dominant geologic/topographic structures labeled. ML, Mammoth Lakes, TP, Tom's Place. 
2) depend principally on seismicity criteria with the constraint that strain rates remain below $\sim 0.1 \mathrm{ppm} /$ day (here we use $\mathrm{ppm}$, or parts per million, to include both strain (microstrain) and tilt (microradians)) or comparable deformation rates $0.5 \mathrm{~mm} /$ day. Such changes over a 24-hour period are below the resolution of both the 2-color EDM and continuous GPS measurements but resolvable by the borehole dilatometers and tiltmeters. The activity levels range from relative quiescence ( $\mathrm{a}$ few $\mathrm{M}<2$ earthquakes per day and no detectable ground deformation) to relatively strong unrest. The latter may involve an earthquake swarm with several hundred earthquakes per day, a number of which may be locally felt (generally $M>3$ ), with perhaps a few as large as $M=4$. Ground deformation may involve strain rates as high as several tenths of a microstrain (ppm) per day. Also included under condition GREEN is the diffuse emission of $\mathrm{CO}_{2}$ gas from around the flanks of Mammoth Mountain at flux rates that average a few hundred tons per day (Gerlach and others, 1999; Sorey and others, 1998). These activity levels, which correspond to status levels N, E, D, and C in the previous, alphabetic system (Hill and others, 1991), have recurred frequently in the caldera since 1980. The November-December swarms of 1997 certainly qualified as "strong unrest" and, as described under Recent Unrest (appendix A), this activity came close to meeting the criteria for condition YELLOW.

\section{Condition YELLOW}

Under condition YELLOW, activity is sufficiently intense to warrant a USGS on-site response as a basis for expanded monitoring in the field and direct communication with local civil authorities. The criteria for condition YELLOW places comparable importance on both seismicity and deformation rates. The transition to condition YELLOW, for example, may be prompted by either an intense earthquake swarm within the caldera or along the Mono-Inyo volcanic chain including one or more $\mathrm{M}>5$ earthquakes and (or) deformation with strain or deformation rates exceeding $1 \mathrm{ppm} /$ day or $5 \mathrm{~mm} /$ day, respectively, sustained for at least two days. In general, we would expect deformation rates at these levels to be accompanied by elevated seismicity rates, the onset of shallow volcanic earthquakes (including harmonic tremor), or perhaps increased flux rates of $\mathrm{CO}_{2}$ or $\mathrm{SO}_{2}$. Instrumental indications of possible increased deformation rates without such corroborating signs of magmatic or tectonic processes must be viewed as suspicious and carefully checked for alternate explanations (such as meteorological effects or instrumental problems). Had this color code system been in effect prior to the onset of unrest in 1980, condition YELLOW would have been attained twice-once during the May 1980 sequence, which included four $M=6$ earthquakes, one of which was inside the caldera, and once during the January 1983 swarm, which included two $M=5.3$ earthquakes in the south-moat seismic zone (SMSZ) of the caldera.

\section{Condition ORANGE}

A condition ORANGE and the likelihood that an eruption may develop within hours to days depends primarily on pro- nounced and accelerating ground deformation with sustained rates exceeding $50 \mathrm{~mm} /$ day (strain rates $>10 \mathrm{ppm} /$ day) for at least 24 hours, consistent with the intrusion of magma into the shallow crust. Such an intrusion will almost certainly be accompanied by intense earthquake activity, although the seismic swarm itself may not necessarily be any more intense than that under a condition YELLOW. Supporting activities under the criteria for the transition to condition ORANGE include frequent, shallow long-period (LP) volcanic earthquakes, sustained harmonic tremor, and (or) flux rates of $\mathrm{CO}_{2}$ or $\mathrm{SO}_{2}$ exceeding 10,000 or 1,000 tons/day, respectively (table 2).

Note that the transition to condition ORANGE does not necessarily require an increase in the intensity of earthquake swarm activity above that already specified for condition YELLOW for the following reasons:

- Precursory seismic activity to volcanic eruptions need not necessarily be significantly more intense than that already specified for condition YELLOW. Indeed, the seismic activity prior to some volcanic eruptions is less vigorous than the stronger swarm sequences that have occurred in Long Valley Caldera since 1980.

- In the absence of significant ground deformation, even more intense earthquake sequences most likely reflect relaxation adjustments to gradually accumulated stresses rather than a response to the active intrusion of magma into the shallow crust. In the former, observed surface deformations will generally be consistent with aggregate seismic slip estimated from the cumulative seismic moment of the sequence. In the case of magmatic intrusion, observed surface deformations commonly far exceed those expected for the aggregate seismic slip of the associated earthquake sequence.

(To date, early 2002, no activity levels corresponding to condition ORANGE have been observed in Long Valley Caldera.)

\section{Condition RED}

The transition to condition RED is triggered by the onset of a volcanic eruption. Under this document, the onset of a volcanic eruption coincides with the initial explosive or effusive eruption at the surface of particulate and (or) fluid material. Condition RED will be attained with any of the following activities: phreatic (steam) blasts, emergence of a lava dome (the passive extrusion of viscous lava flows), onset of lava fountains (such as with basaltic eruptions in Hawaii), or the onset of explosive ash eruptions. We include a phreatic blast here because (1) it is often only possible in hindsight to determine with confidence that an explosion is phreatic or magmatic, and (2) phreatic blasts may be followed in short order (minutes to hours) by the eruption of fresh magma. The latter is particularly true for the eruption of highly fluid, basaltic magmas of the sort that produced the Red Cones south west of Mammoth Mountain and lava flows that extend from the west moat of Long Valley Caldera down both the south and north moats.

Unlike a major earthquake, which is usually followed by declining activity in the form of an aftershock sequence, the 
onset of a volcanic eruption usually represents just the beginning of a prolonged crisis that may persist for days, weeks, months, or even years. Quite commonly, the strongest, most hazardous phase of an eruption develops days to weeks (but occasionally months to years) after the eruption onset. To account for varying intensities in eruptive activity once an eruption is underway, condition RED is subdivided into four levels [levels 1 through 4 correspond roughly to the Volcanic Explosivity Index (VEI) levels 1 through 4 (Newhall and Self, 1982); the principal difference is that Level 1 includes both VEI 0 and 1 and Level 4 includes VEI 4 and greater]:

- RED LEVEL 1-Minor eruptive activity characterized by either (1) small explosive blasts (either phreatic or magmatic), (2) effusive lava fountains feeding fluid lava flows, or (3) dome growth. Eruption column, if present, may reach elevations of 1 $\mathrm{km}$ (3,000 feet) above vent level. Hazardous zones subject to ballistic ejecta or small pyroclastic flows are generally limited to 1 to $2 \mathrm{~km}$ ( 0.5 to 1 mile) from the eruption vent(s). Minor downwind ash fall possible.

- RED LEVEL 2-Moderate, explosive eruption characterized by an ash column reaching elevations as high as $5 \mathrm{~km}$ (15,000 feet) above eruption vent. Hazardous zones subject to pyroclastic flows or surges may extend as much as $5 \mathrm{~km}$ (3 miles) from the eruption vent(s). Moderate downwind ash fall likely.

- RED LEVEL 3-Strong, explosive eruption accompanied by an ash column reaching elevations as high as $15 \mathrm{~km}(45,000$ feet) above vent level. Hazardous zone subject to pyroclastic flows or surges may extend $10 \mathrm{~km}$ (6 miles) from the eruptive vents, and the ash cloud may intersect some commercial aircraft flight paths over the region. Expect moderate to heavy ash fall downwind from eruptive vents.

- RED LEVEL 4-Massive, explosive eruption with ash column reaching or exceeding elevations of $25 \mathrm{~km}(75,000$ feet) above vent levels. Hazardous zones subject to large pyroclastic flows or surges may extend more than $20 \mathrm{~km}$ (12 miles) from the eruptive vents. Ash cloud pervades most aircraft flight paths in the region with heavy ash fall downwind from eruptive vents.

\section{An Important Caveat:}

The criteria specified for each Color-Code transition as described above and outlined in table 2 serve as guidelines only. In particular, these criteria must not be viewed as a rigid, infallible recipe (algorithm) that invariably leads to the appropriate designation of a Color-Code condition and response. PERSONAL JUDGMENT AND EXPERIENCE WILL INEVITABLY PLAY A CRITICAL ROLE IN DECISIONS ON THE TRANSITION FROM ONE COLOR CODE TO THE NEXT.

Final decisions on Color-Code transitions will be made by the Long Valley Observatory Scientist-in-Charge in consultation with other scientists involved in the event response, the Science Advisory Team, and the Chief Scientist for the Volcano Hazards Team.

Two issues deserve special emphasis in this regard:

- Because eruptions have not occurred in Long Valley Caldera or along the Mono-Inyo volcanic chain within historic time, scientists have no direct record of specific variations in unrest patterns that precede eruptions within this volcanic system. It is therefore important to be prepared to incorporate unexpected variations in within the transition criteria in the future.

- Numerical values for activity rates, magnitudes and other factors associated with each status suggest only approximate activity levels. Initial estimates of earthquake magnitudes, for example, may be uncertain by a quarter of a magnitude unit, and adverse conditions, such as high winds, noisy telemetry, and dead stations may reduce the activity rate reported by the real-time computer system by 10 to 20 percent or more. Furthermore, instrument problems may result in spurious signals in the monitoring data, which could initially but incorrectly be interpreted as changes in the state of the volcanic system.

\section{Standdown Criteria}

Following the onset of episodic activity in Long Valley Caldera in 1980, each of the unrest episodes has eventually declined to low-level or background activity (condition GREEN). Most future episodes of unrest will likely do the same. Table 3 specifies the criteria for standing down from a given color condition after the activity triggering that condition has decreased in intensity below the transition criteria.

The standdown criteria of table 3 specify a minimum time interval that a given color condition will remain in effect after activity triggering the condition as fallen below the threshold for that condition. At the end of a specified time interval, the condition will automatically drop to the next lower level consistent with any ongoing activity unless explicitly extended by the Scientist-in-Charge for the Long Valley Observatory.

The intense activity that warrants a condition YELLOW also triggers an EVENT RESPONSE and an intensive field monitoring effort within the caldera (section III). The USGS will continue intensive field monitoring for two weeks after the activity falls below the criteria for condition YELLOW to insure continuity of field data and to minimize remobilization costs in case the drop in activity is only a temporary lull. Evidence from volcanoes worldwide suggests that, in many cases, a temporary quiescence interrupts the unrest leading to an eruption just prior to the initial outbreak of the eruption. This premonitory quiescence, should it occur, commonly lasts a few hours to a few days (Shimozuru and Kagiyama, 1989). Accordingly we will normally extend a condition ORANGE for one week beyond the time activity drops below the threshold for condition ORANGE and then drop to a condition YELLOW and continue intensive field monitoring for a second week. If the activity has remained at a level consistently below the criteria for a condition YELLOW for this entire two-week period, we will drop to the level under condition GREEN consistent with the level of activity at the time.

Condition RED indicates an eruption in progress, and the four levels within condition RED indicate the current intensity of the eruptive activity. The condition will revert to ORANGE 
Table 3.-Standdown rules for Color-Code conditions under declining activity levels.

\begin{tabular}{|c|c|c|}
\hline CONDITION & $\begin{array}{l}\text { EXPIRES } \\
\text { AFTER* }\end{array}$ & $\begin{array}{l}\text { SUBSEQUENT } \\
\text { CONDITION }\end{array}$ \\
\hline $\begin{array}{l}\text { GREEN (No immediate risk) } \\
\text { Weak Unrest } \\
\text { Minor Unrest } \\
\text { Moderate-to-Strong Unrest }\end{array}$ & $\begin{array}{l}1 \text { day } \\
2 \text { days } \\
3 \text { days }\end{array}$ & $\begin{array}{l}\text { GREEN } \\
\text { Background } \\
\text { Weak Unrest } \\
\text { Minor Unrest }\end{array}$ \\
\hline YELLOW (Watch) & 14 days & $\begin{array}{l}\text { GREEN (to appropriate } \\
\text { Unrest level under green) }\end{array}$ \\
\hline ORANGE (Warning) & 7 days & YELLOW \\
\hline RED (Alert: Eruption in progress) & 1 day & ORANGE \\
\hline
\end{tabular}

*Number of days after the activity level falls below the threshold for a given CONDITION.

within 24 hours of the cessation of eruptive activity. Likewise, in the case of waning eruptive activity, the condition will drop to the level consistent with the current activity within 24 hours after the more intense eruptive phase has stopped. The 24-hour delay is intended to minimize frequent (and potentially confusing) switching between RED and ORANGE or between levels within RED in the case of rapidly fluctuating changes in eruption intensity or sporadic low-level eruptive activity over an extended duration.

\section{Organization and Response}

This section describes the USGS organizational structure for response to activity in the Long Valley Caldera-Mono Craters (LVC/MC) region. This structure is based on that described IN USGS Open-File Reports 84-500 (U.S. Geological Survey, 1984) and 91-270 (Hill and others, 1991) but modified to incorporate the color code defined in table 1 and organizational changes within the USGS since OFR 91-270 was released.

The Long Valley Observatory is one of five volcano observatories within the Volcano Hazards Team and under the overall supervision of the Volcano Hazards Team Chief Scientist (fig. 3). The Volcano Hazards Team is part of the Geologic Discipline in the Western Region of the U.S. Geological Survey, and it is located in the USGS Menlo Park, California, campus. The diagram in figure 4 illustrates how LVO fits in this organizational structure during normal conditions (GREEN), when the Long Valley Observatory Scientistin-Charge (LVO SIC) has the role of coordinating monitoring, hazard assessment, and public information activities in the Long Valley Caldera-Mono Craters region as they are carried out under normal USGS management channels. The organizational structure for LVO during an EVENT RESPONSE (conditions YELLOW through RED), however, is illustrated in figure 4. During an EVENT RESPONSE, the LVO SIC derives authority from the USGS Director's Office through the Western Regional Geologist to direct all USGS activities concerning the response.

\section{Organizational Structure}

\section{Western Regional Geologist}

The Western Regional Geologist (WRG) is responsible for overseeing and coordinating geological investigations and response activities in the Western Region for the USGS. This responsibility includes general oversight of USGS response to both earthquake and volcanic crises. The WRG has the authority to declare an EVENT RESPONSE when the Long Valley Observatory Scientist-in-Charge has determined that condition YELLOW or higher is in effect in the Long Valley Caldera-Mono Craters region.

\section{Chief Scientist, Volcano Hazards Team}

The Chief Scientist for the Volcano Hazards Team (TCS) has overall responsibility under both routine and EVENT RESPONSE conditions for monitoring, hazards assessment, and all operations relating to volcanic and earthquake hazards in the Long Valley Caldera-Mono Craters region (fig. 3). The TCS is responsible for ensuring that accurate summaries of geologic, monitoring, and hazards information are prepared and transmitted as frequently as conditions require to the 
Western Regional Geologist and the Director's Office, as well as to the California Division of Mines and Geology and the California Office of Emergency Services. The TCS is also responsible for ensuring that policies and instructions of the Western Regional Geologist are transmitted to, and followed by, personnel under their direction. The TCS is assisted, as necessary, by the Coordinator of the Volcano Hazards Program.

\section{Scientist-in-Charge, Long Valley Observatory}

During periods of routine activity, the Long Valley Observatory Scientist-in-Charge (LVO SIC) acts as a coordinator and works through the appropriate line managers to coordinate monitoring, hazards assessment, and information dissemination for the Long Valley Caldera - Mono Craters region. The SIC ensures that the USGS is in an appropriate state of readiness for a timely response to increased activity in the region, as spelled out in the color code of Table 1. The SIC ensures that monitoring and hazards assessment are conducted efficiently, effectively, and thoroughly, and that activities of LVO are summarized in the form of quarterly or other periodic and interim reports and that these are distributed in a timely manner. The SIC also ensures that the monitoring and hazards data are adequately analyzed and periodically reviewed for scientific quality and completeness. This review process should include periodic meetings of all monitoring and hazards assessment personnel, as well as meetings and discussions with the Scientific Advisory Team, relevant USGS managers, and the LVO team leaders (see fig. 3), as appropriate. The SIC is responsible for ensuring that accurate and timely hazards assessments and supporting scientific information are issued to all concerned parties, including local, state, and Federal officials and the public.

When activity within the caldera or along the Inyo-Mono volcanic chain becomes sufficiently intense to prompt the declaration of an EVENT RESPONSE (based on condition YELLOW or above) by the Western Regional Geologist, the LVO SIC initiates the establishment of the center for LVO operations in the Mammoth Lakes Field Office and ensures

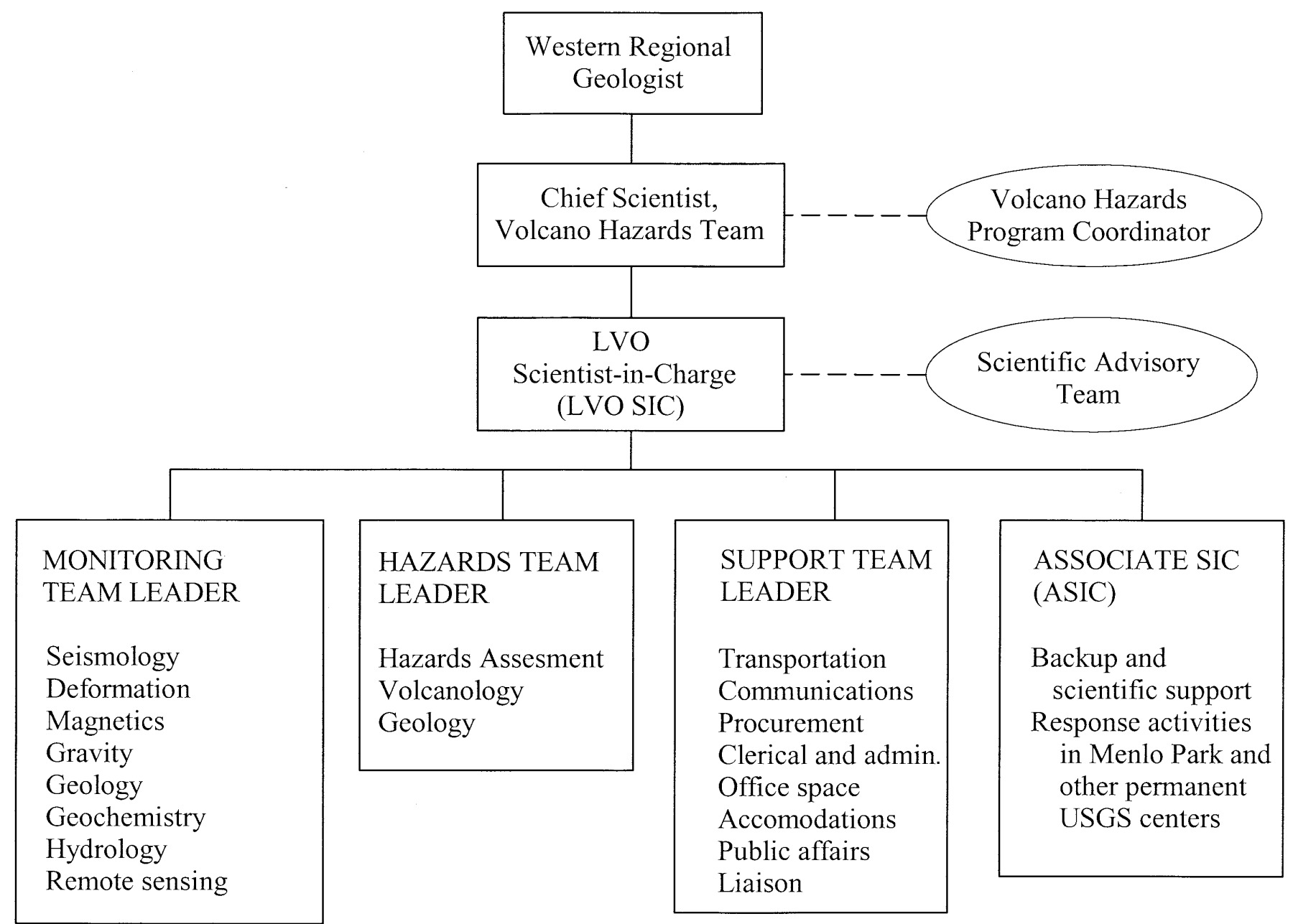

Figure 3.-Organizational structure for the Long Valley Observatory under normal (noncrisis) operation (Condition GREEN). Rectangles represent positions of line authority; ovals and dashed lines represent input from advisory positions or groups. USGS, U.S. Geological Survey; LVO, Long Valley Observatory; SIC, Scientist-in-Charge; ASIC, Associate Scientist-in-Charge. 
that all relevant monitoring, hazards, and support personnel are rapidly mobilized and dispatched to field office and, as appropriate to the backup operations center in the Mono County Sheriff's Office in Bridgeport (fig. 4). Under these EVENT RESPONSE conditions, the LVO SIC has full authority from the USGS Director (see appendix F) to direct all USGS personnel engaged in the response, wherever physically or organizationally located, and to call upon the resources of all USGS units assigned to and necessary for monitoring, hazards assessment, and support activities (see Response and General Operational Procedures below).

\section{Long Valley Observatory Team Leaders}

To assist the LVO Scientist-in-Charge are three team leaders-Monitoring Team Leader, Hazards Assessment Team Leader, and Support Team Leader (fig. 3). During routine activity, these Team Leaders act as coordinators for their respective functions and work through normal management channels while assisting the LVO SIC to accomplish his or her goals. Under EVENT RESPONSE conditions, however, these Team Leaders report directly to the LVO SIC and, through the SIC, have full authority to issue instructions to their respective team members, determine team strategy, and assign necessary personnel to specific tasks.

\section{Monitoring Team Leader}

The Monitoring Team Leader serves as a consultant and advisor to the SIC in determining monitoring requirements and in analyzing and interpreting monitoring results. During periods of routine activity, the Monitoring Team Leader maintains an overview of all monitoring activities, in order to

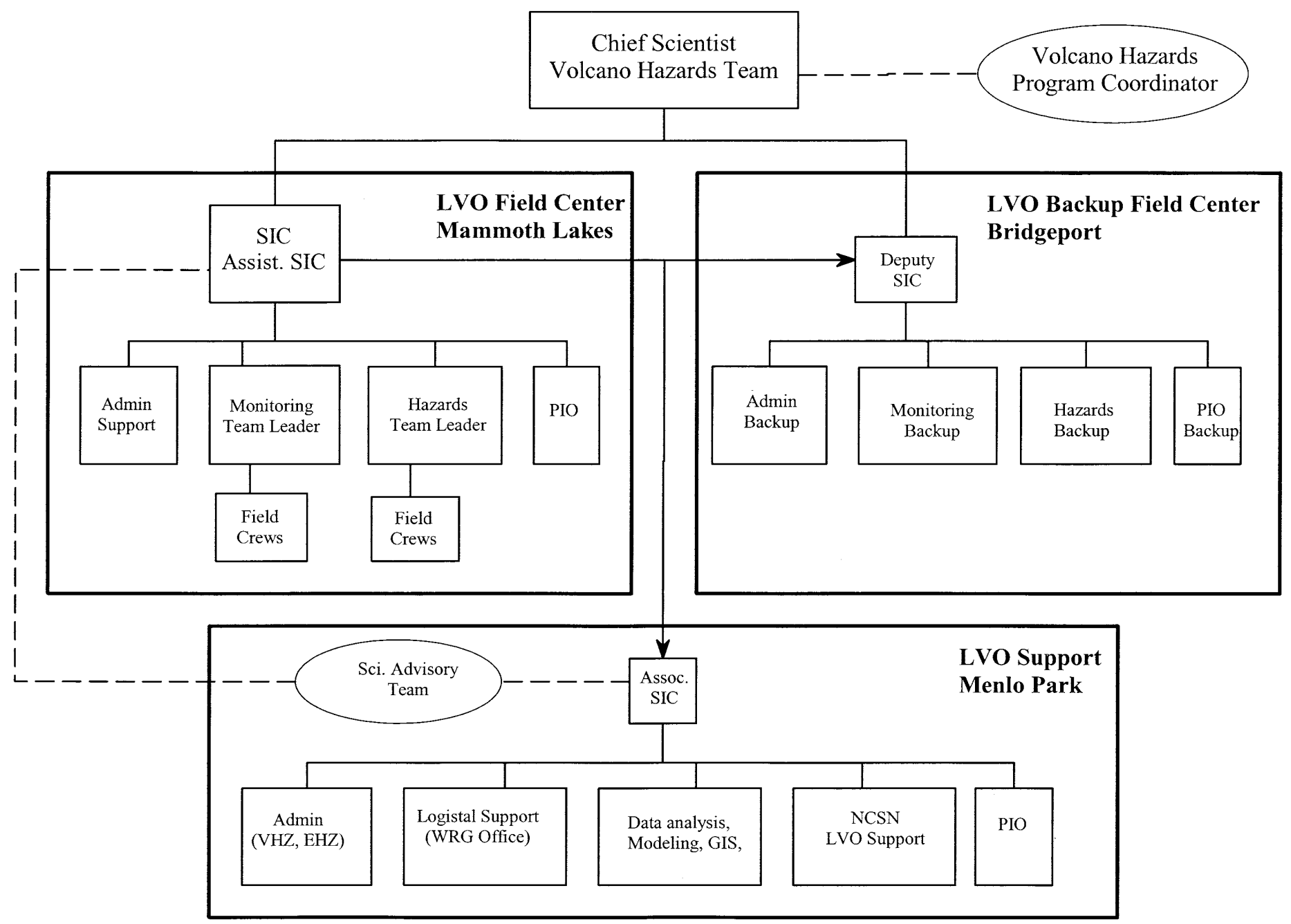

Figure 4.--Organizational structure for the Long Valley Observatory under an EVENT RESPONSE (conditions YELLOW, ORANGE, or RED). Rectangles and solid lines indicate line authority; dashed lines and oval indicate advisory communication paths; heavy rectangles outline organizational units. LVO, Long Valley Observatory; GIS, Geographical Information System; NCSN, Northern California Seismic Network; PIO, Public Information Officer; VHZ, Volcano Hazards Team; EHZ, Earthquake Hazards Team; SIC, Scientist-in-Charge; WRG, Western Regional Geologist. 
ensure that all monitoring networks are maintained and that measurements are carried out thoroughly and with adequate frequency. Under EVENT RESPONSE conditions, the Monitoring Team Leader directs monitoring activities carried out at the LVC/MC area and ensures that the results of all monitoring activities are collected, integrated, analyzed, and made available promptly to the SIC and the Hazards Assessment Team Leader.

\section{Hazards Assessment Team Leader}

Under both routine conditions and EVENT RESPONSE conditions, the Hazards Assessment Team Leader prepares long-term and short-term hazard assessments as needed. The Team Leader also ensures that these assessments are accurate, are based on thorough integration of the current monitoring data with past and present behavior of the volcanic system, and are prepared in a timely manner. The Hazards Assessment Team Leader presents and explains these hazards assessments and their scientific basis to local, state, and Federal officials and to the public.

\section{Support Team Leader}

The Western Regional Geologist normally serves as the Support Team Leader. Under routine conditions, the Support Team Leader is responsible for ensuring that the support that may be required under EVENT RESPONSE conditions is maintained in an appropriate state of readiness. Under Event Response Conditions, the primary function of the Support Team Leader is to relieve, a much as possible, the SIC, the Monitoring Team Leader, the Hazards Assessment Team Leader, and their respective team members of the burdens associated with logistics, liaison with other agencies, and contact with the public and press. The Support Team Leader ensures that all resources necessary for monitoring, hazards assessment, and information dissemination are available or are acquired and emplaced as quickly as possible. Such resources include those relating to transportation, communications, procurement, clerical and administrative support, space, accommodations, and public relations. The Support Team Leader acts as liaison between the SIC and the California Division of Mines and Geology, the California Office of Emergency Services, local, state, and Federal agencies, and other USGS divisions. The Support Team Leader is responsible for the release of information to the public. The Support Team Leader also serves the SIC as a consultant and advisor, particularly concerning agency and interagency policy and regulations and public relations.

\section{Scientific Advisory Team}

This team is selected from recommendations by the LVO SIC and in consultation with the Western Regional Geologist, and appropriate Team Chief Scientists. It consists of several scientists within and outside the USGS with broad volcanological or geophysical knowledge, or with other special expertise or insight, who individually or collectively can develop an overview of the evolving unrest, operations, and potential hazards in the LVC/MC region. The advisory team provides the LVO SIC with background information and advice on the interpretation of monitoring, hazards assessment, and other scientific data, on the possible long- or short-term course of the activity, and on monitoring strategy. The team need not be formally assembled during periods of increased activity. When assembled, however, it does not participate directly in the monitoring, hazards assessment, or support activities. Thus, the team members are able to provide a calm, objective analysis of an evolving situation without being caught up in the time consuming, often stressful operational responsibilities of the USGS response.

\section{Associate Scientist-in-Charge}

When the LVO SIC is away from Menlo Park, the LVO SIC will be represented in Menlo Park by an Associate Scientist in Charge (ASIC). During periods of routine activity (condition GREEN), the ASIC will act for the SIC in all matters concerning the Long Valley Caldera-Mono Craters region. During periods of increased activity when the SIC is at the LVO Field Center, the ASIC will have full authority in Menlo Park and the other permanent USGS centers, through the LVO SIC, to direct activities in support of the LVO Field Center (fig. 4). Under EVENT RESPONSE conditions (conditions YELLOW, ORANGE, and RED), the LVO SIC may appoint a Deputy SIC (DSIC) to serve as an alternate and second-in-command during the 24-hour operation of the LVO Field Office in Mammoth Lakes and a DSIC to oversee establishing the backup field office in Bridgeport and to serve as acting LVO SIC should volcanic activity require moving operations from Mammoth Lakes to Bridgeport (see items 6, 7 , and 8 below).

\section{Response and General Operational Procedures}

The following outlines the general operational procedures and activities for implementation of the USGS LVO Response Plan; the Event Response Structure is shown in figure 4:

\section{(1) Condition GREEN Advisory Calls}

Initial communication of any change in geologic conditions that might possibly increase the level of volcanic hazard in the LVC/MC region will be by a partial or full telephone calldown. At the onset of any unusual activity, the seismologist on duty at Menlo Park, or the person noting the change in activity will call the LVO SIC (or his designated representative). The SIC, who is responsible for the decision whether to activate the calldown procedure, will evaluate the activity and make the appropriate advisory calls. When activity levels 
reach the criteria for Moderate to Strong Unrest (table 2), the SIC may initiate a 24-hour watch using personnel in Menlo Park.

\section{(2) Condition YELLOW-Declaration of EVENT RESPONSE}

If, upon evaluation of the data and consultation with USGS scientific and management personnel, the LVO SIC concludes that the activity warrants a condition YELLOW, the SIC, in consultation with the Volcano Hazards Team Chief Scientist, will recommend that the Western Regional Geologist (or designated deputy), declare EVENT RESPONSE conditions. Such a declaration will activate the establishment of a field center (fig. 4). USGS, local, state, and Federal officials will be notified of this decision through the full calldown procedure (see fig. 5 and item 6 below).
(3) Condition ORANGE-Declaration of GEOLOGIC HAZARD WARNING

If, upon evaluation of the data and consultation with USGS scientific and management personnel, the LVO SIC concludes that the activity strongly suggests that an eruption is likely to occur within hours to a few days, the LVO SIC will, with the concurrence of the Western Regional Geologist (or designated deputy), declare a condition ORANGE and recommend that the Director issue a GEOLOGIC HAZARD WARNING of a possible imminent volcanic eruption. If a condition YELLOW is not already in effect, the condition ORANGE will also trigger an EVENT RESPONSE. Depending on the location of the escalating unrest and the likely site for the eruption outbreak, the LVO SIC may, in the interest of personnel safety and continuity of monitoring activities, move the field-operations center from Mammoth Lakes to Bridgeport (see item 7 below).

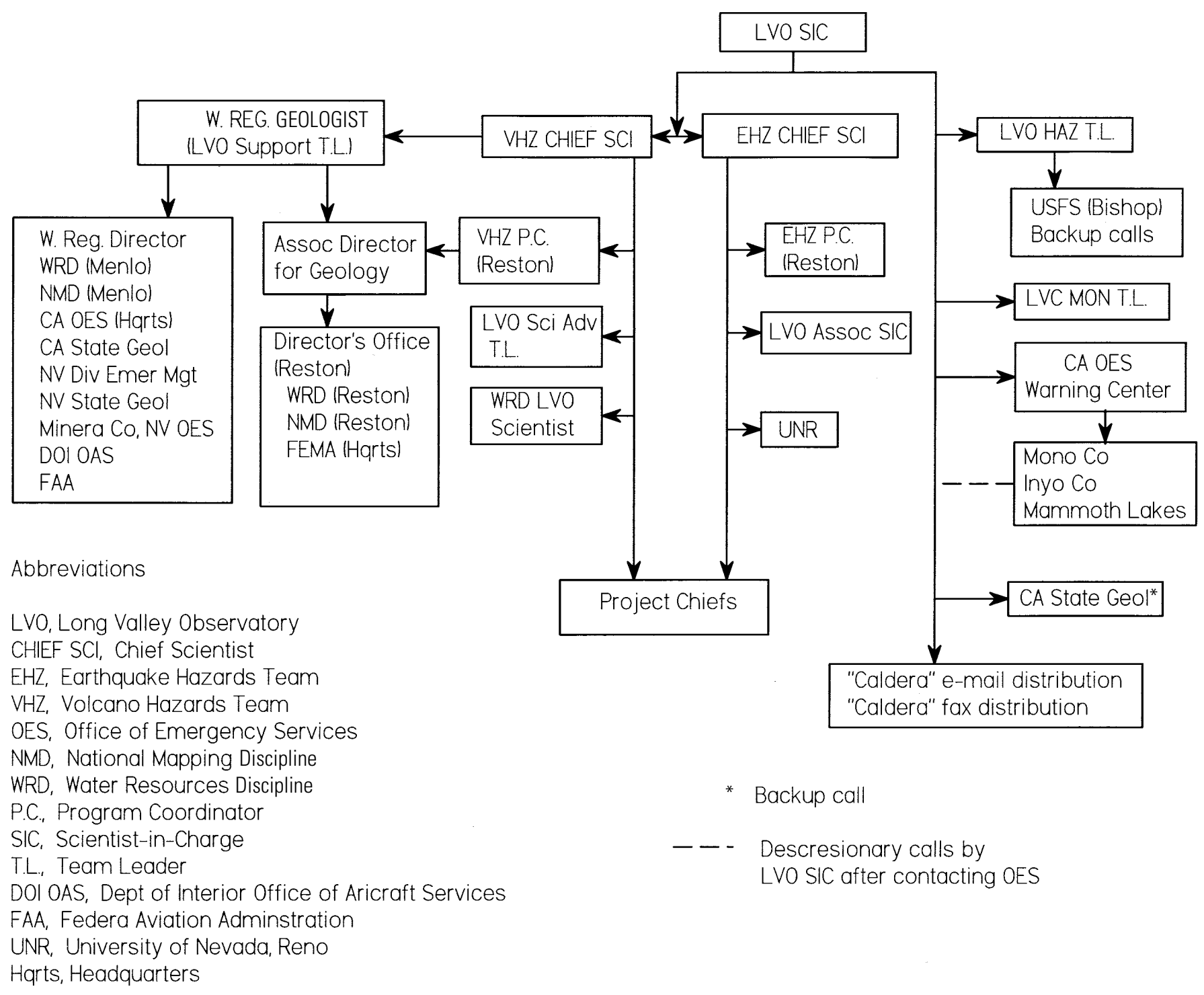

Figure 5.-U.S. Geological Survey (USGS) calldown structure for an EVENT RESPONSE (conditions YELLOW, ORANGE, or RED). 
(4) Condition RED: Continuation of EVENT

RESPONSE and update of GEOLOGIC HAZARD WARNING

With the onset of eruptive activity an EVENT RESPONSE previously established under condition YELLOW or ORANGE will continue, and the GEOLOGIC HAZARD WARNING issued under condition ORANGE will be updated as frequently as needed depending on eruptive activity. In the unlikely event that an eruption should begin with little or no prior warning such that neither conditions YELLOW and ORANGE are in effect, a condition RED will immediately trigger both an EVENT RESPONSE and release of a GEOLOGIC HAZARD WARNING.

\section{(5) Assignment of EVENT RESPONSE Personnel}

Either in advance of, or upon, declaration of EVENT RESPONSE conditions, the Western Regional Geologist, or the LVO SIC, will make arrangements for the assignment of appropriate personnel and other resources from all USGS units. Once these resources are secured, the LVO SIC has the full authority for assignment of EVENT RESPONSE personnel. Normally, the SIC's requests for personnel or equipment will be discussed with, and relayed through, the appropriate supervisor, who must make every effort to supply the resources requested. In the event that a supervisor is not available, the SIC may contact and assign individuals directly. Should a EVENT RESPONSE situation occur simultaneously with heightened activity elsewhere, conflicting demands for personnel and resources will be resolved, if necessary, by the Western Regional Geologist. Once assigned to an EVENT RESPONSE team, all personnel and equipment fall under the authority of the EVENT RESPONSE structure until released by the LVO SIC or the Western Regional Geologist.

\section{(6) Establishment of a Field Center}

Upon declaration of EVENT RESPONSE (conditions YELLOW and above) by the Western Regional Geologist, the LVO SIC will establish a field center for LVO operations in the USGS Field Center in Mammoth Lakes and a backup field office in the Mono County Sheriff's Office in Bridgeport (fig. 4). Deployment of personnel and material to the field centers will be on instructions of the LVO SIC to project personnel, either directly or through appropriate managers. Under usual circumstances (for example, there are no volcanic or seismic crises elsewhere requiring USGS response), the primary field center in Mammoth Lakes will be initially manned by personnel from the USGS Center in Menlo Park and the backup field office in Bridgeport will be initially manned by personnel from the USGS Cascades Volcano Observatory (CVO) in Vancouver, Washington. The LVO SIC must make every effort to see that the primary field center (whether in Mammoth Lakes or Bridgeport) is staffed with sufficient personnel to maintain an effective 24-hour operation. To the extent feasible, the backup field center will duplicate the monitoring and communication capabilities of the primary field office in Mammoth Lakes to insure uninterrupted monitoring of the evolving crisis. Depending on circumstances, the LVO SIC will also appoint (1) a Deputy SIC (DSIC) to serve as his/her alternate during scheduled shifts in a 24-hour watch maintained at the LVO field office, and (2) a second DSIC to oversee operations at the backup field office in Bridgeport (fig. 4). Depending on personnel available, the DSIC positions may be assigned as fulltime responsibilities for specific individuals or they may be assigned as part of the responsibilities for the Hazards or Monitoring Team Leaders.

Under most circumstances, the USGS field center in Mammoth Lakes will be the primary field center for USGS operations and communications during an EVENT RESPONSE (see item 7 below). Regardless, the primary active field office will serve as (1) a communications center for USGS field operations, (2) a staging center for all monitoring, scientific, hazards assessment, and support activities, and (3) an information center for local, state, and Federal officials. The DSIC at the primary active field center (whether Mammoth Lakes or Bridgport) will have authority over any other DISCs.

\section{(7) Field Operations and Communications}

Once EVENT RESPONSE conditions have been declared, each person or field party must contact the appropriate Team Leader prior to beginning field activities in the $\mathrm{LVC} / \mathrm{MC}$ region to (1) inform the Team Leader of their field plans, such as where they will be staying, and (2) receive last minute information on logistics and special arrangements. When operating under EVENT RESPONSE conditions, radio contact is to be maintained with the field center at all times while in the field, and field personnel must be prepared to respond directly to requests and instructions from either the Team Leaders or the SIC concerning monitoring efforts, hazard assessment, data reporting, safety precautions, and other matters. In addition, one or more representatives from each field party must participate in any coordination or dataevaluation meetings called by the SIC or the respective Team Leaders.

The short-term hazard assessment of an impending or in-progress volcanic eruption will depend almost exclusively on the quality and timeliness of data generated by the various monitoring efforts and observations of eruptive activity, and on the ability of personnel to review promptly all scientific data as they are obtained. Therefore, it is essential that the data from each monitoring activity (including on-site eruption documentation) be transmitted through the Monitoring Team Leader to the SIC and the Hazards Assessment Team Leader as quickly and accurately as possible. While responding to heightened activity, the focus of all monitoring and eruption-documentation activities must be on the current situation and how it 
is changing. Everyone involved in monitoring efforts and field observations should bear in mind that their own personal safety, as well as that of their colleagues and the public, may depend on how quickly their data are collected, processed, transmitted, and analyzed in conjunction with the data produced by their coworkers.

\section{(8) Change of Field Centers}

If intense unrest or volcanic activity makes it prudent to abandon the Mammoth Lakes field office as a field center, the LVO SIC will pass authority for LVO operations to the DSIC in the backup office located in the Mono County Sheriff's Office in Bridgeport. The decision to change field centers is the responsibility of the SIC; time permitting, the SIC will consult with the TCS. Specific instructions for change of centers will be issued by radio to all field parties at that time.

\section{(9) Deactivation}

Deactivation of the LVO Field Center will be determined and announced by the LVO SIC in consultation with the TCS, the Western Regional Geologist, and the three Team Leaders. Normally, deactivation will coincide with the termination of a condition YELLOW (see table 3). Personnel must not cease operating from the field center without first notifying their respective Team Leader of their intentions and receiving his or her permission to cease operations.

\section{Coordination Among USGS Disciplines}

In the case of an EVENT RESPONSE, the Western Regional Hydrologist, Cartographer, and Biologist will arrange to have members of their respective disciplines, along with any necessary equipment, assigned to the Event Response Team as appropriate. Once assigned to the Event Response Team, they will be under the supervision of the LVO SIC.

Should a situation develop in which assessment of hydrologic hazards becomes a significant component of the Event Response, the Western Regional Hydrologist will arrange to have a high-level scientist assigned to the LVO SIC's immediate staff. This individual will have the responsibility for advising the SIC on potential hydrologic hazards of the situation at hand and the appropriate response. This individual will work with the SIC and assume supervision of the hydrologic group within the Event Response Team as delegated by the SIC. Regardless, the final responsibility for the USGS response will rest with the LVO SIC.

\section{REFERENCES CITED}

Aoki, Y., Segall, P., Kato, T., Cervelli, P., and Shimada, S., 1999, Imaging magma transport during the 1997 seismic swarm off the Izu Peninsula, Japan: Science, v. 286, p. 927-930.

Bailey, R.A., 1989, Geologic map of Long Valley Caldera, Mono Inyo Craters volcanic chain, and vicinity, eastern California, U.S. Geological Survey Miscellaneous Investigations Series I-1933, 1:62,500, p. 11.

Bailey, R.A., 1990, Magmatic unrest at Long Valley Caldera, California, 1980-1990 [abs]: Geological Association of Canada, Abstracts with Program, v. 15, p. 6.

Bailey, R.A., Dalrymple, G.B., and Lanphere, M.A., 1976, Volcanism, structure, and geochronology of Long Valley Caldera, Mono County, California: Journal of Geophysical Research, v. 81, no. 5 , p. 725-744.

Bailey, R.A., and Hill, D.P., 1990, Magmatic unrest at Long Valley Caldera, California, 1980-1990: Geoscience Canada, v. 17, no. 3, p. 175-179.

Bakun, W.K., Breckenridge, K.S., Bredehoeft, J., Burford, R.O., Ellswroth, W.L., Johnston, M.J.S., Jones, L., Lindh, A.G., Mortensen, C., Mueller, R.J., Poley, C.M., Roeloffs, E., Schulz, S., Segall, P., and Thatcher, W., 1987, Parkfield, California, earthquake prediction scenarios and response plans: U.S. Geological Survey 87-192.

Battaglia, M., Roberts, C., and Segall, P., 1999, Magma intrusion beneath Long Valley Caldera confirmed by temporal changes in gravity: Science, v. 285 , no. 5436 , p. 2119-2122.

Behr, J., Bilham, R., and Beavan, J., 1992, Monitoring of magma chamber inflation using a biaxial Michelson tiltmeter in Long Valley Caldera, California [abs]: Eos, Transactions, American Geophysical Union, v. 73, no. 43, p. 347-348.

Benioff, H., 1951, Earthquakes and rock creep, Part I: Bulletin of the Seismological Society of America, v. 41, p. 31-62.

Blong, R., and McKee, C., 1995, The Rabaul Eruption 1994: Macquarie University, NSW 2109 Australia, Natural Hazards Research Center, 52 p.

Bursik, M.I., and Sieh, K.E., 1986, Late Quaternary faulting in Mono Basin, east central California [abs]: Geological Society of America, Abstracts with Programs, v. 18, no. 2, p. 91.

Castle, R.O., Estrem, J.E., and Savage, J.C., 1984, Uplift across Long Valley Caldera, California: Journal of Geophysical Research, v. 89 , no. 13 , p. $11,507-11,516$.

Chouet, B., 1992, A seismic model for the source of long-period events and harmonic tremor, in Gasparini, P., Scarpa, R., and Aki, K., eds., Volcanic Seismology (3 ed.): IAVCEI Proceedings in Volcanology: Berlin, Heidelberg, New York, Springer-Verlag, p. 133-156.

Chouet, B., 1996, New methods and future trends in seismological volcano monitoring, in Scarpa, R., and Tilling, R.I., eds., Monitoring and Mitigation of Volcano Hazards: Berlin, Heidelberg, Springer-Verlag, p. 23-97.

Chouet, B., and Julian, B.R., 1985, Dynamics of an expanding fluid filled crack: Journal of Geophysical Research, v. 90, no. 13, p. $11,187-11,198$.

Chouet, B.A., 1991, A seismic model for the source of long-period events and harmonic tremor, in Gasparini, P., Scarpa, R., and Aki, K., eds., Volcanic Seismology: IAVCEI Proceedings in Volcanology: Berlin, Springer-Verlag, p. 133-156.

Chouet, B.A., Dawson, P., and Kedar, S., 1998, Waveform inversion of very long period impulsive signals associated with magmatic injection beneath Kilauea Volcano, Hawaii: Journal of Geophysical Research, v. 103, p. 23,839-23,862.

Cockerham, R.S., and Corbett, E.J., 1987, The 1986 Chalfant Valley, California, earthquake sequence: preliminary results: Bulletin of the Seismological Society of America, v. 77, no. 1, p. 280-289. 
Cramer, C.H., and McNutt, S.R., 1997, Spectral analysis of earthquakes in the 1989 Mammoth Mountain swarm near Long Valley, California: Bulletin of the Seismological Society of America, v. 87 , no. 6 , p. $1454-1462$.

Cramer, C.H., and Toppozada, T.R., 1980, A seismological study of the May, 1980, and earlier earthquake activity near Mammoth Lakes, California, in Sherburne, R.W., ed., Mammoth Lakes, California earthquakes of May 1980, California Division of Mines and Geology Special Report 150, p. 91-122.

Decker, R.W., 1986, Forecasting volcanic eruptions: Annual Review of Earth and Planetary Sciences, v. 14, p. 267-291.

Dewey, J.W., Hill, D.P., Ellsworth, W.L., and Engdahl, E.R., 1989, Earthquakes, faults, and the seismotectonic framework of the contiguous United States, in Paksier, L.C., and Mooney, W.D., eds., Geophysical Framework of the Continental United States: Boulder, Colorado, Geological Society of America, p. 541-575.

Dreger, D.S., Tkalcic, H., and Johnston, M., 2000, Dilational process accompanying earthquakes in the Long Valley Caldera: Science, v. 288 , no. 5463 , p. $122-125$.

Dvorak, J.J., and Gasparini, P., 1991, History of earthquakes and vertical ground movement in Campi Flegrei caldera, southern Italy: comparison of precursory event to the A.D. eruption of Monte Nuovo and activity since 1986: Journal of Volcanology and Geothermal Research, v. 48, no. 1/2, p. 77-92.

Ewert, J.W., and Harpel, C.J., 2000, Bibliography and literature pertaining to Long Valley Caldera and associated volcanic fields: U.S. Geological Survey Open-File Report 00-221, v 1.0, http://geopubs.wr.usgs.gov/open-file/of00-221.

Farrar, C.D., Sorey, M.L., Evans, W.C., Howle, J.F., Kerr, B.D., Kennedy, B.M., King, C.-Y., and Southon, J.R., 1995, Forestkilling diffuse $\mathrm{CO} 2$ emission at Mammoth Mountain as a sign of magmatic unrest: Nature, v. 376, no. 6542, p. 675-678.

Galloway, D., Farrar, C.D., Howle, J.F., Roeloffs, E.A., Sneed, M., and Sorey, M.L., 1999, Hydrologic response to the 1997-period of crustal unrest at Long Valley Caldera, California [abs]: Eos, Transactions, American Geophysical Union, v. 80, no. 46, p. 981.

Gerlach, T.M., Doukas, M.P., McGee, K.A., and Kessler, R., 1999, Airborne detection of diffuse carbon dioxide emissions at Mammoth Mountain, California: Geophysical Research Letters, v. 26 , no. 24 , p. 3661-3664.

Gerlach, T.M., Westrich, H.R., and Symonds, R.B., 1996, Preeruption vapor in magma of the climactic Mount Pinatubo eruption: source of the giant stratospehric sulfur dioxide cloud, in Newhall, C.G., and Punongbayan, R.S., eds., Fire and Mud: Seattle, University of Washington Press, p. 415-433.

Gudmundsson, M.T., Sigmundsson, F., and Bjornsson, H., 1997, Ice-volcano interaction of the 1996 Gjalp subglacial eruption, Vatnajokull, Iceland: Nature, v. 389, p. 954-957.

Hanks, T.C., and Kanamori, H., 1979, A moment magnitude scale: Journal of Geophysical Research, v. 84, no. B5, p. 2348-2350.

Hasegawa, A., Zhao, D., Hori, S., Yamamoto, A., and Houruchi, S., 1991, Deep structure of the northeastern Japan arc and its relationship to seismic and volcanic activity: Nature, v. 352, p. 683-689.

Hill, D.P., 1984, Monitoring unrest in a large silicic caldera, the Long Valley Inyo Craters volcanic complex in east central California: Bulletin Volcanologique, v. 47, no. 2, p. 371-395.

Hill, D.P., 1992, Temperatures at the base of the seismogenic crust beneath Long Valley Caldera, California, and the Phlegrean Fields caldera, Italy, in Johnson, R.W., Mahood, G.A., and Scarpa, R., eds., Volcanic Seismology: New York, Springer-
Verlag, p. 432-461.

Hill, D.P., 1996, Earthquakes and carbon dioxide beneath Mammoth Mountain, California: Seismological Research Letters, v. 67, no. 1, p. $8-15$.

Hill, D.P., 1998, 1998 Seismological Society of America MeetingPresidential Address: Science, geologic hazards, and the public in a large restless caldera: Seismological Research Letters, v. 69 , no. 5 , p. $400-404$.

Hill, D.P., Bailey, R.A., and Ryall, A.S., 1985, Active tectonic and magmatic processes beneath Long Valley Caldera, eastern California; an overview: Journal of Geophysical Research, v. 90, no. 13 , p. 11,111-11,120.

Hill, D.P., Ellsworth, W.L., Johnston, M.J.S., Langbein, J.O., Oppenheimer, D.H., Pitt, A.M., Reasenberg, P.A., Sorey, M.L., and McNutt, S.R., 1990, The 1989 earthquake swarm beneath Mammoth Mountain, California; an initial look at the 4 May through 30 September activity: Bulletin of the Seismological Society of America, v. 80, no. 2, p. 325-339.

Hill, D.P., Johnston, M.J.S., Langbein, J.O., and Bilham, R., 1995, Response of Long Valley Caldera to the Mw $=7.3$ Landers, California, earthquake: Journal of Geophysical Research, v. 100, no. B7, p. 12,985-13,005.

Hill, D.P., Johnston, M.J.S., Langbein, J.O., McNutt, S.R., Miller, C.D., Mortensen, C.E., Pitt, A.M., and Rojstaczer, S.A., 1991, Response plans for volcanic hazards in the Long Valley Caldera and Mono Craters area, California, U.S. Geological Survey Open-File Report 91-270, p. 65.

Hill, D.P., Reasenberg, P.A., Michael, A., Arabaz, W.J., Beroza, G., Brumbaugh, D., Brune, J.N., Castro, R., Davis, S., dePolo, D., Ellsworth, W.L., Gomberg, J., Harmsen, S., House, L., Jackson, S.M., Johnston, M.J.S., Jones, L., Keller, R., Malone, S., Munguia, L., Nava, S., Pechmann, J.C., Sanford, A., Simpson, R.W., Smith, R.B., Stark, M., Stickney, M., Vidal, A., Walter, S., Wong, V., and Zollweg, J., 1993, Seismicity remotely triggered by the magnitude 7.3 Landers, California, earthquake: Science, v. 260, p. 1617-1623.

Hill, D.P., Wallace, R.E., and Cockerham, R.S., 1985, Review of evidence on the potential for major earthquakes and volcanism in the Long Valley-Mono Craters-White Mountains regions of eastern California: Earthquake Prediction Research, v. 3, no. 3-4, p. 571-594.

Hough, S.E., Dollar, R.S., and Johnson, P., 2000, The 1998 earthquake sequence south of Long Valley Caldera, California: hints of magmatic involvement: Bulletin of the Seismological Society of America, v. 90 p.

Howle, J.F., and Farrar, C.D., 1996, Hydrologic data for Long Valley Caldera, Mono County, California, 1978-93, U.S. Geological Survey Open-File Report 96-382, p. 286.

Johnston, M.J.S., 1989, Review of magnetic and electric field effects near active faults and volcanoes in the U.S.A.: Physics of the Earth and Planetary Interiors, v. 57, no. 1-2, p. 47-63.

Johnston, M.J.S., Hill, D.P., Linde, A.T., Langbein, J., and Bilham, R., 1995, Transient deformation during triggered seismicity from the 28 June $1992 \mathrm{Mw}=7.3$ Landers earthquake at Long Valley volcanic caldera, California: Bulletin of the Seismological Society of America, v. 85, no. 3, p. 787-795.

Julian, B.R., 1983, Evidence for dyke intrusion earthquake mechanisms near Long Valley Caldera, California: Nature, v. 303, no. 5915, p. 323-325.

Julian, B.R., 1994, Volcanic tremor: nonlinear excitation by fluid flow: Journal of Geophysical Research, v. 99, no. B6, p. 11,859-11,877.

Julian, B.R., Miller, A.D., and Foulger, G.R., 1998, Non-double- 
couple earthquakes: 1. Theory: Reviews of Geophysics, v. 36, no. 4, p. 525-549.

Julian, B.R., and Sipkin, S.A., 1985, Earthquake processes in the Long Valley Caldera area, California: Journal of Geophysical Research, v. 90, no. B13, p. 11,155-11,169.

Kaneshima, S., Kawakatsu, H., Matsubayashi, H., Sudo, Y., Tsutsui, T., Ohminato, T., Ito, H., Uhira, K., Yamasato, H., Oikawa, J., Takeo, M., and Iidaka, T., 1996, Mechanism of phreatic eruptions at Aso Volcano inferred from near-field broadband seismic observations: Science, v. 273, p. 642-645.

Lajoie, K.R., 1968, Late Quaternary stratigraphy and geologic history of Mono Basin, eastern California, University of California, Berkley, Ph.D., 271 p.

Langbein, J.O., 1989, Deformation of the Long Valley Caldera, eastern California, from mid-1983 to mid-1988; measurements using a two-color geodimeter: Journal of Geophysical Research, v. 94, no. B4, p. 3833-3849.

Langbein, J.O., Dzurisin, D., Marshall, G., Stein, R., and Rundle, J., 1995, Shallow and peripheral volcanic sources of inflation revealed by modeling two-color geodimeter and leveling data from Long Valley Caldera, California, 1988-1992: Journal of Geophysical Research, v. 100, no. B7, p. 12,487-12,496.

Langbein, J.O., Hill, D.P., Parker, T.N., Wilkinson, S.E., and Pitt, A.M., 1990, Renewed inflation of the resurgent dome in Long Valley Caldera, California, from mid-1989 to mid-1990 [abs]: Eos, Transactions, American Geophysical Union, v. 71, no. 43, p. 1466.

Langbein, J.O., Hill, D.P., Parker, T.N., and Wilkinson, S.K., 1993, An episode of reinflation of the Long Valley Caldera, eastern California: 1989-1991: Journal of Geophysical Research, v. 98, no. B9, p. 15,851-15,870.

Langbein, J.O., and Johnson, H., 1997, Correlated errors in geodetic time series; implications for time-dependent deformation: Journal of Geophysical Research, v. 102, no. B1, p. 591-604.

Mader, G.G., Blair, M.L., and Olson, R.A., 1987, Living with a volcanic threat; response to volcanic hazards, Long Valley, California: Portola Valley, CA, William Spangle and Associates, 105 p.

Malin, P., Stroujkova, A., and Shalev, E., 1998, A seismological witness to the birth of a dike: micro- hybred- and low-frequence earthquake activity at Mammoth, CA, in 1997 [abs.]: EOS, Transactions, AGU, v. 79, no. 45, p. F949.

Marshall, G.A., Langbein, J., Stein, R.S., Lisowski, M., and Svarc, J., 1997, Inflation of Long Valley Caldera, California, Basin and Range strain, and possible Mono Craters' dike opening from 1990 to 1994 GPS surveys: Geophysical Research Letters, v. 24, no. 9, p. 1003-1006.

McClelland, L., Simkin, T., Summers, M., Nielsen, E., and Stein, T.C., eds., 1989, Global Volcanism 1975-1985: Englewood cliffs, New Jersey, Prentice Hall, 655 p.

McGee, K.A., and Gerlach, T.M., 1998, Annual cycle of magmatic $\mathrm{CO} 2$ in a tree-kill soil at Mammoth Mountain, California; implications for soil acidification: Geology, v. 26, no. 5, p. 463-466.

McNutt, S.R., 2000, Volcanic seismicity, in Sigurdsson, H., ed., Encyclopedia of Volcanology: San Diego, San Francisco, Academic Press, p. 1,015-1,033.

McNutt, S.R., Rymer, H., and Stix, J., 2000, Synthesis of volcano monitoring, in Sigurdsson, H., ed., Encyclopedia of Volcanology: San Diego, Academic Press, p. 1165-1183.

Miller, A.D., Foulger, G.R., and Julian, B.R., 1998, Non-doublecouple earthquakes: 2. Observations: Reviews of Geophysics, v. 36 , no. 4 , p. $551-568$.
Miller, C.D., 1985, Holocene eruptions at the Inyo volcanic chain, California; implications for possible eruptions in Long Valley Caldera: Geology, v. 13, no. 1, p. 14-17.

Miller, C.D., 1989, Potential hazards from future eruptions in California, U.S. Geological Survey Bulletin 1847, p. 17.

Miller, C.D., Mullineaux, D.R., Crandell, D.R., and Bailey, R.A., 1982, Potential hazards from future volcanic eruptions in the Long Valley Mono Lake area, east central California and southwest Nevada; a preliminary assessment, U.S. Geological Survey Circular 877, p. 10.

Mortensen, C.E., and Hopkins, D.G., 1987, Tiltmeter measurements in Long Valley Caldera, California: Journal of Geophysical Research, v. 92, no. 13, p. 13,767-13,776.

Mueller, R.J., Johnston, M.J.S., and Langbein, J.O., 1991, Possible tectonomagnetic effect observed from mid-1989, to mid-1990, in Long Valley Caldera, California: Geophysical Research Letters, v. 18, no. 4, p. 601-604.

Murray, T., and Endo, E.T., 1989, A real-time seismic amplitude measurement system (RSAM): U.S. Geological Survey 89-684.

Newhall, C.G., 2000, Volcano Warnings, in Sigurdsson, H., ed., Encyclopedia of Volcanoes: San Diego, Academic Press, p. 1185-1197.

Newhall, C.G., and Dzurisin, D., 1988, Historical unrest at large calderas of the world, U.S. Geological Survey Bulletin 1855, p. 1108.

Newhall, C.G., and Self, S., 1982, The volcanic explosivity index (VEI): An estimate of explosive magnitude for historical volcanism: Journal of Geophysical Research, v. 87, p. 1,231-1,238.

Ohiminato, T., Chouet, B.A., Dawson, P.B., and Kedar, S., 1998, Waveform inversion of very-long-period impulsive signals associated with magmatic injection beneath Kilauea volcano, Hawaii: Journal of Geophysical Research, v. 103, p. 23,839-23,862.

Okada, Y., and Yamamoto, E., 1991, Dyke intrusion for the 1989 seismo-volcanic activity off Ito, central Japan: Journal of Geophysical Research, v. 96, p. 10,361-10,376.

Pitt, A.M., and Hill, D.P., 1994, Long-period earthquakes in the Long Valley Caldera region, eastern California: Geophysical Research Letters, v. 21, no. 16, p. 1679-1682.

Prejean, S.G., Ellsworth, W.L., Waldhouser, F., and Zoback, M.D., 2000, Earthquake relocations and stress inversions in the Long Valley Caldera, California [abs.]: EOS, Transactions, American Geophysical Union, v. 81, no. 48, p. F1323.

Priestley, K.F., Smith, K.D., and Cockerham, R.S., 1988, The 1984 Round Valley, California earthquake sequence: Geophysical Journal of the Royal Astronomical Society, v. 95, no. 2, p. 215-235.

Rojstaczer, S., Sorey, M.L., Farrar, C.D., and Clark, M.D., 1985, Water wells as strain meters during 1984 within the Long Valley Caldera [abs.]: Eos, Transactions, American Geophysical Union, v. 66, no. 18 , p. 363.

Rosi, M., and Santacroce, R., 1984, Volcanic hazard assessment in the Phlegrean Fields-A contribution based on stratigraphic and historical data: Bulletin Volcanologique, v. 47, no. 2, p. 359-370.

Rundle, J.B., and Hill, D.P., 1988, The geophysics of a restless caldera; Long Valley, California: Annual Review of Earth and Planetary Sciences, v. 16, p. 251-271.

Ryall, A.S., Jr., and Ryall, F., 1980, Spatial-temporal variations in the seismicity preceding the May, 1980, Mammoth Lakes, California, earthquakes, in Sherburne, R.W., ed., Mammoth Lakes, California earthquakes of May 1980, California Division of Mines and Geology Special Report 150, p. 27-39. 
Ryall, A.S., Jr., and Ryall, F., 1983, Spasmodic tremor and possible magma injection in Long Valley Caldera, eastern California: Science, v. 219, no. 4591, p. 1432-1433.

Savage, J.C., 1988, Principal component analysis of geodetically measured deformation in Long Valley Caldera, eastern California, 1983-1987: Journal of Geophysical Research, v. 93, no. B11, p. 13,297-13,305.

Savage, J.C., and Clark, M.M., 1982, Magmatic resurgence in Long Valley Caldera, California; possible cause of the 1980 Mammoth Lakes earthquakes: Science, v. 217, no. 4559, p. 531-533.

Savage, J.C., Cockerham, R., S., Estrem, J.E., and Moore, L.R., 1987, Deformation near the Long Valley Caldera, eastern California, 1982-1986: Journal of Geophysical Research, v. 92 , no. 3, p. 2721-2746.

Savage, J.C., and Cockerham, R.S., 1984, Earthquake swarm in Long Valley Caldera, California, January 1983; evidence for dike inflation: Journal of Geophysical Research, v. 89, no. 10, p. 8315-8324.

Shimozuru, D., and Kagiyama, T., 1989, Some significant features of pre-eruption volcanic earthquakes, in Latter, J.H., ed., Volcanic Hazards: Berlin, Heidelberg, Springer-Verlag, p. 504-512.

Smith, K.D., and Priestley, K.F., 1988, The foreshock sequence of the 1986 Chalfant, California, earthquake: Bulletin of the Seismological Society of America, v. 78, no. 1, p. 172-187.

Sorey, M.L., Evans, W.C., Kennedy, B.M., Farrar, C.D., Hainsworth, L.J., and Hausback, B., 1998, Carbon dioxide and helium emissions from a reservoir of magmatic gas beneath Mammoth
Mountain, California: Journal of Geophysical Research, v. 103, no. B7, p. 15,303-15,323.

Stine, S.W., 1987, Mono Lake; the past 4,000 years: University of California, Berkeley, Ph.D. dissertation, $732 \mathrm{p}$.

Takeo, M., 1990, Analysis of Long-period seismic waves excited by the November 1987 eruption of Izu-Oshima Volcano: Journal of Geophysical Research, v. 95, p. 19,377-19,393.

Tilling, R.I., 1995, The role of monitoring in forecasting volcanic events, in McGuire, B., Kilburn, C.R., and Murray, J., eds., Monitoring Active Volcanoes: London, UCL Press, p. 369-402.

U.S. Geological Survey, 1984, USGS Response Plan for Volcanic Hazards in the Long Valley Caldera - Mono Craters Area, California: U.S. Geological Survey 84-500.

Van Wormer, J.D., and Ryall, A.S., 1980, Sierra Nevada-Great Basin boundary zone: earthquake hazards related to structure, active tectonic processes, and anomalous patterns of earthquake occurrence: Bulletin of the Seismological Society of America, v. 70 , p. $1557-1572$.

Wallace, T.C., Given, J., and Kanamori, H., 1982, A discrepancy between long and short period mechanisms of earthquakes near the Long Valley Caldera: Geophysical Research Letters, v. 9 , no. 10 , p. 1131-1134.

Young, S.R., Francis, P.W., Barclay, J., Casadevall, T.J., Gardner, C.A., Darroux, B., Davies, M.A., Delmelle, P., Norton, G.E., Maciejewski, A.J.H., Oppenheimer, C.M.M., Stix, J., and Watson, I.M., 1998, Monitoring SO2 emission at the Soufriere Hills volcano: Implications for changes in eruptive conditions: Geophysical Research Letters, v. 25, no. 19, p. 3681-3684. 
[Intentionally left blank] 


\section{Appendix A. History of Volcanism in the Long Valley Region}

\section{Geologic Setting}

Long Valley Caldera, located in east-central California, is a 15 - by $30-\mathrm{km}$ (9- by 18 -miles), elliptical depression at the base of a left-stepping offset in the eastern escarpment of the Sierra Nevada range. The Mono-Inyo Craters form a 40-km(24 mile) long chain of rhyolitic volcanic centers that extends northward from the west-central part of the caldera to the south shore of Mono Lake. The adjacent eastern escarpment of the Sierra Nevada, which is dominated by large, eastdipping normal faults, forms the western margin of the extensional Basin and Range Province (fig. A1; also see figs. 1, 2).

Earthquake and volcanic activity in this part of eastcentral California and the Owens Valley corridor to the south reflect the long-term interaction between tectonic and magmatic processes in the Earth's crust and upper mantle underlying the Sierra Nevada and the Basin and Range Province to the east. The tectonic processes are driven by a combination of the Pacific Plate sliding northwestward past the North American Plate along the San Andreas Fault System in coastal

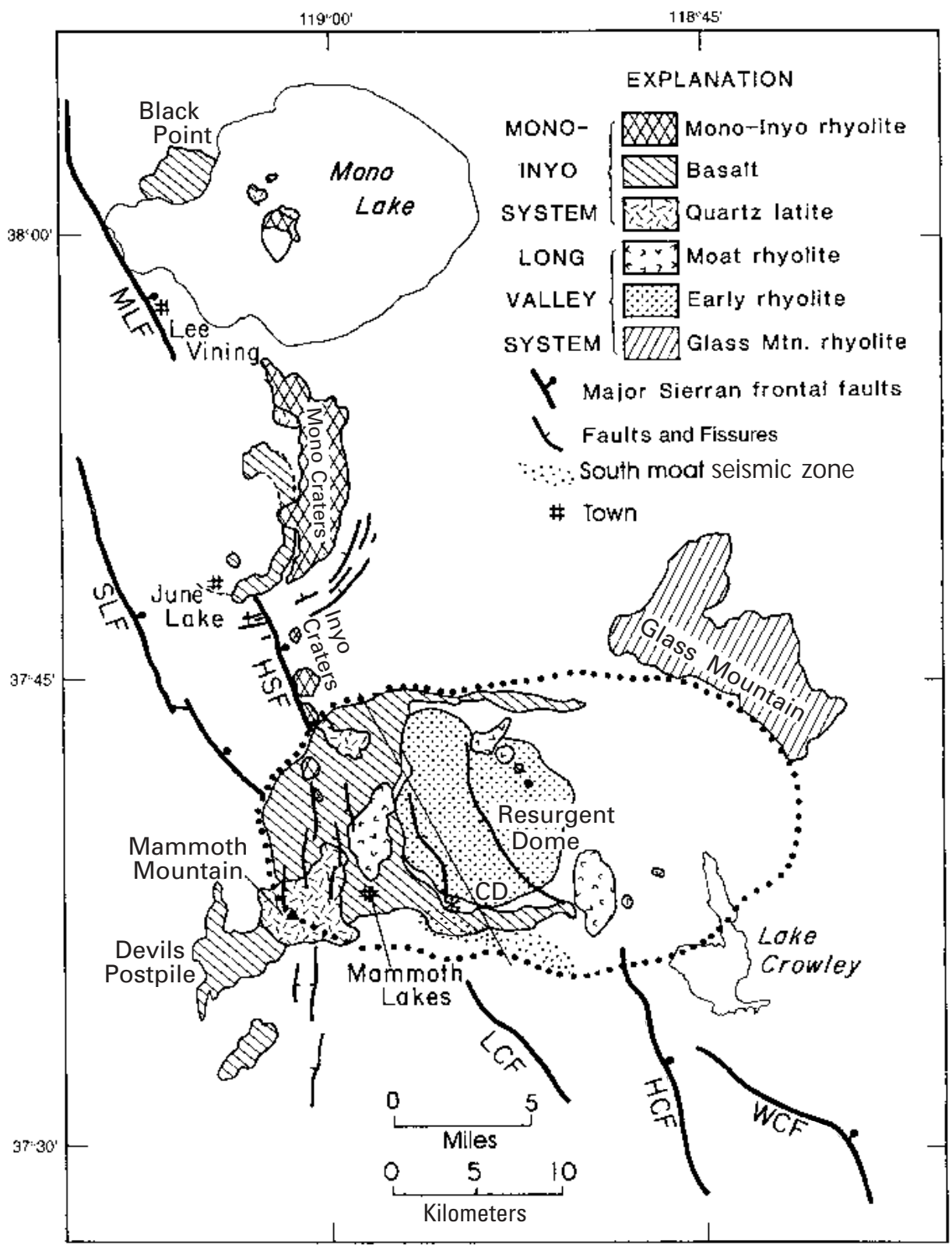

Figure A1.-Simplified geologic map for Long Valley Caldera and the Mono-Inyo Craters volcanic chain (based on Bailey, 1989). CD, Casa Diablo; HC Hot Creek; HCF Hilton Creek Fault; HSF, Hartley Springs Fault; LCF, Laurel Creek Fault; MLF, Mono Lake Fault; SLF, Silver Lake Fault; WCF, Wheeler Crest Fault. 
California and the westward extension of the crust across the Basin and Range Province between the Sierra Nevada and the Wasatch Mountains in central Utah (Dewey and others, 1989). In contrast to most volcanic systems along the Circum-Pacific "Ring of Fire," which are associated with subduction (sink- ing) of the relatively thin and dense oceanic lithosphere as it is overridden by thicker and less-dense continental lithosphere, magmatic processes and volcanism in eastern California are related to the upwelling of magma into the crust from the underlying mantle as the crust stretches, thins, and occasion-

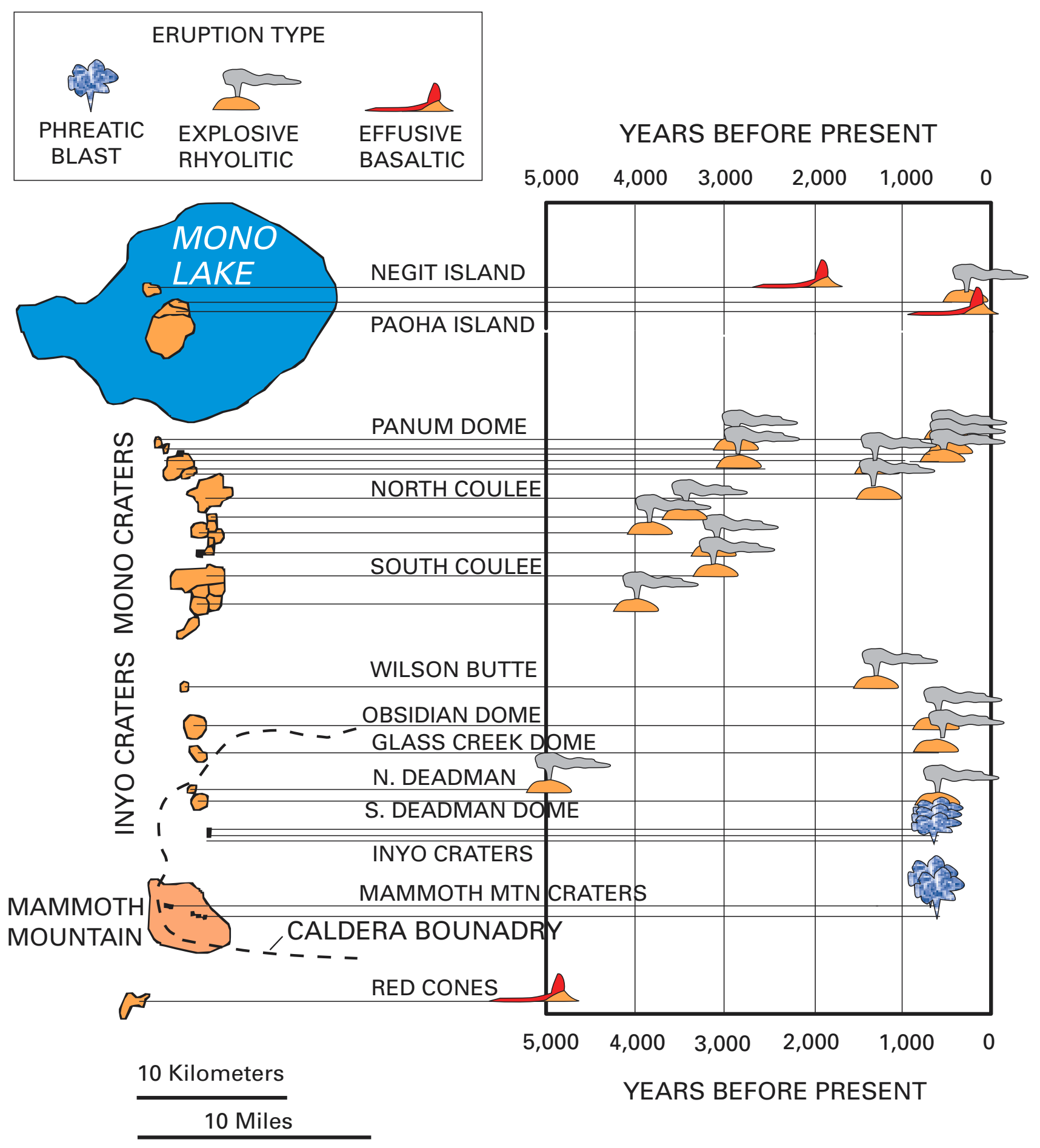

Figure A2.-Eruptive history for the Mono-Inyo Craters volcanic chain for the past 5,000 years. Eruption volumes have all been relatively small (generally less than $0.1 \mathrm{~km}^{3}\left(0.024 \mathrm{mi}^{3}\right.$ compared with the $0.25 \mathrm{~km}^{3}\left(0.06 \mathrm{mi}^{3}\right)$ for the magmatic component of the May $1980 \mathrm{Mount}$ St. Helens eruption). Several of the explosive eruptions, however, have produced pyroclastic flows extending as far as $8 \mathrm{~km}(5 \mathrm{miles})$ from the vent. Phreatic, steam blast produced by superheated ground water; basalt, a hot, fluid lava that solidifies into dark volcanic rock containing 54 to 62 percent silica (typical of the lavas erupted by Hawaiian volcanoes); rhyolite, a viscous, gas-rich lava that solidifies into light-colored volcanic rock or obsidian (volcanic glass) with 69 to 80 percent silica $\left(\mathrm{SiO}_{2}\right)$. 
ally fractures in response to extension across the Basin and Range Province. These tectonic and magmatic interactions are complex, and they remain a focus of active geoscience research.

The region of eastern California that includes Long Valley Caldera has been a persistent source of volcanic activity throughout much of its geologic history (Bailey and others, 1976). The most recent episode of volcanism began about 3 million years (m.y.) ago with wide-spread eruptions of intermediate and basaltic lavas accompanying the onset of large-scale normal faulting and formation of the eastern front of the Sierra Nevada. Beginning about 2 m.y. ago, multiple rhyolitic eruptions from vents along the northeast rim of the present-day caldera formed the Glass Mountain complex (fig. A1). Long Valley Caldera was formed about 760,000 years ago by the catastrophic eruption of more than $600 \mathrm{~km}^{3}(130$ miles $^{3}$ ) of rhyolitic lavas (the Bishop Tuff), accompanied by subsidence of an elliptically shaped crustal block 1 to 2 $\mathrm{km}$ (0.6 to 1.2 miles) into the partially evacuated magma chamber. Smaller eruptions from the residual magma chamber accompanied uplift of the west-central section of the caldera over the next 100,000 years to form the resurgent dome. Subsequent eruptions of rhyolite lavas occurred around the margin of the resurgent dome at 500,000, 300,000, and

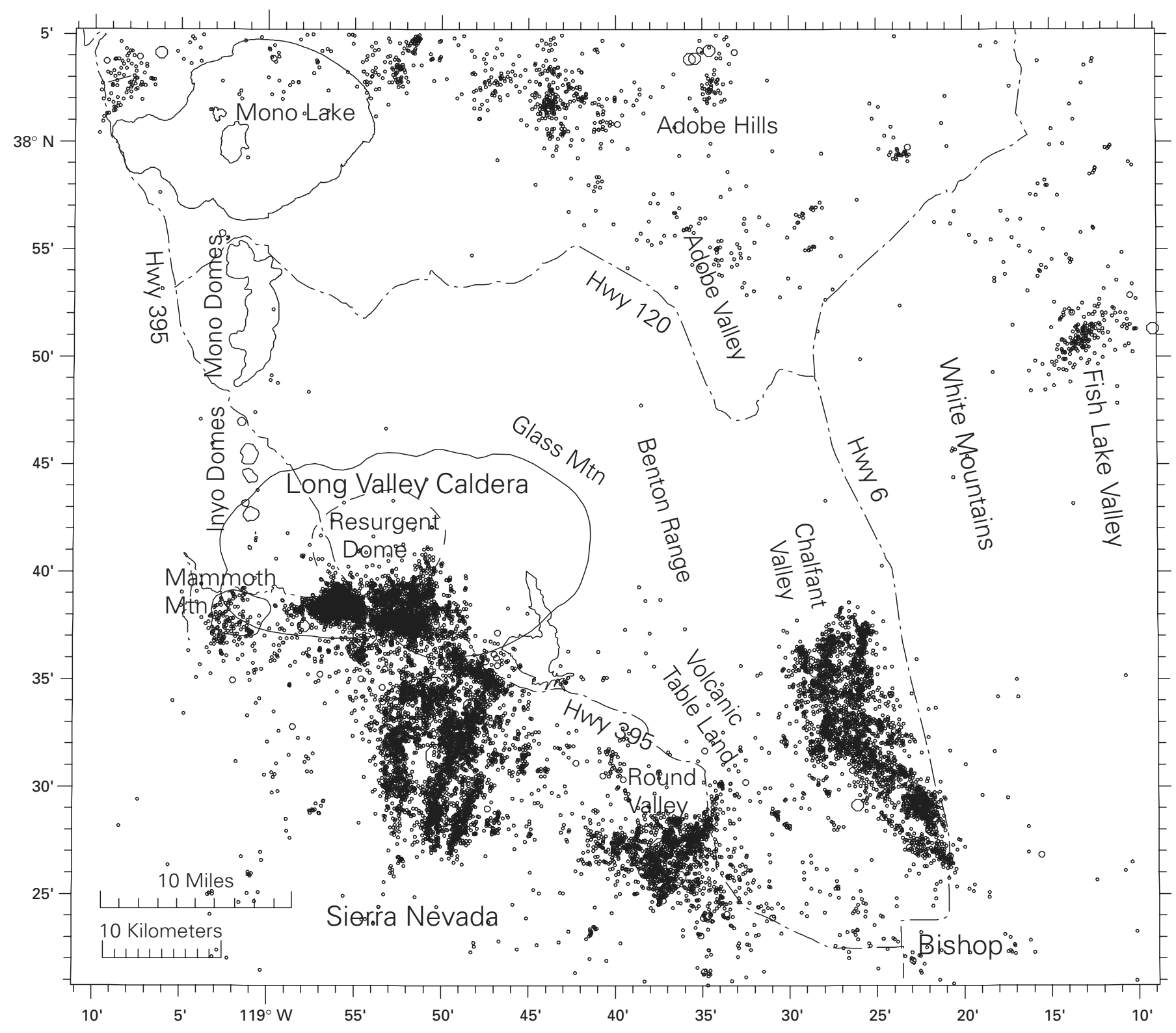

Figure A3.-Seismicity map for magnitude (M) $\geq 2.0$ earthquakes in the Long Valley Caldera and Mono-Inyo Craters region for the period 1978 through 1999. Circles indicate earthquake epicenters with circle size scaling with earthquake magnitude in five steps from $M=2.0$ to $M=6.0$. Dominant earthquake clusters for this period include: (1) recurring swarms in the south moat of Long Valley Caldera and the Sierra Nevada block immediately to the south, (2) the 1984 Round Valley cluster, (3) the 1986 Chalfant Valley cluster, (4) the Mono Lake-Adobe Hill clusters, and (5) the Fish Lake Valley cluster located just east of the northern end of the White Mountains and the north end of the Death Valley-Furnace Creek Fault. 
100,000 years ago (Bailey, 1989, 1990; Bailey and others, 1976).

Between about 220,000 and 50,000 years ago, basaltic and rhyodacitic lavas erupted from widespread vents in the west moat of the caldera. During this same interval, repeated rhyodacitic eruptions from a tightly clustered group of vents on the southwestern rim of the caldera produced the domes and flows that form Mammoth Mountain (Bailey, 1989).

The most recent eruptions in the region occurred along the Mono-Inyo Craters volcanic chain. Rhyolitic eruptions began along this chain about 40,000 years ago and have continued through recent times with eruptions along the north end of the Mono Craters about 600 years ago (Bursik and Sieh, 1986) and along the south end of the Inyo Craters about 550 years ago (Miller, 1985). In both cases, the eruptions resulted from the intrusion of an 8-10 km-long, north-striking feeder dike into the shallow crust that vented several places along strike. Intrusion of a shallow crypto dome beneath
Mono Lake 250 years ago uplifted the lake-bottom sediments to form Pahoa Island and vented in a small eruption of andesitic lavas from vents on the north side of the island (Lajoie, 1968; Stine, 1987). As illustrated in figure A2, the eruptive history of the Mono-Inyo volcanic chain over the past 5,000 years includes some 20 small eruptions at intervals ranging from 250 to 700 years. Although small, most of these eruptions have been explosive in nature. Given this 5,000-year eruptive history, the odds of another eruption somewhere along the Mono-Inyo volcanic chain are about one in 200 in any given year (0.05 percent per year).

See Ewert and Harpel (2000) for a bibliography on Long Valley Caldera and the associated volcanic field.

\section{Recent Unrest: 1978-2000}

The region south of Long Valley Caldera that includes the eastern Sierra Nevada and Owens Valley has been one of the

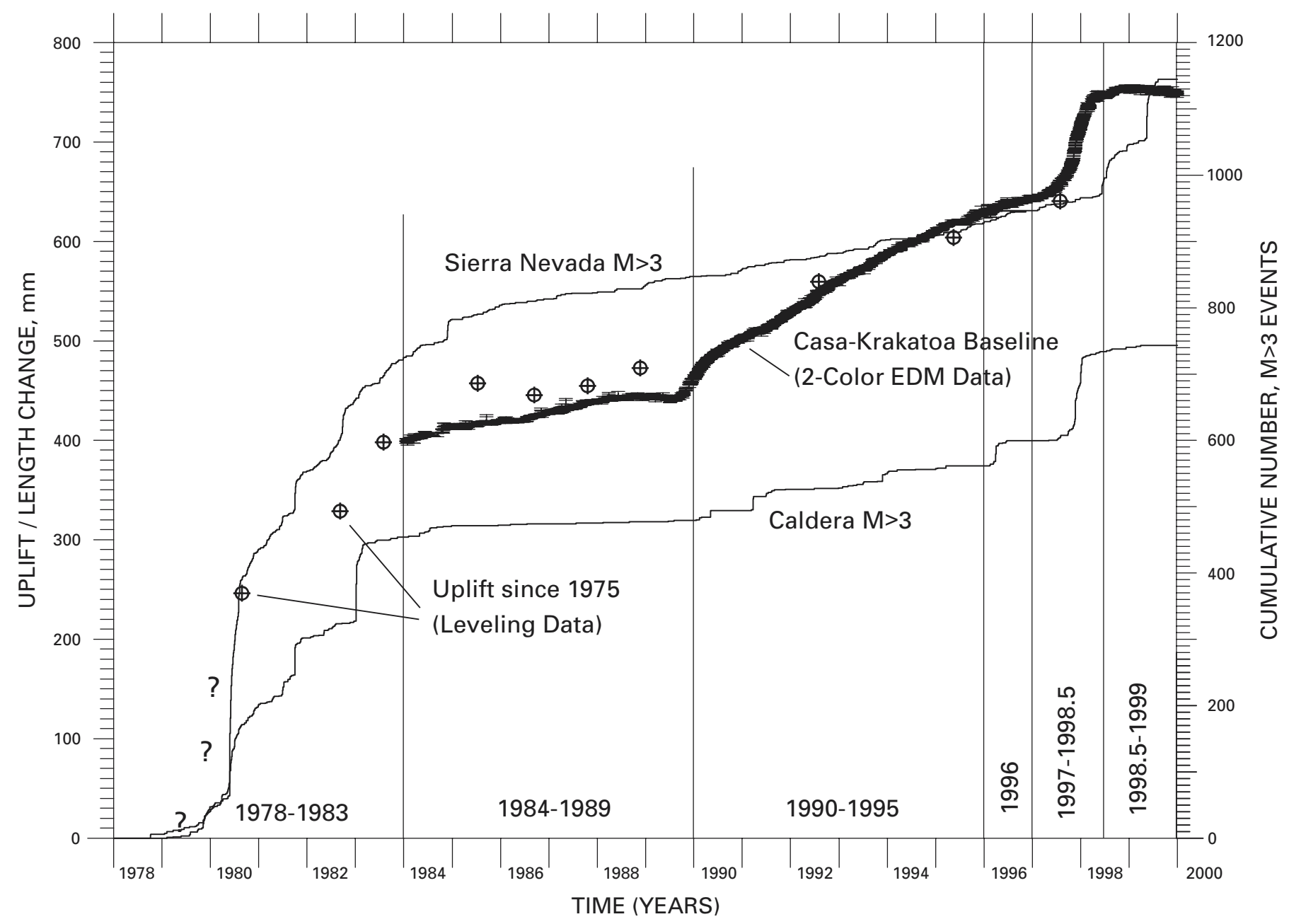

Figure A4.-The history of earthquake activity and swelling of Long Valley's resurgent dome from 1978 through 1999 in terms of (1) the cumulative number of magnitude $(M) \geq 3$ earthquakes within both Long Valley Caldera (Caldera $M>3$ ) and the Sierra Nevada block to the south (Sierra Nevada $\mathrm{M}>3$ ), and (2) deformation of the resurgent dome reconstructed from the uplift history of a benchmark near the center of the resurgent dome (near the intersection of lines 4 and 5 in fig. D5) from leveling surveys through mid-1997 and the extension (thick line) of the 8-km-long (5 mile long) baseline spanning the resurgent dome between the monuments CASA and KRAKATOA since mid-1983 based on frequent measurements with the two-color EDM instrument (see fig. C3). 

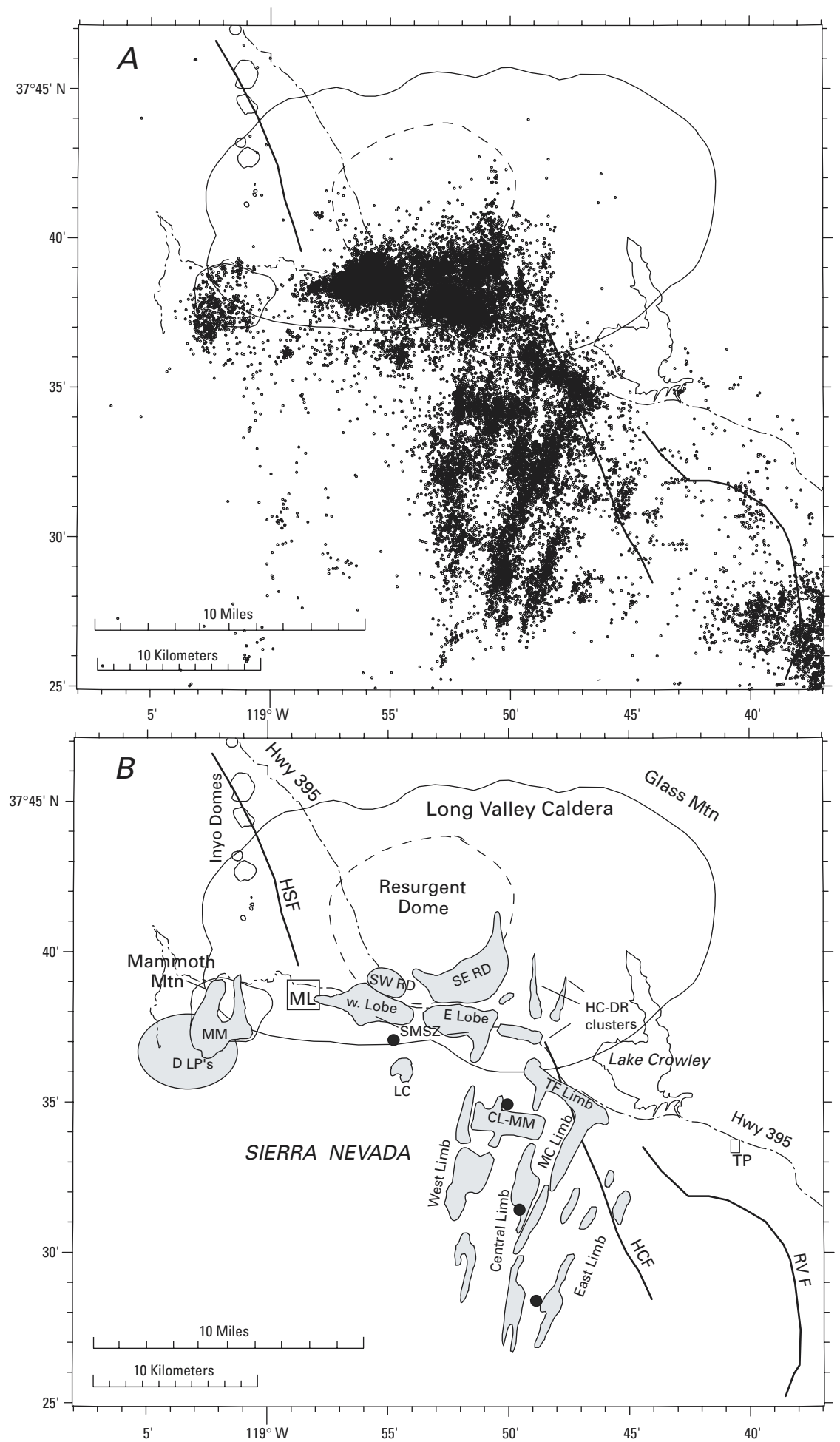

Figure A5.-A, Seismicity patterns in Long Valley Caldera and the adjacent Sierra Nevada block defined by magnitude (M) $\geq 1.5$ earthquakes from 1978 through 1999. B, Dominant seismicity clusters for the same period along with selected landmarks in the area; solid dots are epicenter of the $M \sim 6$ earthquakes of May 25-27, 1980. Abbreviations for seismic clusters (shaded areas) are: CL-MM, Convict Lake-Mt. Morrison; DLP's, deep long-period earthquakes (epicenters not plotted in A); HC-DR, Hot Creek-Doe Ridge; LC, Laurel Creek; MC limb, McGee Creek limb; MM, Mammoth Mountain; SMSZ, south moat seismic zone with east (E) and west (W) lobes; SE RD, southeast resurgent dome; SW RD, southwest resurgent dome; TF limb, Tobacco Flat limb. Abbreviations for major, range-front normal faults (heavy lines) are: HCF, Hilton Creek Fault; HSF, Hartly Springs Fault; and RVF, Round Valley Fault. Abbreviations for roads and places are: Hwy 395, Highway 395; ML, Mammoth Lakes; TP, Tom's Place. 

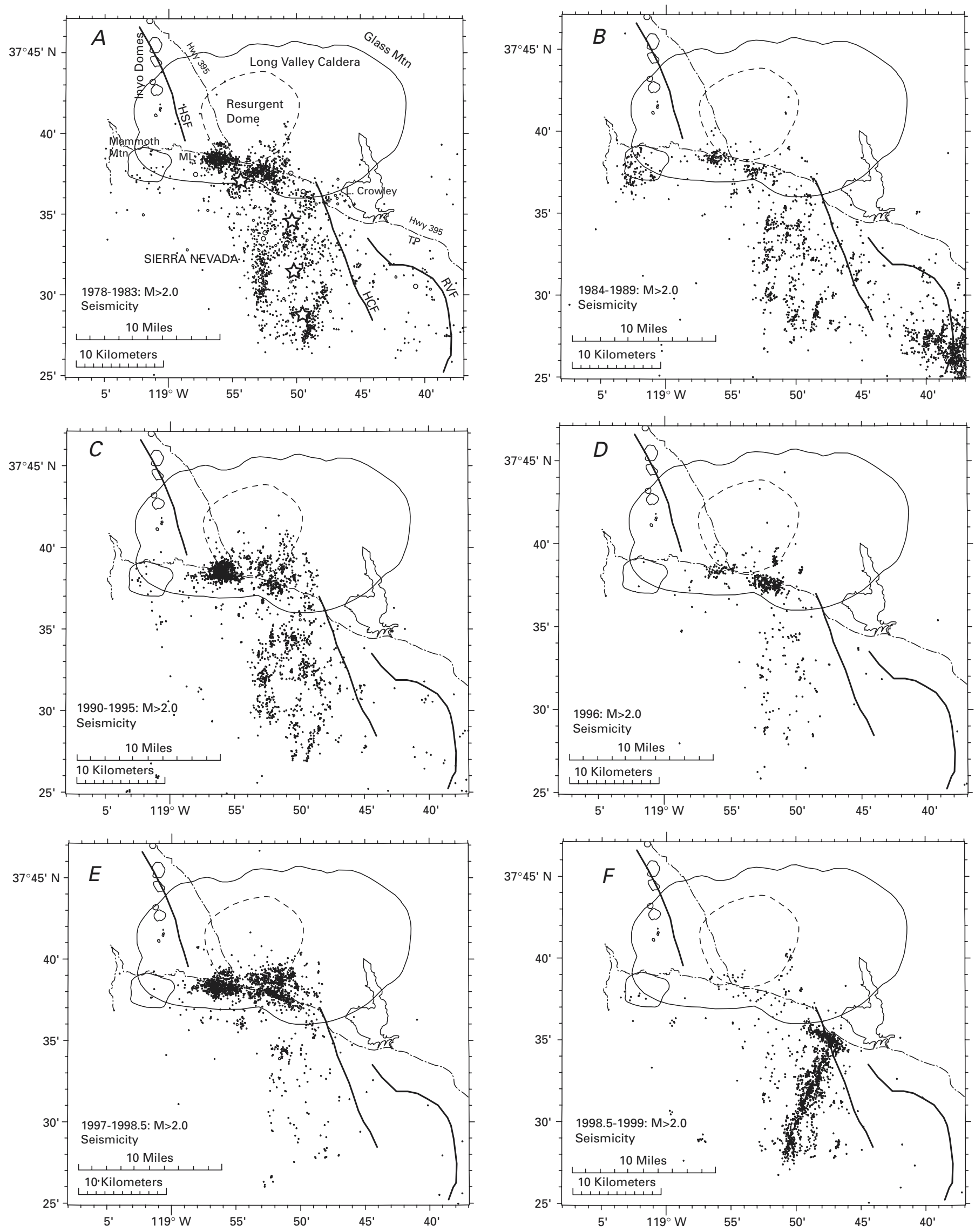

Figure A6.-Seismicity patterns in the Long Valley region for the six time intervals identified in figure A4. Names identified in A: ML, Mammoth Lakes; TP, Tom's Place; HCF, Hilton Creek Fault; HSF, Hartley Springs Fault; WC-RVF, Wheeler Crest-RoundValley Fault. The stars in A are the epicenters of the four $M=6$ earthquakes of May 25-27, 1980. 
most persistent sources of moderate to strong earthquakes in California in historical time (dating from the 1860's in eastern California) (Hill, Wallace, and Cockerham, 1985; Ryall and Ryall, 1980). The northern end of the rupture zone of the great (magnitude 8) Owens Valley earthquake of 1872 extended to within $60 \mathrm{~km}$ of the caldera. From 1910 through 1970, some 20 magnitude $(M)=5$ to 6 earthquakes occurred within 40 $\mathrm{km}$ of the south margin of Long Valley Caldera, including a cluster of four $M \geq 5$ events and one $M=6$ event in September1941 near Tom's Place approximately $10 \mathrm{~km}$ southeast of the caldera (Cramer and Toppozada, 1980). However, none of the $M>5$ earthquakes during the 1910-70 interval were located within the caldera. The same appears to be true for M>3 earthquakes as far back as the 1940's when the evolving regional seismic networks operated by the California Institute of Technology and the University of California at Berkeley became capable of detecting and locating $M>3$ earthquakes in eastern California.

The following paragraphs describe the unrest in Long Valley Caldera and vicinity that began in 1978 and persisted through the end of the $20^{\text {th }}$ century. Figures A3, A4, and A5 summarize the activity through this period (1978-99) in terms of (1) the distribution of $M \geq 2$ earthquakes in the greater Long Valley Caldera-Mono Craters region (also see the frontispiece for a map of $M \geq 3$ earthquakes for the same period), (2) the uplift history of the resurgent dome and the cumulative number of $\mathrm{M} \geq 3$ earthquakes in the caldera and the Sierra Nevada block, and (3) the dominant seismicity clusters within Long Valley Caldera and the adjacent Sierra Nevada.

\section{Increasing unrest: 1978-83}

Earthquakes of $\mathrm{M}=3$ to 4 began occurring intermittently within the south moat of the caldera in the months following a M=5.8 earthquake on October 4, 1978, located beneath Wheeler Crest midway between Mammoth Lakes and Bishop, some $15 \mathrm{~km}$ southeast of the caldera (see figure A6; Van Wormer and Ryall, 1980). This activity culminated in an intense earthquake sequence that began in late May 1980 and then gradually slowed through the summer. The late-May activity included four $M \sim 6$ earthquakes. Three occurred on May 25-the first located just west of Convict Lake near the south margin of the caldera (the CL-MM cluster in fig. A5), the second beneath the south moat (within the west lobe of the south-moat seismic zone (SMSZ) of fig. A4), and the third within the Sierra Nevada block about $5 \mathrm{~km}$ south of the caldera (midway along the central limb of the Sierra Nevada cluster of fig. A5). Aftershocks continued to shake the region, and on May 27 the Director of the USGS announced a Hazard Watch (see appendix B) for additional potentially damaging earthquakes in the region. A fourth $\mathrm{M} \sim 6$ earthquake on May 27 struck an area about $10 \mathrm{~km}$ south of the caldera (the southern section of the central limb in the Sierra Nevada cluster of fig. A3) later that day (Hill, Bailey, and Ryall 1985; Hill, Wallace, and Cockerham, 1985).

The focal mechanisms of the May 1980 M 6 earthquakes all showed dominantly strike-slip solutions with $T$-axes (extension directions) having a northeast-southwest orientation generally consistent with right-lateral slip within the west-northwest-trending SMSZ and left-lateral slip in the north-northeast trending seismicity lineations in the adjacent Sierra Nevada block. This basic kinematic pattern with a northeast-southwest extension direction prevailed for earthquakes in the caldera and the adjacent Sierra Nevada block at least through the end of the $20^{\text {th }}$ century. Two of the May 1980, M=6 earthquakes (the northernmost and southernmost in the Sierra Nevada block), as well as the $M=5.8$ earthquake of October 1978, also showed significant nondouble-couple components consistent with either fluid (magma) injection or simultaneous shear failure on fault segments at oblique angels to one another (Chouet and Julian, 1985; Julian and Sipkin, 1985; Wallace and others, 1982). Similar nondoublecouple patterns have appeared in the focal mechanisms of a number of earthquakes over the subsequent 20 years (see, for example, Dreger and others, 2000).

Leveling and trilateration measurements completed in 1980 showed that the central section of the caldera (the resurgent dome) had developed a $25-\mathrm{cm}$ domical uplift between the fall of 1979 and the summer of 1980 (fig. A4, Savage and Clark, 1982). Earthquakes continued to occur in the Sierra Nevada block south of the caldera, including a $\mathrm{M}=5.9$ event on September 30, 1981 located beneath the west end of the Convict Lake-Mt. Morrison cluster (fig. A5B) and just 2 to $3 \mathrm{~km}$ west of the initial M=6.1 earthquake of May 1980. Earthquake swarm activity within the caldera, which commonly included $\mathrm{M}=3$ to 4 earthquakes, continued in the SMSZ through 1982 (fig. A4, A6A). Concerns raised by these persistent earthquake swarms and inflation of the resurgent dome, together with new fumarolic activity in the Casa Diablo area at the southwestern margin of the resurgent dome in January 1982, prompted the Director of the USGS to issue a Notice of Potential Volcanic Hazards (appendix B) on May 25, 1982. Strong reaction to this Hazards Notice within the local community, the news media, federal, state, and local agencies overshadowed the relatively modest earthquake swarm activity that persisted within the caldera through remainder of 1982 (Hill, 1998; Hill, Bailey, and Ryall, 1985; Mader, and others, 1987).

On January 7, 1983, an intense earthquake swarm, which included two $M=5.3$ earthquakes and a multitude of smaller events, began in the west lobe of the SMSZ (near the epicenter of the second M 6 earthquake of May 25, 1980). This swarm was accompanied by an additional $7 \mathrm{~cm}$ uplift of the resurgent dome, the possible intrusion of a dike to within $4 \mathrm{~km}$ of the surface beneath the south moat, and by roughly $20 \mathrm{~cm}$ of rightlateral slip along the SMSZ (Savage and Cockerham, 1984). The January 1983 swarm, which involved the entire SMSZ, gradually subsided in intensity over the next several months and was followed by occasional smaller swarms through the remainder of 1983 and the first half of 1984. The Notice of Potential Volcanic Hazard issued in May 1982 was withdrawn de facto on September 30, 1983, when the USGS changed its formal hazard notification terminology from the three-level Notice-Watch-Warning system to a single-level Hazard Warning system (appendix B; Mader, and others, 1987). 


\section{Slowing Caldera Unrest and Regional Earthquakes: 1984-88}

Following an earthquake swarm in the west lobe of the SMSZ in the last half of July 1984, which included M=3.6 and $\mathrm{M}=3.2$ earthquakes, activity within the caldera declined to a relatively low level that persisted through early 1989 (figs. A4, A6B). Strong earthquake activity continued in the vicinity of the caldera, however, with a $\mathrm{M}=5.8$ earthquake in Round Valley $20 \mathrm{~km}$ southeast of the caldera on November 23, 1984 (fig. A3; Priestley and others, 1988) and a $M=6.4$ earthquake in Chalfant Valley, $30 \mathrm{~km}$ east of the caldera, on July 21, 1986 (Cockerham and Corbett, 1987; Smith and Priestley, 1988). Both these earthquakes produced felt shaking throughout the region, and both were followed by prolonged aftershock sequences. The Chalfant earthquake sequence was particularly intense. It was preceded by an energetic foreshock sequence that increased in intensity during the month prior to the $\mathrm{M}=6.4$ mainshock and included a $\mathrm{M}=5.9$ earthquake 24 hours before the mainshock. The protracted aftershock sequence included four $\mathrm{M}>5$ earthquakes, the largest of which was a M=5.8 event on July 31 .

Deformation measurements (fig. A4) showed continued but slowing inflation of the resurgent dome with the uplift rate dropping below $1 \mathrm{~cm}$ per year from 1984 through late 1989. The cumulative uplift over the central part of the resurgent dome, with respect to its pre-1980 level, exceeded $50 \mathrm{~cm}$ by mid-1989 (Langbein, 1989; Savage, 1988).

\section{The 1989 Mammoth Mountain Swarm, Long-Period Earthquakes, and $\mathrm{CO}_{2}$ Emissions}

In early May 1989, an 8-month-long swarm of small earthquakes began under Mammoth Mountain on the southwest rim of the caldera (fig. A6B; the MM cluster in fig. A5B) and persisted to the end of that year. This swarm appears to have been associated with a dike-like (tabular shape with a vertical orientation) intrusion of magma to depths as shallow as $3 \mathrm{~km}$ beneath Mammoth Mountain (Hill and others, 1990; Langbein and others, 1993). Although the swarm was not particularly energetic, it was prolonged. It was accompanied by minor deformation (approximately $1 \mathrm{~cm}$ of uplift) and included only four $\mathrm{M} \sim 3$ earthquakes in addition to thousands of smaller earthquakes and frequent spasmodic bursts, the latter of which were likely associated with very-long-period (VLP) earthquakes (see appendix C). This swarm marked the onset of (1) a continuing series of deep, long-period (LP) volcanic earthquakes centered at depths of 10 to $25 \mathrm{~km}$ ( 6 to 15 miles) beneath the southwest flank of Mammoth Mountain and the Devils Postpile (see DLP's in fig. A5), and (2) the diffuse emission of cold, magmatic $\mathrm{CO}_{2}$ in the soil in several areas around the flanks of Mammoth Mountain (Farrar and others, 1995; Hill, 1996). Both the deep LP earthquakes and $\mathrm{CO}_{2}$ emissions have continued into 2001, and both appear to be related to the presence of basaltic magma at mid-crustal depths (10 to $25 \mathrm{~km}$ or 6 to 15 miles) beneath the southwest flank of Mammoth Mountain and Devils Postpile (Gerlach and others, 1999; Sorey and others, 1998).

Efforts to keep local civil authorities appraised of the significance of the evolving Mammoth Mountain swarm activity led to the development of a five-level, alphabetic status scheme (E through A) for relating activity levels to response actions. This alphabetic status scheme was formally adopted for the Long Valley Caldera-Mono Craters region with the publication of USGS Open File Report 91-270 in June 1991 (Hill and others, 1991).

\section{Unrest Returns to the Caldera: $1990-95$}

Beginning in late September 1989, measurements with a two-color Electronic Distance Meter (EDM) showed that the extension rate across the resurgent dome had increased abruptly from less than $1 \mathrm{~cm}$ ( 0.4 inches) per year to more than $7 \mathrm{~cm}$ (2.8 inches) per year, heralding a return of unrest within the caldera (fig. A4). Three months later (early January 1990), earthquake swarm activity resumed in the south moat (Langbein and others, 1993). At about the same time, the $7-\mathrm{cm} / \mathrm{yr}(2.8 \mathrm{in} / \mathrm{yr})$ extension rate began slowing, and by late March 1990, the extension rate had slowed to 2 to $3 \mathrm{~cm}$ ( 0.8 to 1.2 in) per year. This rate persisted with only minor variations through 1995 (fig. A4). The renewed earthquake swarm activity began in the western lobe of the SMSZ (fig. A5B). By the end of 1990, it involved both the east and west lobes, as well as much of the southern section of the resurgent dome. The strongest swarm during this 1990-95 period occurred during March 24-27, 1991. It was located in the west lobe of the SMSZ and included more than 1,000 detected events with twenty-two $M>3$ earthquakes, two of which had magnitudes of $\mathrm{M}=3.7$.

A south-moat earthquake swarm on June 28 to 30, 1992, is particularly noteworthy, not because of its intensity but because of its timing. This swarm began within seconds after the S-wave from the $\mathrm{M}=7.3$ Landers earthquake of June 28 , 1982, passed through the caldera. (The epicenter of the Landers earthquake was centered in the Mojave Desert some 400 $\mathrm{km}$ south of the caldera.) As it turned out, many areas across the western United States showed an abrupt increase in local seismicity rates following the Landers earthquake, providing the first clearly documented case of remotely triggered seismicity by a large, distant earthquake (Hill and others, 1993). At Long Valley Caldera, the shear waves from the Landers earthquake also triggered a transient, caldera-wide uplift that reached a peak strain of 0.3 parts per million (ppm) 5 to 6 days after the Landers event (Hill, and others, 1995; Johnston, and others, 1995). (Note: the 0.3-ppm peak strain corresponds to a peak uplift of roughly $0.5 \mathrm{~cm}$ or 0.2 inches.) The June 1992 swarm itself included more than 250 located events distributed throughout the SMSZ, the largest of which was $M=3.4$ earthquake in the west lobe. Triggered seismic activity in the Sierra Nevada block immediately south of the caldera included a $\mathrm{M}=3.7$ earthquake.

Caldera earthquake activity and inflation of the resurgent dome gradually slowed from early 1994 through early 1996 (fig. A4). Earthquake activity in the Sierra Nevada block south 
of the caldera, however, continued at a relatively steady rate (fig. A6C). Most of this 1990-95 Sierra Nevada activity was concentrated in elongated clusters forming the western, central, and eastern limbs of the north-northeast trending seismicity lineations south of the caldera (figs. A3, A5, A6C). The most intense of this Sierra Nevada seismic activity was centered beneath Red Slate Mountain in the southern cluster of the west limb (fig. A5B) during August 10 to 15, 1993. This swarm sequence included more than $400 \mathrm{M}>1$ earthquakes, the largest of which had a magnitude of $\mathrm{M}=4.5$.

\section{The March-April 1996 South-Moat Earthquake Swarm}

In contrast to the general tendency of caldera earthquake swarm activity to track the uplift rate of the resurgent dome (fig. A4), one of the strongest earthquake swarms in the caldera occurred in March and April of 1996 as inflation of the resurgent dome was slowing. This seismic sequence began as a series of small earthquake swarms in the east lobe of the SMSZ in early 1996 (figs. A5B, A6D). Activity gradually escalated in intensity through February and early March, culminating in late March and early April with what at the time was the most energetic earthquake swarm within the caldera since the January 1983 swarm. This activity included more than 24 earthquakes of $M=3.0$ or greater, all located within the east lobe of the SMSZ. The three largest events included a pair of $\mathrm{M}=4.0$ events on March 30 and a $\mathrm{M}=4.3$ event on April 1. Altogether, this swarm included more than 1,600 events located by a real-time computer system $(\mathrm{M}>0.5)$, and it had a cumulative seismic moment of roughly $5 \times 10^{22}$ dyne-cm, or the equivalent of a single $M=4.8$ earthquake. The deformation monitoring networks showed no significant ground deformation associated with this swarm activity, and deformation of the resurgent dome indeed continued to slow through 1996 and well into the spring of 1997 (fig. A4). Subsequent seismic activity within the caldera included a series of three minor swarms in the west lobe of the SMSZ in June 1996, followed by nearly ten months of relative quiescence.

The fluctuating unrest within the caldera from 1991 through 1996 frequently activated the lower levels of the alphabetic status ranking of the 1991 response plan. A number of the swarms during this period triggered E- and DSTATUS notifications, and the relatively strong March-April swarm of 1996 triggered a C-STATUS notification. Such communications worked well enough with civil authorities who had been involved in establishing the system, but they were widely misunderstood by the media and the public. Relatively minor swarms with a single $\mathrm{M}>3$ earthquake (E-STATUS), for example, were apt to be reported as "E-level volcano alerts" by the media, producing widely varying levels of unnecessary concern with the public. In an effort to come up with a scheme that would be more intuitively meaningful to the public and the media, USGS scientists worked with local and state civil authorities to develop the four-level color code described in this document. In June 1997, the four-level color code in table 1 was officially adopted to replace the five-level alphabetic status ranking that had been in place since 1991.

\section{Strong Caldera Unrest: 1997 to Mid-1998}

By the end of April 1997, declining extension rates across the resurgent dome had dropped to less than $1 \mathrm{~cm}$ per year (fig. A4). The most notable activity during the first six months of 1997 involved $\mathrm{M}=4.2$ and $\mathrm{M}=4.1$ earthquakes on February 10 and 24, respectively, both located in the Sierra Nevada 4 $\mathrm{km}$ south of the caldera and $2 \mathrm{~km}$ south of Convict Lake (in the CL-MM cluster, fig. A5B, fig A6E). By coincidence, the timing of these minor earthquakes caught the imagination of the media. The first occurred three days after the opening of the movie "Dante's Peak," and the second occurred the day following the prime-time airing of ABC's movie for TV, "Volcano, Fire on the Mountain," which was based on the fictitious eruption of "Angel Peak," a thinly veiled take off on Mammoth Mountain.

The new, four-level color code (table 1) had been in effect for less than a month when, after nearly a year of relative quiescence within the caldera, unrest gradually resumed in mid-1997. The onset of renewed unrest initially appeared in the two-color EDM deformation data as gradually accelerating extension across the resurgent dome in May and June, followed by the onset of minor earthquake swarm activity in the west lobe of the SMSZ (figs. A5B, A6E) in early July (fig. A4). The rates of resurgent dome tumescence and earthquake swarm activity (both event rate and seismic moment rate) continued to increase through the summer and early fall, with peak rates of $2 \mathrm{~mm} /$ day and 1,000 M>1.2 events/day, respectively, on November 22 and an average extension rate of $1 \mathrm{~mm} /$ day (0.04 inches/day) from mid November through early December (fig. A4). The earthquake swarm activity was concentrated at depths between 3 and $8 \mathrm{~km}$ beneath a broad, 15-km-long (9 mile long) zone spanning the entire SMSZ and the southern margin of the resurgent dome. It included more than 12,000 $\mathrm{M}>1.2,120 \mathrm{M}>3.0$, and eight $\mathrm{M}>4.0$ earthquakes during the seven-month period through mid-January, with a cumulative seismic moment of $3.3 \times 10^{24}$ dyne-cm (the equivalent of a single $M=5.4$ earthquake).

The larger $(M \geq 4)$ of these earthquakes involved dominantly right-lateral slip along a WNW-trending fault zone within the south moat. The great majority of earthquakes had the broadband character of brittle, double-couple events (tectonic or volcano-tectonic earthquakes), although a few events had energy concentrated in the $1-$ to $3-\mathrm{Hz}$ band typical of shallow, LP volcanic earthquakes or nondouble-couple focal mechanisms admitting the possibility of a significant dilatational (opening) component in the source process (Dreger and others, 2000). Mammoth Mountain on the southwest margin of the caldera was largely immune from the shallow $(<10$ $\mathrm{km}$ or 6 miles) swarm activity, although numerous LP earthquakes occurred deep (10 to $25 \mathrm{~km}$ or 6 to 15 miles) beneath the southwest flank of the mountain through early April. Continuous gas monitoring showed a marked increase in $\mathrm{CO}_{2}$ soil gas concentrations around the flanks of the mountain 
that persisted from September through December. Both the earthquake swarm activity and inflation of the resurgent dome declined to background levels through March. By the end of March, inflation of the resurgent dome had essentially stopped, at which point the center of the resurgent dome stood roughly $10 \mathrm{~cm}$ (4 inches) higher than in the spring of 1997 (and nearly $80 \mathrm{~cm}$ higher than the pre-1980 profile; see fig. A4).
The 1997 to mid-1998 earthquake activity was exceeded in intensity only by the January 1983 swarm with two $M=5.3$ earthquakes and the May 1980 sequence with two M 6 earthquakes within or immediately adjacent to the caldera. Although the condition remained GREEN throughout the 1997-98 unrest, the activity levels closely approached the criteria for condition YELLOW on November 22 and again at the end of that month (see tables 1,2).

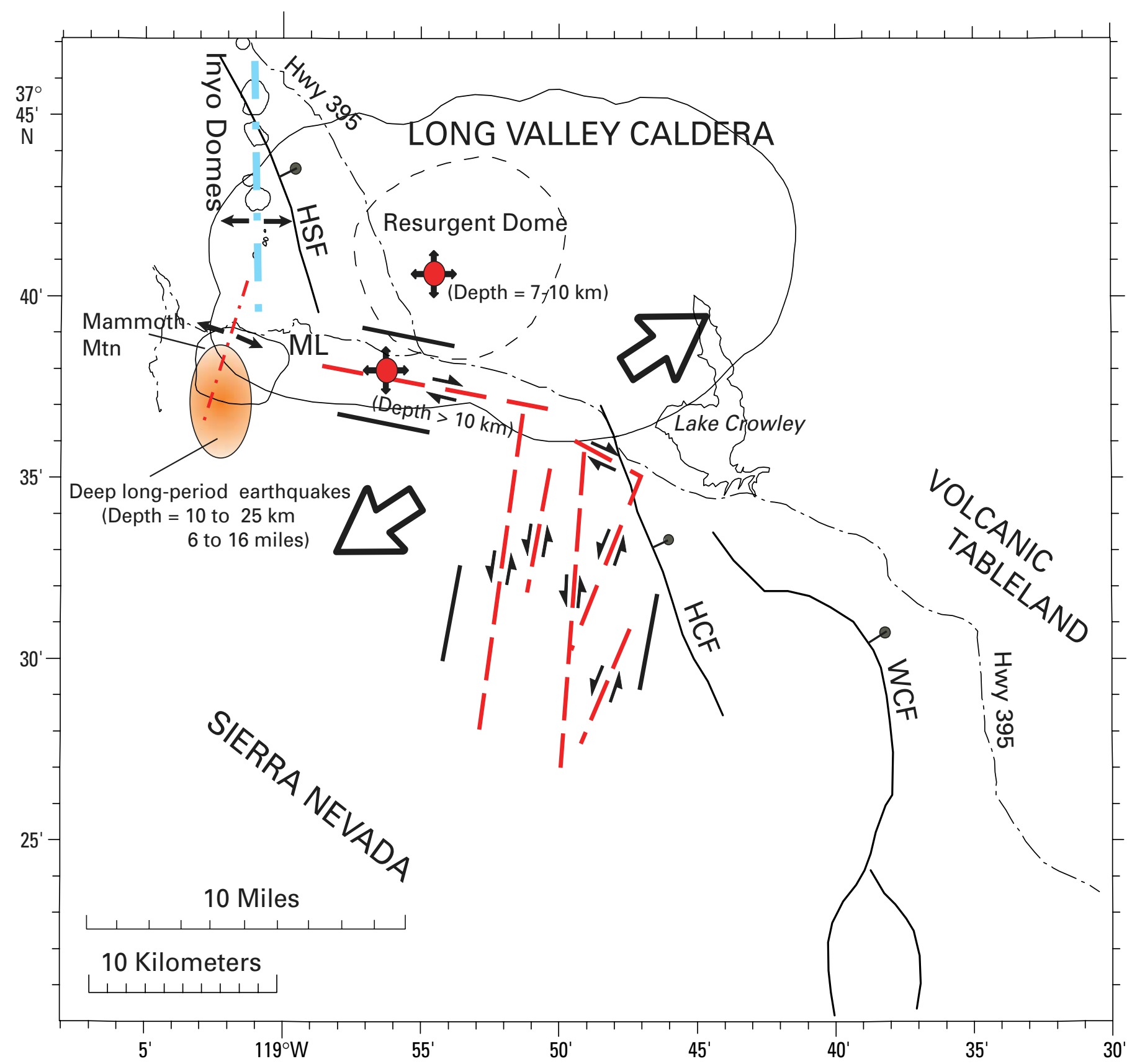

Figure A7.-Map showing locations of recognized sources (in red) contributing to the 1978-99 unrest in Long Valley Caldera and vicinity. Red circles with radial arrows indicate pressure centers of inflating magma bodies. Heavy dashed red lines indicate near-vertical fault zones (small, single-barbed arrows indicate sense of slip across individual faults zones). The larger double-barbed arrows indicate an average sense of slip across all the fault systems. Large open arrows schematically indicate regional, east-northeast extension direction. Thin dot-dashed red line indicates the dike intruded beneath Mammoth Mountain in 1989 with small arrows indicating opening direction. Heavy dot-dashed blue line is the dike that fed the Inyo Dome eruptions 500 to 600 years ago. Major range-front normal faults indicated by solid black lines with the ball on the down-dropped block. HSF, Hartley Springs Fault; HCF, Hilton Creek Fault; WCF, Wheeler Crest Fault; ML, town of Mammoth Lakes. 


\section{Caldera Quiescence and $M>5$ Earthquakes in the Sierra Nevada Block: Mid-1998 to 1999}

By mid-spring of 1998, unrest within the caldera had declined to negligible levels. Deformation data showed that swelling of the resurgent dome had essentially stopped and seismic activity within the caldera involved just a few small $(\mathrm{M}<3)$ earthquakes per day. The caldera remained quiet with virtually no additional deformation through 1999 . Meanwhile, the focus of seismic activity shifted to the Sierra Nevada block south of the caldera with $\mathrm{M}=5.1$ earthquakes on June 8 and July 14, 1998, and a M=5.6 earthquake on May 15, 1999 (figs. A4, A6F).

The $\mathrm{M}=5.1$ earthquakes of June 8 (10:24 PM, Pacific Daylight Time (PDT)) and July 14 (8:53 PM, PDT), 1998, and the M=5.6 earthquake of May 15, 1999 (6:22 AM PDT), all occurred within the footwall block of the east-dipping Hilton Creek Fault with epicenters located 1.5, 4.2, and 8.0 $\mathrm{km}$ south of the caldera boundary, respectively (fig. A6F). The rich aftershock sequences to these $\mathrm{M} \geq 5.1$ earthquakes define an orthogonal pattern with the apex pointing eastward toward Lake Crowley (the TF and MC limbs in fig. A5B) and the south-southwest MC (McGee Creek) limb extends some $14 \mathrm{~km}$ (9 miles) into the Sierra Nevada south of the caldera. The southeast trend of aftershocks to the June 8 mainshock coincides with the right-lateral slip plane of the strike-slip focal mechanism for this event, and the southsouthwest trend defined by the aftershocks to the July 14, 1998, and May 15, 1999, events coincides with the leftlateral plane of the dominantly strike-slip focal mechanism for the $M=5.6$ event of May 15. The focal mechanism for the July 14 mainshock was dominantly normal with a northerly strike. All three focal mechanisms have the direction of maximum extension ( $T$-axis) oriented to the east-northeast. These earthquakes were sufficiently close to the caldera boundary that they initially raised concerns over a transition to condition YELLOW. All, however, had the mainshock-aftershock behavior typical of "tectonic" earthquakes, and, more importantly, none was followed by an increase in seismicity or deformation within the caldera. Accordingly, the condition remained GREEN (no immediate risk of volcanic activity).

At the end of 1999, the aftershocks to the $M>5$ earthquakes south of the caldera continued to wane, and the caldera itself had remained quiet for more than a year with little seismicity and virtually no further deformation.

\section{Sources of the 1989-99 Unrest}

The following is a brief summary of the current, and still incomplete, understanding of the proximal sources driving the 1978-99 unrest, based on analysis of the data collected to monitor the unrest. Figure A7 is a schematic representation of these sources.

Dominant sources contributing to the ground deformation and earthquake activity include:
(1) Inflation of a magma reservoir centered at a depth of 7 to $12 \mathrm{~km}$ beneath the central section of the resurgent dome,

(2) Right-lateral slip along a series of west-northwest-striking faults forming the SMSZ (fig. A5B), and

(3) Left-lateral slip distributed across a 10-km-wide zone of subparallel, north-northeast striking faults in the Sierra Nevada block south of the caldera.

Secondary (more limited influence and less wellresolved) sources include:

(4) Inflation of another magmatic source centered beneath the western half of the SMSZ in the caldera at a depth of $10 \mathrm{~km}$ or more (fig. A7),

(5) A small, north-northeast trending dike beneath Mammoth Mountain that was intruded to within $4 \mathrm{~km}$ of the sur face during the 1989 Mammoth Mountain earthquake swarm, and

(6) The volume defined by the deep, LP volcanic earthquakes at depths of 10 to $25 \mathrm{~km}$ beneath the southwest flank of Mammoth Mountain.

The dominant source driving deformation within the caldera is an inflating magma reservoir beneath the resurgent dome centered at a depth of 7 to $12 \mathrm{~km}$ (4 to 7.5 miles). Although the size and shape of this magma body remain poorly resolved, the cumulative, $80-\mathrm{cm}$ ( 2.6 foot) uplift of the resurgent dome since the late 1970's (see fig. A4) implies a volume increase for this magma body of roughly $0.3 \mathrm{~km}^{3}$ $\left(0.07 \mathrm{mi}^{3}\right)$ reflecting an infusion of additional magma from greater depths (Battaglia and others, 1999; Langbein and others, 1995). Such a volume increase is comparable to the volume of magma erupted during the May 1980 eruption of Mount St. Helens. USGS scientists conclude that the earthquake activity within the caldera occurs in response to the more fundamental, magmatic process associated with intrusion of magma into the crust beneath the resurgent dome because (1) the deformation associated with inflation of this magma body is significantly larger than can be accounted for by the earthquakes within and immediately adjacent to the caldera, and (2) accelerated episodes of deformation (magma-body inflation) generally precede increases in earthquake activity by several weeks (Langbein and others, 1990).

Most of the earthquakes in the area (particularly those with magnitudes $M>4$ ) are generated by slip on a series of near-vertical, west-northwest striking faults within the south moat of the caldera (the SMSZ) and north-northeast striking faults in the Sierra Nevada block south of the caldera (see figs. A3, A5, and A6). Focal mechanisms for these earthquakes indicate that the sense of slip on along these faults is dominantly right-lateral in the SMSZ and left-lateral in the Sierra Nevada block (fig. A7). Cramer and Topozada (1980) recognized that this fault geometry is consistent with local eastnortheast extension such that the crustal block including the caldera north of the SMSZ moving to the east-northeast with respect to the corner of the Sierra Nevada south and west of the caldera. Kinematically, this geometry requires an opening (extensional) mode within one or both of these fault zones. Indeed, focal mechanisms for a subset of earthquakes in both 
fault zones involve significant oblique-normal displacement components, and, in a few cases, significant nondouble-couple components consistent with a local volume increase (Dreger and others, 2000; Julian, 1983). In principle, these are "leaky" strike-slip fault zones providing potential pathways for magmatic fluids to migrate into the upper $10 \mathrm{~km}$ (6 miles) of the crust from mid- to lower-crustal depths. The high-resolution analysis of seismicity patterns and focal mechanisms in the Sierra Nevada block by Prejean and others (2000), however, suggests that the nondouble-couple mechanisms for earthquakes within the north-northeast striking fault system reflect simultaneous slip along obliquely aligned faults rather than fluid injection. As an aside, it is worth noting that the "faults" depicted in figure A7 have no clear surface expression, which is not unusual for faults associated with $\mathrm{M} \sim 6$ or smaller earthquakes; they very likely consist of a series of sub-parallel fault segments rather than a single, through-going fault plane.

Interestingly, the Hilton Creek Fault and the other large, range-front normal faults defining the eastern escarpment of the Sierra Nevada (solid lines in fig. A7) have not been involved in the 1978-99 activity in any significant way. Nevertheless, the overall extension direction associated with the recent earthquake activity is essentially perpendicular to the north-northwest strike of these large, range-front, normal faults, and thus consistent with the geologic evidence for pure dip-slip displacement on these faults.

A second, relatively deep (depth, $z>10 \mathrm{~km}$ or 6 miles) inflation source (magma body?) beneath the south moat seems to be required to account for local deviations from the deformation dominated by inflation of the shallower magma body beneath the resurgent dome (Langbein, and others, 1995). This deeper but smaller inflation source may serve as a temporary way station for magma as it migrates from even greater depths to the shallower magma body beneath the resurgent dome, and it may be the magma source for small intrusions into the south moat that apparently accompanied the 1983 and 1997 south moat earthquake swarms (Malin, and others, 1998; Savage and Cockerham, 1984). Alternatively, it may represent a distributed source of elevated fluid pressures in the form of magmatic "brine" that permeates the SMSZ to facilitate recurring brittle failure (earthquake activity) within the south moat in preference to the seismically quiescent zones elsewhere around the resurgent dome with comparable strains. We have yet, however, to see independent evidence in the form of deep LP earthquakes or harmonic tremor beneath the south moat or resurgent dome that might be associated with active fluid (magma or magmatic brine) transport at depths of $10 \mathrm{~km} \mathrm{(6}$ miles) or greater.

The north-northeast orientation of the small dike intruded to depths as shallow as 3 to $4 \mathrm{~km}$ (1.8 to 2.5 miles) beneath Mammoth Mountain during the 1989 earthquake swarm (Hill and others, 1990; Langbein, and others, 1993), together with focal mechanisms of individual swarm earthquakes, indicates that the extension direction in the vicinity of Mammoth Mountain has a west-northwest orientation. The nearly northsouth strike of the dike that fed the Inyo Dome eruptions 500 to 600 years ago suggests an east-west extension direction in the vicinity of the Inyo volcanic chain and the west moat of the caldera. Together, these intrusive sources emphasize the spatially heterogeneous nature of active deformation in the vicinity of Long Valley Caldera.

Finally, the deep LP earthquakes beneath the southwest flank of Mammoth Mountain, which became active at the time of the 1989 Mammoth Mountain swarm, appear to coincide with a volume of distributed basaltic magma moving through a plexus of small dikes and sills (Pitt and Hill, 1994). This volume of distributed basaltic magma also is the likely source of the carbon dioxide $\left(\mathrm{CO}_{2}\right)$ that began emerging through the soil at several sites around Mammoth Mountain in early 1990 (Farrar and others, 1995; Hill, 1996), and it may be the source of the volatiles producing the VLP earthquakes detected beneath Mammoth Mountain in 1996 and 2000 (see appendix C).

\section{Character of Possible Eruptive Activity}

Future eruptions in the Long Valley-Mono Craters region are most likely to consist of the types and scales of eruptive activities that have occurred in the past. Eruptions within the last 50,000 years in the region include explosive eruptions of rhyolitic and rhyodacitc (silicic) lavas like those that formed the Mono Craters and Inyo Domes 500 to 600 years ago (Bailey, 1989; Miller, 1985). Such eruptions produced ashfalls, pyroclastic flows and surges of small to large volume, and relatively nonexplosive eruption of silicic lava domes and flows (Miller, 1989; Miller and others, 1982). Some other relatively nonexplosive eruptions within the last 50,000 years have also produced lava flows and cinder cones of basaltic (mafic) composition such as the several-thousand-year-old Red Cones south of Mammoth Mountain. In individual future eruptions, scientists expect to see one or the other of these eruptive types but likely not both. The geologic record suggests that silicic eruptions are somewhat more probable than mafic ones. Both silicic and mafic eruptions are likely to be preceded by phreatic (steam blast) eruptions similar to those that formed the Inyo Craters. Such eruptions often occur when magma comes sufficiently close to the surface to interact explosively with shallow ground water, without the magma itself necessarily reaching the surface.

Specific effects of future eruptions in the Long ValleyMono Craters region will depend upon the composition and volume of magma erupted as well as the location(s) of eruptive vent(s). Although patterns of seismic activity and ground deformation will likely provide strong clues to the locations of the eruptive vents shortly before magma reaches the surface, we cannot yet reliably interpret monitoring data in terms of the likely composition or volume of an impending eruption.

\section{Eruptions of Rhyolitic (Silicic) Magma}

Explosive eruptions of rhyolitic lava could range in volume from small to moderate like those that formed the Inyo and Mono Domes (Miller and others, 1982) to much larger (but less likely) volumes like those that formed Mam- 
moth Mountain and the Mammoth Knolls north of Mammoth Lakes. During their initial explosive phases, the more energetic of these eruptions typically produced large volumes of coarse pumice deposited as a thick blanket of tephra over a wide region, as well as destructive pyroclastic flows and surges capable of causing severe damage to distances of at least $20 \mathrm{~km}$ (12 miles) from a vent. The later phases of such eruptions produced steep-sided lava flows and domes.

\section{Eruptions of Basaltic (Mafic) Magma}

Lava fountains typical of basaltic eruptions would scatter ash and coarser material over the region and spawn lava flows that would flow downhill from the vent at relatively slow speeds (tens of $\mathrm{m} / \mathrm{hr}$ to a few $\mathrm{km} / \mathrm{hr}$ ). Significant accumulations of tephra could develop within $10 \mathrm{~km}$ (6 miles) of the vent. These accumulations would be thickest near and directly downwind from the vent. Basaltic flows could extend several $\mathrm{km}$ down slope from their vents.

See Miller and others (1982) and Miller (1989) for a more extensive discussion of potential hazards from future eruptions, details about the nature and effects of hazardous volcanic processes, and volcano-hazard zonation maps for the Long Valley-Mono Craters region.

\section{Appendix B. USGS Terminology for Geo- logic Hazard Warnings.}

\section{Current Hazard Warnings}

The transition to condition ORANGE from either condition GREEN or YELLOW will be accompanied by a formal HAZARD WARNING issued by the Director of the U.S. Geological Survey (USGS). A formal USGS HAZARD WARNING is defined as follows in the October 11, 1983, issue of the Federal Register (v. 48, n. 197):

GEOLOGIC HAZARD WARNING - a formal statement by the Director of the USGS that discusses a specific geologic condition, process, or potential event that poses a significant threat to the public, and for which some timely response would be expected.

This issue of the Federal Register further states that "The term Hazard Warning (italics added) is reserved for those situations posing a risk greater than normal and warranting considerations of a timely response in order to provide for public safety. Information regarding hazardous conditions that do not meet the criteria for a Hazard Warning (italics added) may, however, also be sent to public officials as it becomes available. Transmittal of such information would not constitute a Hazard Warning." The criteria for a Geologic Hazard Warning are:

(1) A degree of risk greater than normal for the area or a hazardous condition that has recently developed or has only been recently recognized and

(2) A threat that warrants consideration of a near-term public response.

\section{Hazard Warnings Prior to 1983}

Prior to October 1983, official statements by the USGS on geologic hazards were based on the three-level system described in the April 12, 1977, issue of the Federal Register (v. 42. no. 70). The three levels (from lowest to highest) were defined as follows:

\begin{abstract}
NOTICE OF POTENTIAL HAZARD - Information on the location and possible magnitude of a potentially hazardous geologic condition. However, available evidence is insufficient to suggest that a hazardous event is imminent or evidence has not been developed to determine the time of occurrence.
\end{abstract}

HAZARD WATCH—Information, as it develops from a monitoring program or from observed precursors, that a potentially catastrophic event of a generally predictable magnitude may occur within an indefinite time (possibly months to years).

HAZARD WARNING-Information (prediction) as to the time, location, and magnitude of a potentially disastrous geologic even.

Official statements by the USGS on geologic hazards in the Long Valley Caldera-Mono Craters region issued in May 1980 (HAZARD WATCH for potentially damaging earthquakes) and May 1982 (NOTICE OF POTENTIAL VOLCANIC HAZARD) were based on this three-level system.

\section{Appendix C. Scientific Rationale for Activity Criteria Under Color Codes Background}

Because the most recent eruptions in the Long Valley region occurred 250 to 600 years ago, no historical or instrumental records exist for the specific patterns of precursory activity that preceded previous eruptions in Long Valley Caldera or along the Mono-Inyo volcanic chain. Accordingly, the activity levels specified in table 2 for successive color codes are based on a combination of (1) patterns for premonitory activity to eruptions of well-monitored volcanoes elsewhere in the world (see Decker, 1986; McClelland and others, 1989; McNutt, 2000; Newhall, 2000; Newhall and Dzurisin, 1988), (2) the multiple episodes of unrest in Long Valley Caldera that followed the four M 6 earthquakes in May 1980 summarized under appendix A; and (3) a general understanding of the geophysical and geochemical processes associated with the intrusion of magma into the shallow crust prior to a volcanic eruption.

The intrusion of magma into the shallow crust generally can be detected instrumentally because relatively cold, hard rocks of the shallow crust must deform to accommodate the volume of intruding magma. Stresses associated with that deformation induce brittle failure (earthquakes) in the adjacent crust and warping of the overlying surface. The magma itself may produce detectable seismic waves as it flows through constrictions in a conduit or as a super-saturated, bubble-rich magma reverberates in magma-filled cracks. As magma ascends toward the surface, confining pressures due to the weight of overlying rocks decrease, allowing dissolved magmatic gasses (principally water vapor, carbon dioxide, 
and sulfur dioxide) to exolve and escape to the atmosphere through fractures in the crust well in advance of the rising magma. At sufficiently shallow depth, some of the heat contained in the magma will be transferred to the local ground water, which may induce a variety of changes in the hydrothermal system, including changes in water-table depths and temperatures. If the heat transfer is sufficiently rapid, shallow ground water may flash to steam generating phreatic (steam) explosions of the sort that produced the Inyo Craters at the southern end of the Inyo volcanic chain. A complete boil off of the hydrothermal system may allow sulfur dioxide $\left(\mathrm{SO}_{2}\right)$ from the intruding magma body to escape to the atmosphere.

In general, these phenomena accompanying magmatic intrusions are rather pronounced in volcanic systems that erupt infrequently, such as Long Valley Caldera and the Mono-Inyo volcanic chain, where the uppermost 5 to 10 $\mathrm{km}$ of the crust is relatively cold and hard. They are often more subdued in the case of central-vent volcanoes that erupt relatively frequently, because the well-established and oftenused magma conduit offers less resistance to a new batch of magma as it ascends toward the surface.

Seismicity and ground deformation in particular have long been recognized as the two most robust precursors to volcanic eruptions (Decker, 1986; Tilling, 1995). Major advances in the systematic, quantitative measurement of carbon dioxide $\left(\mathrm{CO}_{2}\right)$ and $\mathrm{SO}_{2}$ over the past couple of decades, however, have clearly demonstrated that knowledge of the flux rates of these two important volcanic gasses can aid significantly in judging the likelihood that volcanic unrest will culminate in an eruption (Gerlach and others, 1996; McNutt and others, 2000; Young and others, 1998). Accordingly, the Color-Code criteria in table 2 are based on seismicity rates, ground deformation rates, and the mass flux of $\mathrm{CO}_{2}$ and $\mathrm{SO}_{2}$.

Available information on the preeruptive behavior of the Long Valley Caldera-Mono Craters volcanic system is currently inadequate to support robust statistical calculations for the probabilities that a specific activity level will culminate in an eruption within a specified time interval. The USGS recognizes, however, the importance of establishing meaningful probability estimates for each status and this remains a goal pending further advances in the understanding of preeruptive processes. In the meantime, the USGS will use the Color-Code scheme outlined in tables 1 and 2 to guide its response to future episodes of unrest within Long Valley Caldera and along the Mono-Inyo volcanic chain.

\section{Seismic Criteria}

Although increased earthquake activity precedes nearly all volcanic eruptions, the intensity, duration, and style of the precursory seismicity vary considerably from one volcano to the next and even from one eruption to the next at a given volcano. Many earthquakes in volcanic systems result from abrupt brittle failure along faults or fractures similar to earthquakes in purely tectonic environments. Most restless or active volcanic systems also produce so-called "volcanic" earthquakes, which result from fluid dynamic processes associated with the transport of magmatic and associated hydrothermal fluids. Because of their close association with the transport of magmatic fluids, their associated volatiles, and heat, these "volcanic" earthquakes are particularly diagnostic as precursory signs to possible volcanic activity.

\section{Definitions and Examples of Seismic Events}

A consensus has yet to be reached in the scientific literature on the classification of seismic events occurring in areas of current or recent volcanism (Chouet, 1996; McNutt and others, 2000). In this response plan, the distinction is made between two broad groups of earthquakes - one with sources dominated by brittle failure and the other with sources dominated by fluid dynamic processes. Ordinary earthquakes resulting from brittle failure are common to both tectonic and active volcanic regimes. Earthquakes with sources dominated by fluid dynamic processes, however, are almost exclusively limited to active volcanic regimes and geothermal areas.

\section{High-Frequency Earthquakes and Spasmodic Bursts}

Earthquakes that result from brittle failure are most commonly referred to simply as ordinary "earthquakes." Such earthquakes in volcanic environments may be variously referred to as tectonic or volcano-tectonic (VT) earthquakes, high-frequency (HF) earthquakes, broad-band (BB) earthquakes, or A-type earthquakes. In this document we use the qualifier "high frequency" (HF) to distinguish ordinary earthquakes from long-period (LP) or very long period (VLP) volcanic earthquakes (see next section) when necessary. Whether differential stresses that lead to brittle failure and frictional slip are due to regional tectonic processes (tectonic earthquakes), local magmatic/volcanic processes, or some combination thereof (volcano-tectonic earthquakes), the result is the same; abrupt slip of rock surfaces past one another along a fault plane producing the classic double-couple radiation pattern. In some cases, particularly in volcanic and geothermal areas, brittle failure may also involve the abrupt opening of tensile cracks to produce nondouble-couple radiation patterns (Julian and others, 1998; Miller and others, 1998). HF earthquakes typically have clear $\mathrm{P}$ and $\mathrm{S}$ waves with substantial energy at frequencies above $10 \mathrm{~Hz}$ (fig. C1A). They radiate seismic energy over a broad frequency range with a flat spectrum at frequencies, $f$, below a corner frequency, $f_{c}$ and with spectral amplitudes that roll off as $f^{-1}$ to $f^{-3}$ for frequencies above the corner frequency $\left(f>f_{c}\right)$. Fluids may trigger brittle failure by, for example, reducing the effective frictional strength across a fault plane through increasing pore pressure, but the fluid phase does not directly contribute to the radiated seismic energy. The vast majority of earthquakes associated with the unrest in Long Valley Caldera and vicinity over the past two decades have been ordinary HF events.

"Rapid-fire" bursts of small (generally M $\leq 2$ ) HF earthquakes with overlapping coda (fig. $\mathrm{C} 1 B$ ) are common in 
volcanic areas. These spasmodic bursts (sometimes called spasmodic tremor) typically have durations ranging from tens of seconds to 30 minutes or more. They frequently accompanied earthquake swarms beneath Long Valley Caldera's south moat in 1982 (Ryall and Ryall, 1983), and they were common during the 1989 swarm beneath Mammoth Mountain (Hill and others, 1990). Individual events within a spasmodic burst have the appearance of HF earthquakes, although the signal level between events may remain above background noise levels well beyond the decay times for waves from tectonic earthquakes of comparable size. The focal mechanisms determined for two of the larger events within a spasmodic burst beneath Mammoth Mountain on September 4, 1997, which was recorded on a temporary network of digital, three-component stations, have large isotropic components (volume increase) and rotational symmetry about the T-axis consistent with hydraulic fracturing of previously unbroken rock. As described in the following section, spasmodic bursts accompanied the very-long-period (VLP) earthquakes that occurred beneath Mammoth Mountain in October 1996 and July and August 2000. Spasmodic bursts rarely, if ever, occur in purely tectonic regimes. The process producing spasmodic bursts remains a topic of research, although currently available evidence strongly points to an association with fluid transport and hydraulic fracturing within the brittle crust.

\section{Earthquakes Generated by Fluid-Dynamic Processes (Volcanic Earthquakes)}

Fluid dynamic processes driven by pressure and (or) temperature gradients associated with crustal magma may excite seismic waves by a variety of processes including resonances within fluid-filled cracks (Chouet, 1992) and unsteady, nonlinear flow along conduits with irregular geometry (Julian, 1994). The seismic waves generated by such processes typically produce earthquakes deficient in frequencies above 5 to $10 \mathrm{~Hz}$ and with extended coda that "ring" for many cycles at a nearly constant frequency (fig. C2). Spectra from seismograms of these earthquakes are typically comb-like with individual peaks showing a harmonic relation to a fundamental mode or a period-doubling
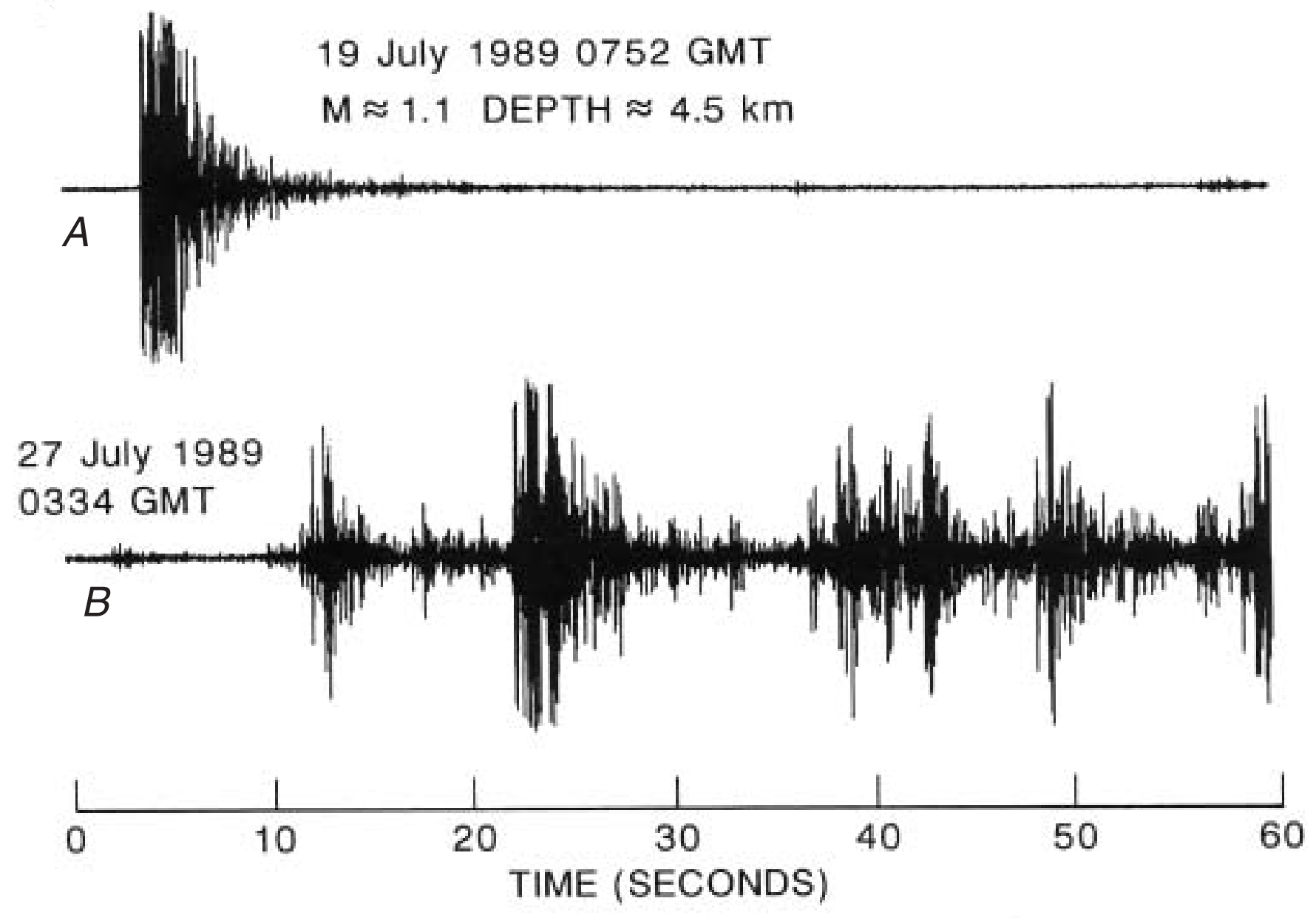

Figure C1.-Examples of seismograms recorded on Mammoth Mountain station MMPM (see fig. D1) (A) for a typical high-frequency (volcano tectonic) earthquake with a magnitude $(M)=1.1$ and $(B)$ for the onset of a spasmodic burst (total duration was about 30 minutes). Both occurred beneath Mammoth Mountain during the 1989 earthquake swarm (from Hill and others, 1990). 

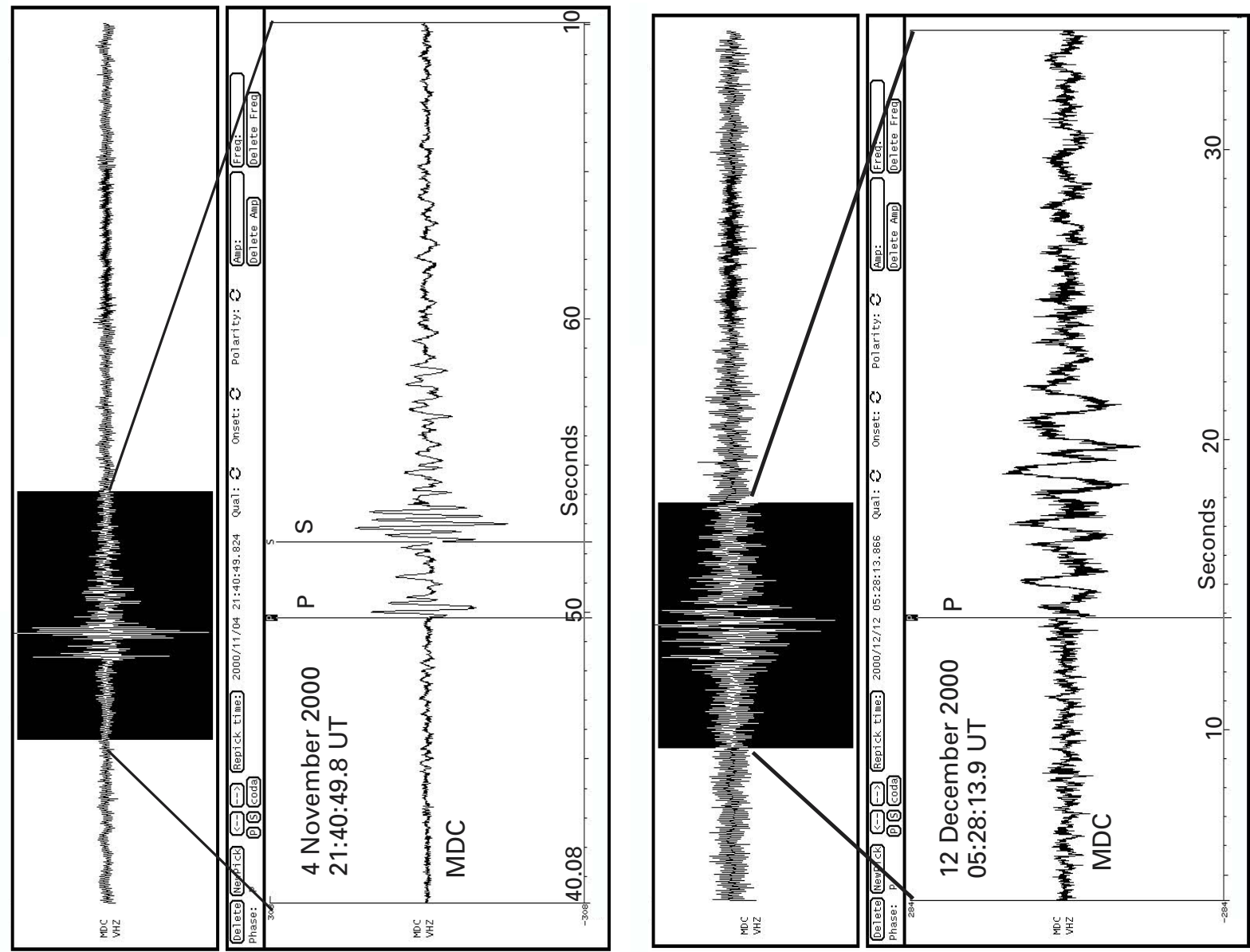

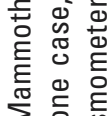

प

흔 흥

क人

ब을

들 정

트 3

으 응

엄 튼

언

뜨 헝 을

들 음

$\sum \cong \frac{1}{\pi}$

ভ

$\sum$ 을

드르

范 $\overline{0}$

Ф 은

등 는

으. 드

응 ․ㅡㅁ

인 프

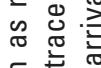

듕 Ð

을응 진

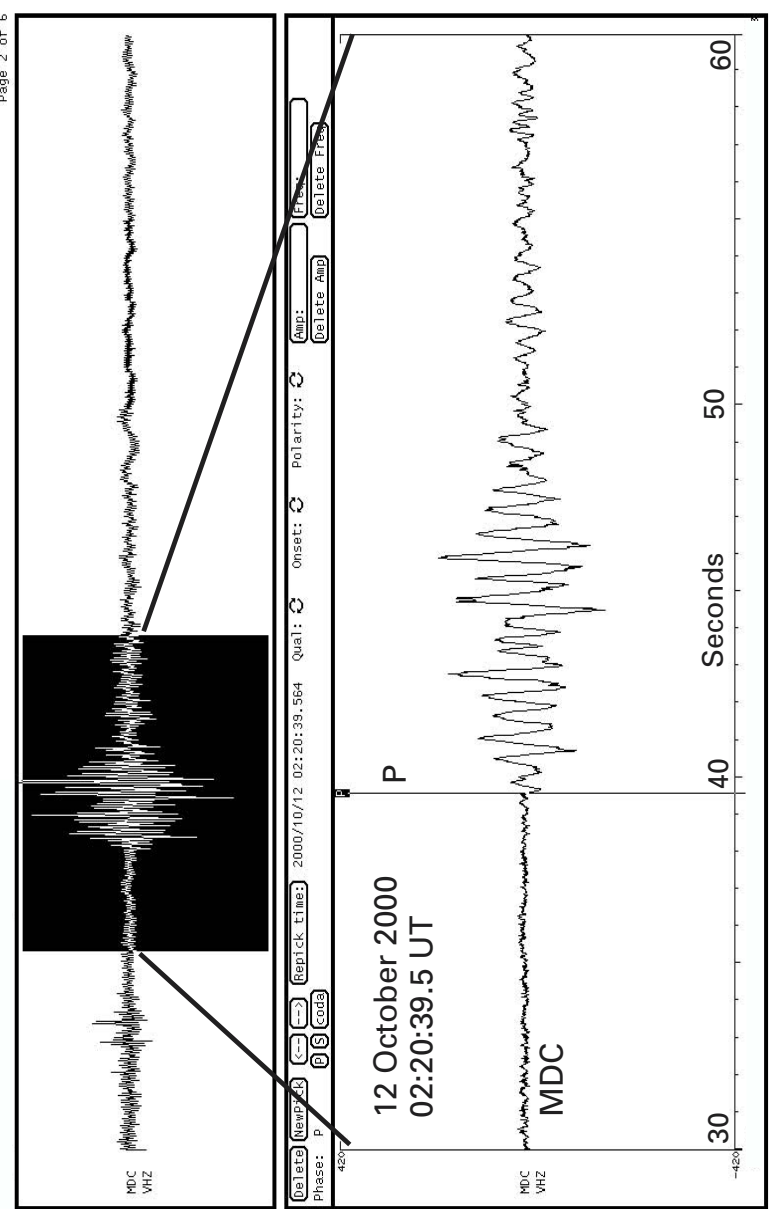

$\sum \stackrel{0}{\infty}$

ᄃ吕至

这

으음 등

\& \&

즐 은

들 음 정

는 등

.

衣占它

응 흐

도웜

च हू ह

은 점듬

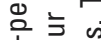

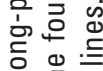

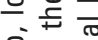

웜

응 등

넝

州

힌히 인

ह 휴

$\frac{\omega}{\omega}$

\&

กิ

తి

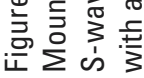

물목

崇等 
relation characteristic of nonlinear systems (Julian, 1994). Such earthquakes are variously referred to as long-period (LP) earthquakes, low-frequency earthquakes, or B-type, volcanic earthquakes (Chouet, 1996; McNutt, 2000). The dominant frequencies for these volcanic earthquakes are typically in the range 1 to $5 \mathrm{~Hz}$. At shallow depths (less than $5 \mathrm{~km}$ or 3 miles), LP earthquakes appear to involve the resonance of bubbly fluids in fluid-filled cracks associated with degassing or boiling (Chouet, 1992). At greater depths, nonsteady fluid flow may be a more common process (Julian, 1994), although basaltic magmas may behave as a bubbly fluid at pressures typical of mid-crustal depths (10 to $20 \mathrm{~km}$ or 6 to 12 miles) with carbon dioxide as the gaseous phase. The deep LP earthquakes beneath Mammoth Mountain that began in late 1989, for example, may be associated with resonances within a basalt-carbon dioxide froth (Pitt and Hill, 1994).

Clear examples of VLP volcanic earthquakes have also been documented beneath a number of volcanoes (Chouet and others, 1998; Kaneshima, and others, 1996; Takeo, 1990). These VLP earthquakes have dominant spectral peaks at periods of tens of seconds and appear to be associated with the transport of slugs of fluid (magma, magmatic brine, or gas) through cracks or dikes within or beneath the volcanic edifice.

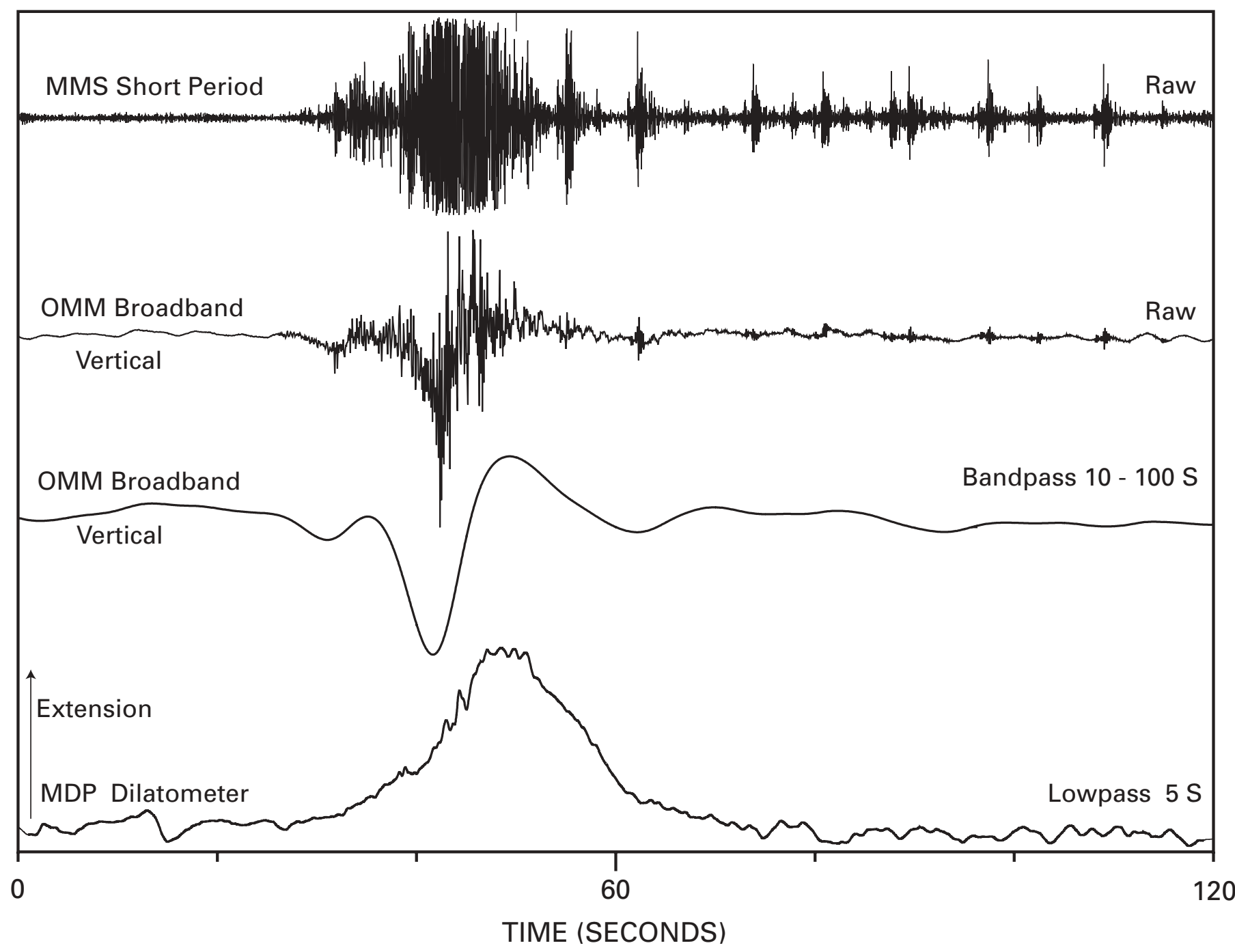

Figure C3.- Seismograms of the August 13, 2000, very-long-period (VLP) earthquakes beneath Mammoth Mountain. Top is unfiltered trace from the short-period (1 second, vertical seismometer) Northern California Seismic Network (NCSN) station (MMSM) on top of Mammoth Mountain (note the spasmodic burst). Middle two traces are unfiltered and filtered (10 to 100 second bandpass) vertical component records, respectively, from the CMG-3 broadband station (OMM) installed in a shaft of the Old Mammoth Mine (4 km (2.5 miles) southeast of Mammoth Mountain) and operated by the University of Nevada, Reno. Bottom is a low-pass (5-second cutoff) trace from the POP borehole dilatometer located $4 \mathrm{~km}$ ( 2.5 miles) due west of the Mammoth Mountain summit (see fig. D1 for station locations). 
beneath Mammoth Mountain; one on October 13, 1996, and the other two on July 6 and August 13, 2000 (fig. C3). These events were detected in the seismic band $(0.1$ to $400 \mathrm{sec})$ of the POPA borehole dilatometer, which is located $4 \mathrm{~km}$ (2.5 miles) due west of the summit of Mammoth Mountain. Each developed as a single-sided, dilatational strain transient over periods of 30 to $120 \mathrm{sec}$ with peak strain amplitudes of $\sim 1$ nanostrain. The first two showed small ( 0.2 nanostrain) compressional offsets. Each was accompanied by spasmodic bursts of HF earthquakes and LP earthquakes. Based on hypocentral locations for the associated impulsive events occurred at depth of roughly $4 \mathrm{~km}$ beneath the surface of Mammoth Mountain. Spasmodic bursts were common during the 1989 Mammoth Mountain earthquake swarm, and the coincidence of spasmodic bursts with these VLP earthquakes opens the possibility that VLP activity was an integral part of the 1989 activity, but no instruments were in place to record the 100-1 sec band at the time. These Mammoth Mountain VLP earthquakes are similar to VLP earthquakes recorded beneath the summit of Kilauea Volcano, Hawaii, which Ohiminato and others (1998) interpret as being generated by the transport of a slug of magma or gas through a crack.

\section{Harmonic tremor}

Harmonic tremor is a nearly monochromatic sequence of seismic waves with dominant frequencies typically ranging from 1 to $5 \mathrm{~Hz}$ that may persist with relatively steady to strongly fluctuating amplitude levels for minutes to hours (fig. C4). Harmonic tremor accompanies nearly all volcanic eruptions and commonly precedes the onset of eruptive activity by hours to days. In some cases, harmonic tremor evolves from a sequence of overlapping LP earthquakes pointing to a common source process. A few isolated sequences of what may be harmonic tremor were recorded during the 1997-98 earthquake swarm activity in Long Valley Caldera (fig. C5)

\section{Earthquakes Intermediate in Character (Hybrid Earth-} quakes)

Earthquakes intermediate in character between (HF) earthquakes at one extreme and narrow-band, volcanic earthquakes at the other (hybrid earthquakes) are common on active volcanoes, and they appear to result from a variety of processes. In some cases, for example, HF earthquakes produce seismograms with a low-frequency appearance because

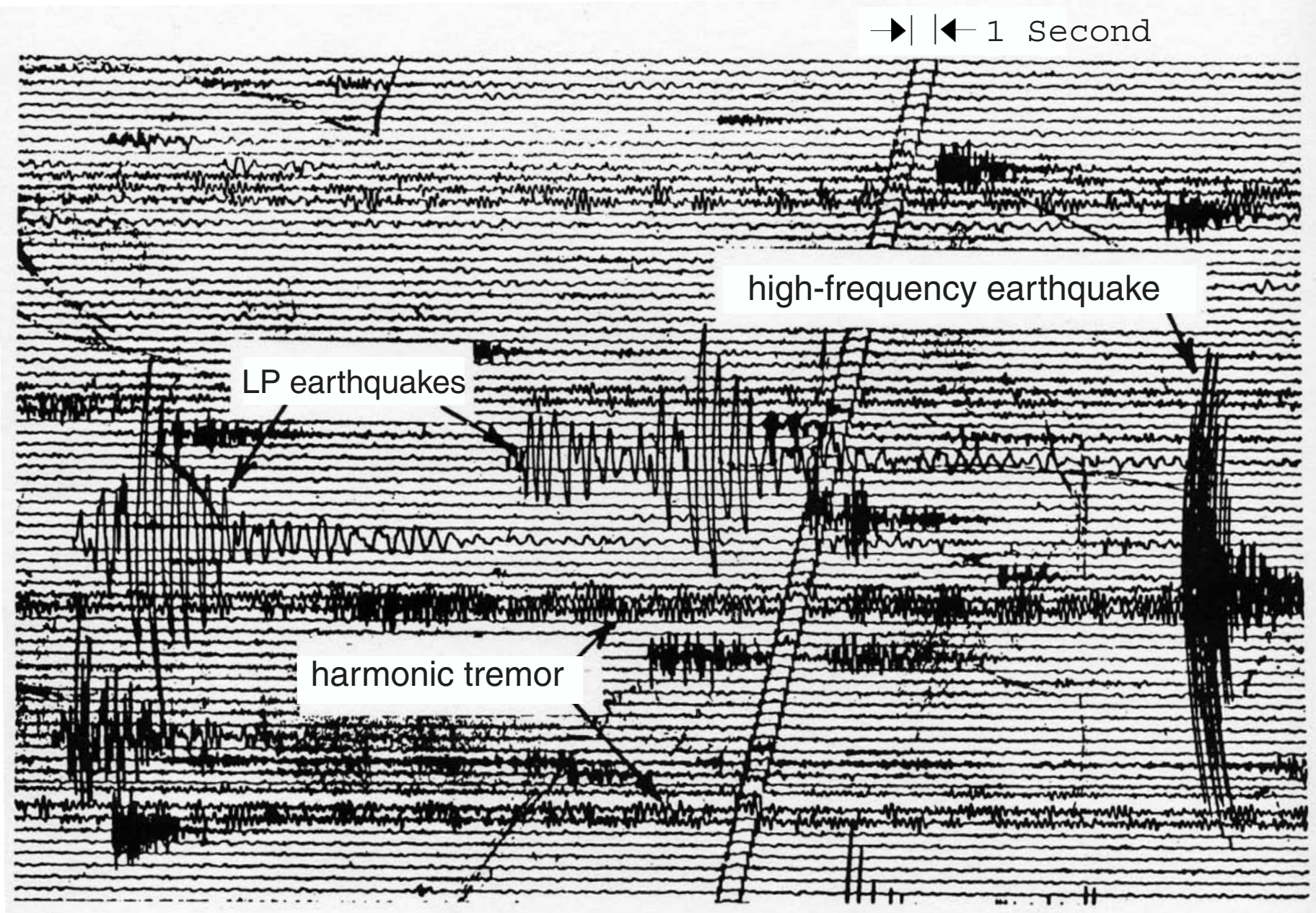

Figure C4.-Example of seismogram showing weak harmonic tremor along with long-period (LP) and high-frequency (HF) earthquakes recorded on Nevada del Ruiz Volcano, Colombia, on September 9, 1985 (modified from Chouet, 1991). 
the high-frequency energy generated at the source is scattered by strong heterogeneities in the crust (commonly true for extremely shallow earthquakes-depths less than 2 to $3 \mathrm{~km}$ or 1 to 2 miles) or attenuated by propagation through a "soft" volume such as a magma body. In other cases, the earthquake may result from an initial brittle failure event that then triggers resonance in an adjacent, fluid-filled crack. A number of isolated earthquakes in Long Valley Caldera that fall in this intermediate category have been recorded (see Cramer and McNutt, 1997).

\section{Using Spectrograms to Distinguish Earthquake Types}

Identification of volcanic seismic signals by their respective signatures on seismograms can be difficult when background activity levels are elevated (due say to weathergenerated noise or an intense swarm of high-frequency earthquakes). Real-time spectrograms provide an invaluable aid in this regard. Spectrograms display spectral amplitudes as a function of time using a color scheme to represent the relative amplitude of a given spectral component (usually
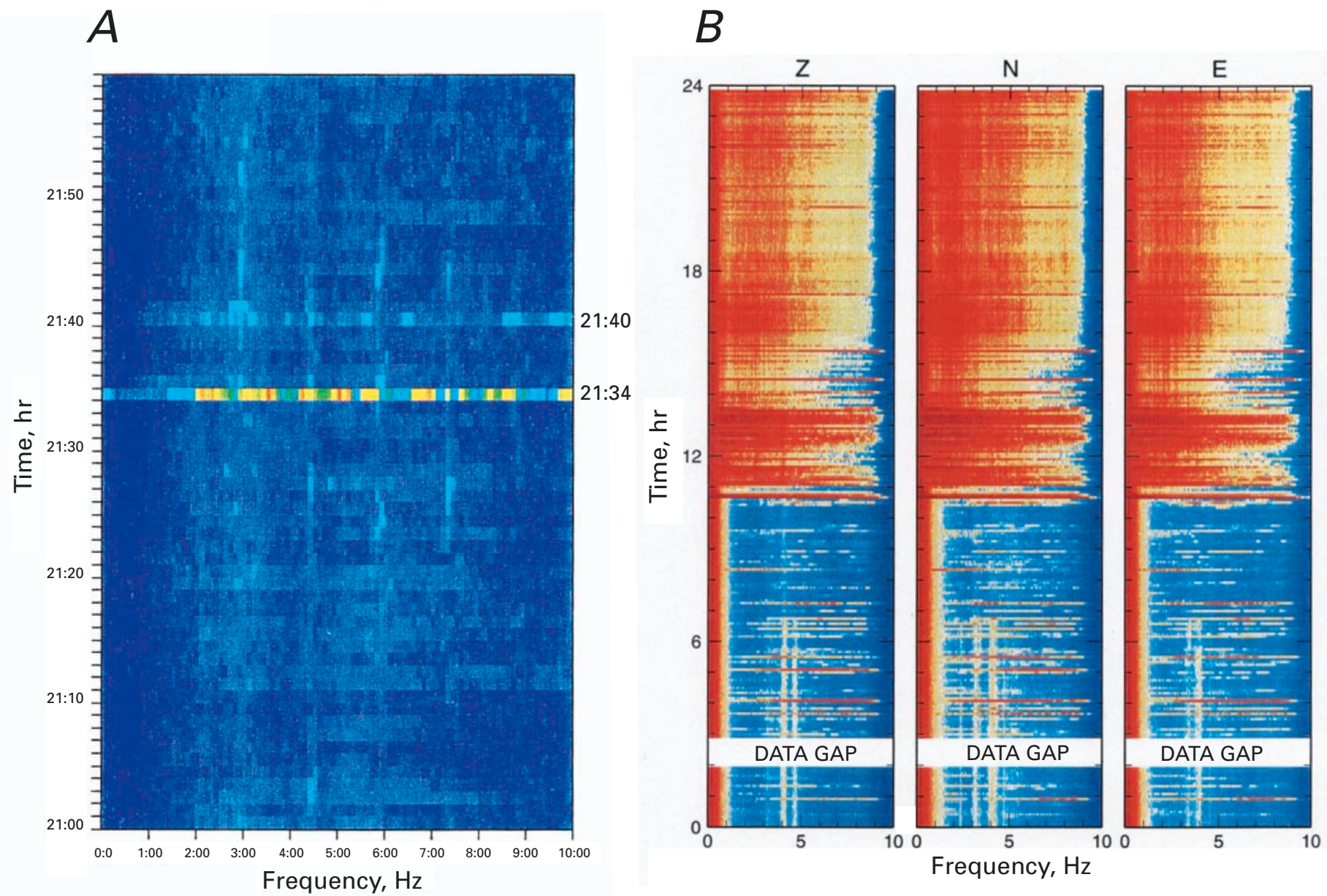

Figure C5.-Examples of spectrograms illustrating the distinctive signatures of high-frequency (HF) (volcano tectonic) earthquakes and harmonic tremor in the time-frequency domain. The abrupt, broadband nature of HF earthquakes produces horizontal bands spanning all frequencies while the comb-like spectrum and extended duration of harmonic tremor results in multiple vertical lines in the spectrogram. In combination, these two seismic sources produce spectrograms with a madras-like pattern. Warmer colors represent higher spectral amplitudes on these plots. A, Spectrogram for a 1-hour (21:00-22:00 Universal Time (UT)) period on July 30, 1998, from station MEMM in Long Valley Caldera (see fig. D1). This is a vertical-component, short-period $(1 \mathrm{~Hz})$ station. The distinct horizontal bands at 21:34 and 21:40 UT are HF earthquakes (a magnitude (M)=2.9 earthquake located $8 \mathrm{~km}$ ( 5 miles) south of MEMM and a $\mathrm{M}=2.6$ earthquake located $15 \mathrm{~km}$ (9 miles) southeast of MEMM, respectively). The weak, vertical bands at frequencies of $2.9,4.5,5.8$, and $7.2 \mathrm{~Hz}$ are spectral peaks of a tremor-like signal. The source of this signal is unknown, except that its amplitude is strongest on station MEMM, and the source is presumably somewhere in the vicinity of the station on the resurgent dome in the caldera. B, Spectrograms for a 24-hour period for day 273 (September 30), 1996, from the three-component station H0T23 on Vatna Jökull Glacier, which covers Grimsvötn Volcano in Iceland. The first 6 hours show multiple, horizontal, broadband streaks associated with an earthquake swarm together with vertical spectral bands of harmonic tremor (with several pronounced spectral peaks between 3 and $5 \mathrm{~Hz}$ ). Both the tremor and swarm activity decline some 4 hours prior to the onset of a volcanic eruption beneath the glacier at about 11:00 hours (UT) marked by the onset of the pronounced, nearly continuous red pattern spanning most of the spectrogram. Although the tremor is clear on in the early part of this spectrogram, it was essentially lost in the coda of the swarm earthquakes and not recognized in the seismograms prior to the eruption (Gudmundsson and others, 1997). 

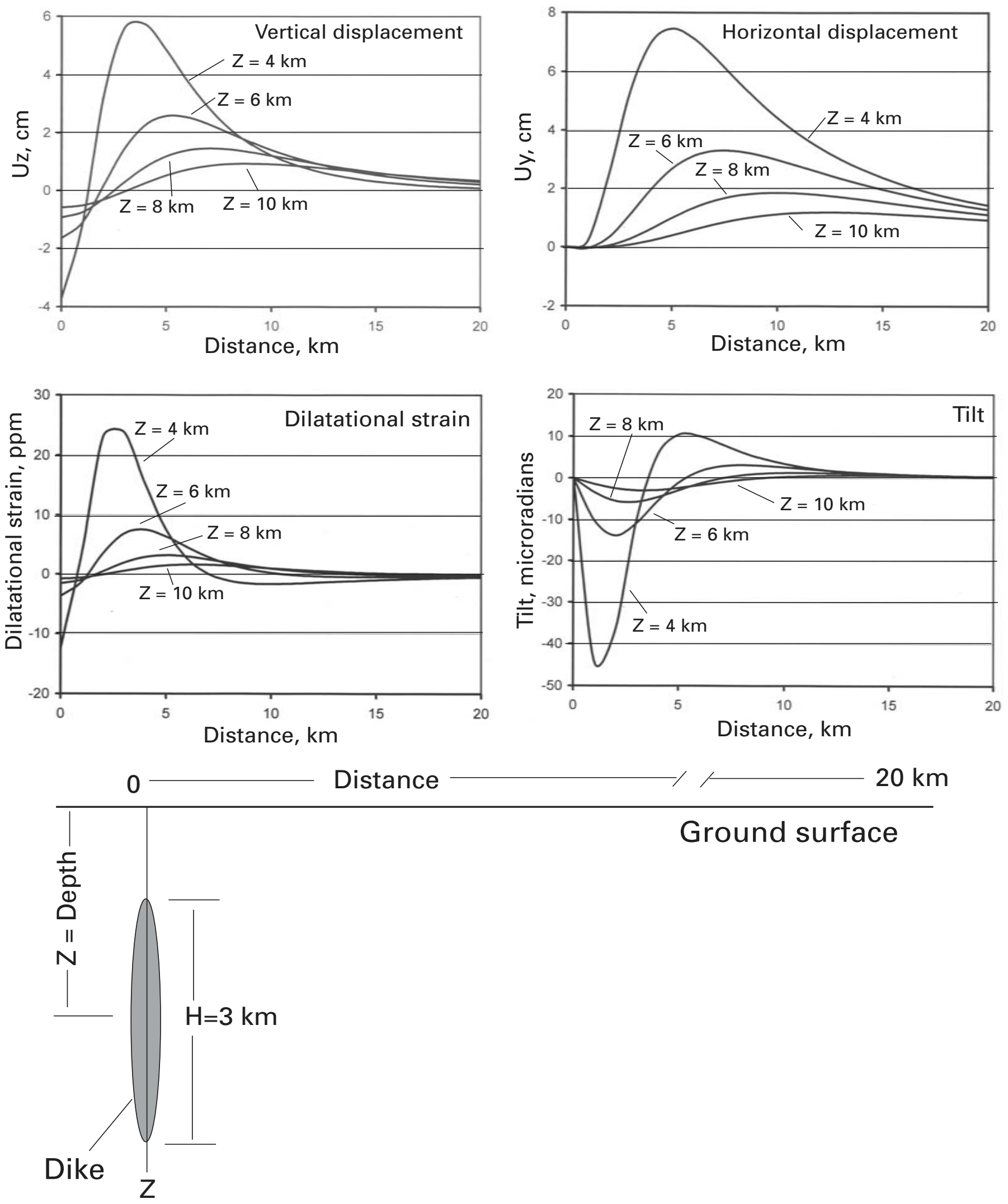

Figure C6.-Theoretical deformation profiles for an intruding dike in an elastic half space. The profiles are perpendicular to the long axis of a north-striking dike. They extend $20 \mathrm{~km}$ (12 miles) to the east from a point on the surface directly above the mid-point of the dike. The dike is 5 $\mathrm{km}$ (3 miles) long ( $\mathrm{N}-\mathrm{S}$ ) and $3 \mathrm{~km}$ (1.8 miles) high with a width of 1 meter (1 yard). The profiles show deformation at the surface when the dike is centered at depths of 10,8,6, and $4 \mathrm{~km}$ (the top of the dike extends to within $2.5 \mathrm{~km}$ (1.5 miles) of the surface in the latter case). Note that for a fixed dike length and height, the amplitudes of the surface deformations scale directly with dike width. Thus, the deformation amplitudes for a 10 -cm-thick (4 inch thick) dike will be one tenth of those for the 1-meter-thick (3 foot thick) dike. 
with warmer colors indicating higher amplitudes). Spectrograms are commonly plotted with increasing time on the vertical axis and frequency on the horizontal axis (see fig. C5). On such a display, high-frequency earthquakes appear as horizontal streaks of warm colors that span most of the spectral band with each streak corresponding to the time of an individual earthquake. Harmonic tremor, in contrast, appears as a series of vertical streaks over an extend time interval with each streak representing a spectral peak constituting the tremor signal. LP earthquakes also appear as vertical streaks but with limited vertical (temporal) extent. Hybrid earthquakes typically appear as a series of short vertical streaks extending above a horizontal streak, the latter representing the relatively abrupt, broadband onset of Hybrid events. The result is a madras-like pattern as illustrated by the examples in figure $\mathrm{C} 5$, the basic aspects of which can often be recognized through an irregular "warming" of the spectrogram due to elevated background noise.

\section{Application to Seismic Criteria for Color-Code Tran- sitions}

\section{High-Frequency Earthquakes}

The seismic criteria in the condition codes (table 2) involving high-frequency ( $\mathrm{HF}$ ) earthquake activity are expressed in terms of a threshold magnitude (for example, one or more $M \geq 4$ earthquakes per day) or a daily activity rate for smaller earthquakes (for example, $>5 \mathrm{M} \geq 3$ earthquakes/day). These seismic criteria apply to earthquake swarm activity within the confines of the caldera, along the Mono-Inyo volcanic chain, and beneath Mammoth Mountain. They will not normally apply to seismic activity in adjacent areas such as Sierra Nevada block south of the Long Valley Caldera, the upper Owens Valley, or the Chalfant Valley that, based on the geologic record, are unlikely sites for the onset of volcanic activity in the near future.

Particular choices of magnitude and rate thresholds for the four activity levels within condition GREEN and for the transition from GREEN to YELLOW reflect the varying levels of earthquake swarm activity within the caldera since 1980 . Earthquake swarm activity under "intense unrest" and a condition YELLOW, for example, includes one or more $M \geq 5$ earthquakes, five or more $M \geq 4$ earthquakes/per day, or 30 or more $M \geq 3$ earthquakes per day. This choice of these parameters for condition YELLOW, which requires a commitment of personnel and resources in an EVENT RESPONSE (table 2 ), is based on the following considerations:
- The largest earthquakes precursory to volcanic eruptions rarely have magnitudes much larger than $M=5$ to 6 (McNutt and others, 2000).

- The rupture surfaces of earthquakes with magnitudes of $\mathrm{M}=5$ to 6 have dimensions of 5 to $10 \mathrm{~km}$ ( 3 to 6 miles). This is roughly the thickness of the brittle crust within the Long Valley Caldera (Hill, 1992), and earthquakes in this size range thus represent disruption of a significant fraction the brittle crust.

- Precursory seismic swarms to recent volcanic eruptions within large calderas or distributed volcanic systems have included one or more $\mathrm{M} \geq 5$ earthquakes. The 1989 eruption off the Izu Peninsula (Japan) and the 1994 eruption in Rabaul Caldera (Paupa New Guinea), for example, were both preceded by earthquake swarms that included $\mathrm{M}>5$ earthquakes.

- The two most intense seismic episodes in the caldera-the May 1980 sequence and January 1983 swarm-included a $\mathrm{M}=6.0$ and two $\mathrm{M}=5.2$ earthquakes, respectively, all located in the south moat seismic zone (fig. A6). In both instances, the USGS responded by establishing a temporary field center in the caldera to monitor the activity. Future seismic activity at this level will trigger a similar USGS response consistent with an EVENT RESPONSE under condition YELLOW.

Activity rates for smaller earthquakes governing the criteria for transition from one activity level to another are based on the Benioff strain equivalent to the corresponding threshold magnitude (Benioff, 1951). Benioff strain is proportional to the square root of radiated seismic energy and thus to the square root of seismic moment, which in turn is proportional to the radiated energy (Hanks and Kanamori, 1979). Thus the Benioff strain equivalent of a $M=5$ earthquake is approximately $5 \mathrm{M}=4$ earthquakes and $30 \mathrm{M}=3$ earthquakes while the energy (or moment) equivalent is approximately $30 \mathrm{M}=4$ earthquakes and $900 \mathrm{M}=3$ earthquakes. For the purposes of this document, a strain criteria is more useful than one based on seismic moment (or radiated energy) because (1) a strain-based criteria gives greater importance to smaller earthquakes than does a criteria based on radiated energy or seismic moment, and (2) strains and strain rates associated with magmatic intrusions more relevant than the cumulative slip along a single fault.

\section{Volcanic Earthquakes}

Because volcanic earthquakes (LP earthquakes, VLP earthquakes, and harmonic tremor) are a robust seismic indicator of actively intruding magma, an escalation of their occurrence in the upper $5 \mathrm{~km}$ of the crust beneath Long
'Note: Usage here and in tables 1 and 2 of weak, minor, moderate-to-strong, and intense applied to increasing levels of volcanic unrest should not be confused with the qualitative terminology used for individual earthquakes (for example, minor for $M=3.0$ to 3.9 , light for $M=4.0$ to 4.9 , moderate for $M=5.0$ to 5.9 , strong for $M=6.0$ to 6.9 , major for $M=7.0$ to 7.9 , and great for $M>8.0$ ). This distinction is based on the recognition that (1) intense unrest, which includes an earthquake swarm with at least one $\mathrm{M} \geq 5$ (moderate) earthquake, is near the upper limit for seismic swarm activity in most volcanic areas, (2) a swarm of this intensity typically includes frequent, locally felt earthquakes (magnitudes in the $M=3$ to $M=4$ range) giving the subjective impression of "intense" earthquake activity to anyone who happens to be in the vicinity, and (3) deformation accompanying volcanic unrest is typically many times that associated with an individual earthquake with a magnitude matching the largest earthquake in a volcanic swarm sequence. 
Table C1.-Criteria for deformation and strain rates for Color-Code conditions under table 2.

\begin{tabular}{|c|c|c|c|c|c|c|}
\hline \multirow[t]{2}{*}{ Condition Code } & \multicolumn{3}{|c|}{ Strain and/or tilt rates ${ }^{1}$} & \multicolumn{3}{|c|}{ Displacement rates 2} \\
\hline & $\begin{array}{l}\text { 24-hr } \\
(\mathrm{ppm} / \mathrm{d})\end{array}$ & $\begin{array}{l}\text { weekly } \\
(\mathrm{ppm} / \mathrm{w})\end{array}$ & $\begin{array}{l}\text { annual } \\
\text { (ppm/y) }\end{array}$ & $\begin{array}{l}24-\mathrm{hr} \\
(\mathrm{mm} / \mathrm{d})\end{array}$ & $\begin{array}{l}\text { weekly } \\
(\mathrm{mm} / \mathrm{w})\end{array}$ & $\begin{array}{c}\text { annual } \\
(\mathrm{mm} / \mathrm{y})\end{array}$ \\
\hline $\begin{array}{l}\text { GREEN } \\
\text { Quiescence \& } \\
\text { Weak unrest }\end{array}$ & $<0.01$ & $<0.1$ & $<5$ & $\mathrm{NA}^{* *}$ & NA & $<5$ \\
\hline Minor unrest & $>0.01$ & $>0.1$ & $>5$ & NA & NA & $>5$ \\
\hline $\begin{array}{l}\text { Moderate-to- } \\
\text { strong unrest }\end{array}$ & $>0.1$ & $>1$ & $>50$ & NA & $>5$ & $>20$ \\
\hline YELLOW & $>1$ & $>10$ & $>500$ & $>5$ & $>50$ & $>2,000$ \\
\hline ORANGE & $>10$ & $>100$ & $>5,000$ & $>50$ & $>500$ & $>20,000$ \\
\hline
\end{tabular}

\footnotetext{
${ }^{1}$ Strain and tilt rates based on corresponding displacement rates over a $5-\mathrm{km}$ baseline.

${ }^{2}$ Displacements below $1 \mathrm{~mm}$ and not resolvable by the 2-color EDM and GPS systems. Notes:
}

- $\mathrm{Read}>5 \mathrm{~mm} / \mathrm{d}$ as several millimeters per day, $>10 \mathrm{~mm} / \mathrm{w}$ as tens of millimeters per week (or centimeters per week), etc.

- Approximate annual rates indicate corresponding long-term cumulative displacements and strains: (1) Read >500 mm/y a few meters per year (this long-term rate includes, for example, the $\sim 1$-meter uplifts accumulated over one year (1983) in Campi Flegrei caldera, Italy, and Rabaul caldera, Papua New Guinea (see Figure 1 of Battaglia and others, 1999). (2) $\operatorname{Read}>5,000 \mathrm{~mm} / \mathrm{y}$ as many meters to tens of meters per year.

Valley Caldera, Mammoth Mountain, or the Mono-Inyo volcanic chain will play a progressively more important role in the transition criteria to conditions YELLOW and ORANGE, respectively (table 2). As with other precursory activity, however, volcanic earthquakes do not inevitably culminate in an eruption; nor does the absence of precursory volcanic earthquakes preclude an eruption. For example, the intense earthquake swarm that began 27 hours prior to the onset of the September 1994 eruptions in Rabaul Caldera did not include readily identifiable LP earthquake activity or harmonic tremor.

At current levels, the deep LP earthquakes (focal depths between 10 to $25 \mathrm{~km}$ ) beneath Devils Postpile and the southwest flank of Mammoth Mountain (fig. A5), the three VLP earthquakes beneath the summit of Mammoth Mountain, and the occasional deep LP earthquakes just to the west of the Mono Craters qualify as background activity. Although these volcanic earthquakes indicate that magmatic processes are currently active, they do not portend an imminent volcanic eruption, at least at the activity rates documented since the onset of this activity in 1989 (Pitt and Hill, 1994), which ranged from several per month to a peak of 15 to 20 events per week during November and December, 1997. Midcrustal LP earthquake activity at these levels seems to be a relatively common, long-term phenomenon beneath many young volcanic systems (Hasegawa and others, 1991). The same applies to the occasional events with the appearance of shallow LP earthquakes and harmonic tremor recorded within Long Valley Caldera (Cramer and McNutt, 1997; Hough and others, 2000).

\section{Deformation Criteria}

Ground deformation precedes nearly all volcanic eruptions in response to increasing pressures within shallow crustal magma chambers or subsurface displacements produced by the upward intrusion of magma into the shallow crust. The deformation may be minimal for volcanoes that erupt frequently from a well-established conduit system. In most well-documented cases of eruptions from volcanic systems that have been in repose for several decades or more, however, precursory ground deformation is pronounced. Documented surface displacements in the hours to days prior to volcanic eruptions in such systems commonly range from tens of $\mathrm{cm}$ to several $\mathrm{m}$, and the associated strains and tilts may range from tens to several hundred ppm. [Note: In this document parts per million (ppm) is used to include both strain and tilt expressed as microstrain $\left(1 \times 10^{-6}\right)$ and microradians $\left(1 \times 10^{-6}\right.$ radians), respectively.]

Table $\mathrm{C} 1$ summarizes the deformation rate criteria used in the condition codes of table 2 . These criteria are based on order-of-magnitude (factor of ten) differences in deformation rates in order to reflect both 1) the broad range of deformation rates observed before eruptions and (2) the fuzzy nature of these criteria. In particular, the single significant figures used in these order-of-magnitude criteria should be regarded as uncertain by at least a factor of two. A “ ” followed by a single significant figure emphasizes the approximate nature of these values. Thus, for the purposes of this document, 
$20 \mathrm{~cm} / \mathrm{yr}$ ( 8 inches/yr) is approximately equivalent to a 0.5 $\mathrm{mm} /$ day rate sustained for one year.

As with other precursory phenomena, however, episodes of pronounced ground deformation do not inevitably culminate in a eruption, at least in the short term. The 1-ppm/day or 1-mm/day thresholds for condition YELLOW, for example, are based in part on recognition that large, restless calderas can sustain deformation rates of several $\mathrm{mm}$ per day for extended periods (months to a year or more) without necessarily culminating in a volcanic eruption. Uplift rates of 2 to $3 \mathrm{~mm} /$ day ( 0.08 to $0.12 \mathrm{inch} /$ day) sustained for over 12 months at both Campi Flegrei Caldera, Italy (Dvorak and Gasparini, 1991), and Rabaul Caldera, Paupa New Guinea (Blong and McKee, 1995), in 1983-84, for example, were followed in each case by a decade or more of relative quiescence. Rabaul Caldera, however, began erupting in September of 1994 following 27 hours of intense precursory unrest that include a swarm with two $M=5$ earthquakes and uplift of more than $6 \mathrm{~m}$ (20 feet) in the vicinity eruptive vents. Deformation precursory to the 1989 and 1997 dike intrusions off the Izu Peninsula, Japan, included tilts more than 5 microradian (ppm) per day (Aoki and others, 1999; Okada and Yamamoto, 1991). Both of these weeklong intrusive episodes were accompanied by strong earthquake swarms, each including a M=5 earthquake. The 1989 episode culminated in a small basaltic eruption (Okada and Yamamoto, 1991); the 1997 episode did not culminate in an eruption. These examples from the Izu Peninsula emphasize the challenge in determining whether a magmatic intrusion in progress has sufficient energy to breach the surface.

The theoretical deformation profiles (fig. C6) calculated for an intruding dike show that the initial strain and displacement changes for the onset of intrusion of a 1-meter-thick (1-yard-thick) dike at a depth of $10 \mathrm{~km}$ (6 miles) will begin to exceed these threshold amplitudes (the actual strain rates, of course, will depend on the dike intrusion rate). Likewise, a 10-cm-thick (4 inch thick) dike will begin to exceed these changes when its top reaches a depth of about $5 \mathrm{~km} \mathrm{(3}$ miles). Both the January 1983 swarm beneath the SMSZ and the 1989 Mammoth Mountain swarms appear to have involved the intrusion of thin dikes (thicknesses $<10 \mathrm{~cm}$ ) to within $3 \mathrm{~km}$ (1.8 miles) of the surface (Hill, and others, 1990; Langbein, and others, 1993; Savage and Cockerham, 1984). As is evident from the two-dimensional plots in figure C6, the amplitude and sense of strain, tilt, and deformation about a specified intrusion (in this case a dike) show considerable spatial variation (the variation is even greater in a full, threedimensional plot). This can be either an advantage or disadvantage, depending on the location of the intrusion with respect to the array of deformation-monitoring instrumentation and the density of instrument sites within the array. In particular:

- Details of the strain and deformation fields resolved by a densely instrumented array, spanning the area above an active intrusion, provide considerable leverage for a robust inversion for the geometry and location (including depth) of the intruding body. In principle, this advantage should permit near real-time tracking of the progress of the intrusion as it develops.
- In contrast, deformation and strain data from a sparse array above an intrusion (or even a dense array if the intrusion is beyond the array perimeter) will likely miss the maxima in the deformation or strain fields and will certainly lead to poorly constrained interpretations of the deformation data in terms of the location and geometry of the intrusion.

The threshold for the transition to condition ORANGE is set at the relatively high strain rate of $10 \mathrm{ppm} /$ day (corresponding displacement rates on the order of $10 \mathrm{~cm} /$ day or 4 inches/day) for the Long Valley Caldera-Mono Craters region. Although a real-time deformation monitoring network was not in operation in Rabaul Caldera at the time of the September 1994 eruption, scientists at the Rabaul Observatory describe a 6-m uplift that had developed overnight prior to the onset of eruptive activity at 6:06 AM (local time) on September 19 (Blong and McKee, 1995). Chronicles of the 1538 eruption in Campi Flegrei Caldera, Italy, describe a remarkably similar ground uplift of 6 to $9 \mathrm{~m}$ (20 to $30 \mathrm{ft}$ ) that developed overnight in the vicinity of the vent that erupted to produce Monte Nuovo cone in the center of the caldera (Dvorak and Gasparini, 1991; Rosi and Santacroce, 1984). The strain and displacement rates associated with such pronounced uplifts far exceed those specified above for condition ORANGE and would easily be detected by the real-time, deformation-monitoring network in Long Valley Caldera.

These criteria require that elevated deformation or strain rates be detected on multiple instruments or baselines to guard against being misled by spurious strain or deformation signals (instrument malfunction or disturbances local to a particular monument or instrument site, such as surficial slumping, or disruptions due to animal or human activities). Any single deformation signal meeting the criteria listed in table $\mathrm{C} 1$ in the absence of one or more of the additional precursors should raise suspicions that the source of the deformation may be a nonmagmatic intrusion. In this unlikely situation, it would be especially important to confirm that suspicious deformation signals were not due to meteorological processes associated with a strong storm system or perhaps local flooding. Obviously, the unlikely coincidence of a magmatic intrusion and a strong storm or flooding would present special challenges to all concerned.

\section{Gases and Geochemical Criteria}

As with the other precursory parameters (seismicity and deformation), it is not possible to realistically anticipate all significant variations in the patterns of gas emissions and geochemical activity that might precede an eruption in Long Valley Caldera or along the Inyo-Mono Craters chain. The significance of the measurements of $\mathrm{CO}_{2}$ concentration and soil $\mathrm{CO}_{2}$ flux during periods of increasing unrest remains uncertain because of limited experience to date with these newly developed monitoring tools. Also, it is necessary to be prepared to incorporate less commonly used geochemical indicators in many decisions involving the transition from one condition to the next. For example, scientists monitoring the unrest may become aware of widespread reports of intense "rotten-egg" odors $\left(\mathrm{H}_{2} \mathrm{~S}\right)$ and/or 
energetic steam venting and blasting (but not involving the ejection of rock fragments). Either or both of these may result from the boil-off of hydrothermal fluids by a shallow intrusion and either would provide strong support for making the transition from condition GREEN to YELLOW. Such activity would probably be coupled with greatly elevated $\mathrm{CO}_{2}$-emission rates and minimal $\mathrm{SO}_{2}$-emission rates. The latter tends to be scrubbed (absorbed in solution) by hydrothermal waters thus masking its presence as a magmatic gas. The onset of elevated $\mathrm{SO}_{2}$-emission rates would suggest that the hydrothermal system had completely boiled away and would provide support for making the transition from conditions YELLOW (or GREEN) to ORANGE.

Just as for seismicity rates, magnitudes, and strain rates specified in table 2, the $\mathrm{CO}_{2}$ - and $\mathrm{SO}_{2}$-flux rates specified for the transition between color conditions are approximate only. Initial estimates for gas emission rates may be uncertain by 20 to 30 percent because of normal wind variability. Soil-gas concentrations and fluxes can be severely influenced by weather and seasonal factors.

\section{Additional Phenomena}

Intruding magma may be accompanied by a host of other phenomena, such as changes in the level and temperature of ground water, magnetic properties of rock, electrical conductivity, induced electro-magnetic signals, fumarole activity, and ground cracking. The transition criteria do not explicitly include these phenomena, which in many cases involve monitoring techniques that are still in the research/experimental stage. Confirmed recognition of such phenomena, however, may help decide the transition to condition YELLOW or ORANGE in otherwise marginal situations. The most important of these additional precursory indicators include:

- Pronounced ground cracking with displacements across individual cracks of a few $\mathrm{cm}$ or more. Distributed sets of tension cracks and (or) slip on opposing sets of normal faults bounding a graben commonly developed as magma approaches the surface prior to an eruption.

- Development of new fumaroles and (or) hot springs or a vigorous increase in the output from several existing fumaroles and (or) hot springs.

- Increases in helium isotope ratio $\left({ }^{3} \mathrm{He} /{ }^{4} \mathrm{He}\right)$ in fumarole gases, which would suggest an infusion of fresh magma into the volcanic system.

- Differential magnetic field changes of $\sim 5$ nanotessla (nT) or more over a week to ten days between three or more stations.

Coherent changes in several of these parameters will carry more weight than a pronounced change in a single parameter.

\section{Appendix D. Monitoring Networks and Instrumentation}

This appendix summarizes the instrumentation currently operating in Long Valley Caldera that fulfills the monitoring requirement for prompt identification of changes in activity. The USGS continues to upgrade the monitoring networks as funding permits, and this summary applies to the instrumentation configurations as of early 2002. The telemetered networks provide continuous data on seismicity, deformation, water-well levels, and $\mathrm{CO}_{2}$-gas concentrations and flux rates for real-time review and analysis on computer systems in the LVO Field Center in Mammoth Lakes, the USGS in Menlo Park, California, and the Cascades Volcano Observatory in Vancouver, Washington. Routine measurements of the two-color electronic distance meter (EDM) network provide data on deformation changes on time scales of a week or more. The regional, survey-mode geodetic networks (GPS and leveling) are normally measured just once a year, and they will generally not contribute to rapid evaluation of activity levels. In the case of condition YELLOW or above, however, field crews may be mobilized to measure critical parts of these networks on a frequent basis to help better define the areal extent, magnitude, and rate of the associated ground deformation. Each of these monitoring networks is summarized below. For descriptions of some of the more experimental networks for tracking variations in gravity, hydrological, electromagnetic, and geochemical parameters measured at infrequent or irregular intervals, see (Battaglia and others, 1999; Gerlach and others, 1999; Hill, 1984; Sorey and others, 1998). Nearreal-time summaries of most of these monitoring data are available through the Long Valley Observatory web page at http://lvo.wr.usgs.gov.

\section{Seismic Network}

The seismic network monitoring Long Valley Caldera and vicinity (fig. D1) was being upgraded as of early 2002. The network in its current (early 2002) form was established in the summer of 1982. From the beginning, the seismic network was operated as part of the Northern California Seismic Network (NCSN of the USGS) in cooperation with the University of Nevada Reno (UNR). In 1995, the NCSN became a cooperative effort between the USGS and U.C. Berkeley. Data from the Long Valley seismic network are analyzed, catalogued, and archived as part of routine NCSN processing. The archived data reside on a mass-storage device maintained jointly by U.C. Berkeley and the USGS. The archived data are available through the Internet at http://quake.geo.berkeley.edu/ncedc/catalog-search.html.

As currently configured, the Long Valley seismic network consists of some 20 seismic stations within $10 \mathrm{~km}$ of the caldera boundary (fig. D1) and an additional 15 to 20 stations within $100 \mathrm{~km}$ (60 miles) of the caldera. Most stations involve a single-component (vertical) seismometer with a free period of $1 \mathrm{sec}$ packaged with a voltage-controlled oscillator (VCO) and preamplifier. The FM output from each of these analog stations is telemetered to LVO Field Center in Mammoth Lakes and, from there, by a frame relay link to the USGS in Menlo Park. The data are processed in real-time on Earthworm/Earlybird computer systems in both the LVO Field Center and USGS facilities in Menlo Park for initial 
hypocentral locations, magnitude estimates, and preliminary focal mechanisms (fig. D1). Seismic data from this analog network spans a 1 - to $20-\mathrm{Hz}$ frequency band with a dynamic range of 40 to $50 \mathrm{db}$. As funding permits, the USGS will upgrade this seismic network over the next several years by replacing selected analog stations with six-component, broadband, digital stations.

The existing network also includes three, six-component (three velocity and three acceleration components) digital stations colocated with the borehole dilatometers POPA, BSP, and MCX (fig. D2). The signals from these stations, digitized at $200 \mathrm{sps}$, are also transmitted to Menlo Park by the $128 \mathrm{Kbps}$ frame relay. The 3 -km-deep (1.8 mile deep) borhole in the center of the resurgent dome (see LVEW in fig. D4) is currently being developed as a borehole observatory that will include a 6-component seismic package installed at a depth of between 2 and $3 \mathrm{~km}$ (1.2 and 1.8 miles), as well as a borehole dilatometer and tiltmeter plus a variety of hydrological monitoring instruments.
The station MLAC co-located with the long-base tiltmeter (figs. D1 and D2A) is a broadband, wide-dynamic range seismometer that is operated as part of the California Institute of Technology TERRAscope network (see http:// www.gps.caltech.edu/seismo/earthquake/ for more information on the Caltech TERRAscope stations). The station OMM is a broadband seismometer (CMG-3) installed by the University of Nevada, Reno, in the summer of 2000 in a mine adit located $4 \mathrm{~km}$ (2.5 miles) southeast of Mammoth Mountain.

The existing analog network routinely detects and locates earthquakes with magnitudes as small as $\mathrm{M}=0.3$ (the detection threshold), and it systematically detects and locates 90 percent or more of all earthquakes with magnitudes $\mathrm{M}=1.2$ and greater (the completeness threshold) occurring within the network. These thresholds increase somewhat during periods of intense earthquake activity when the waves from earthquakes occurring in rapid succession overlap. The detection and completeness thresholds are somewhat higher for events along the Inyo-Mono Craters chain, because the

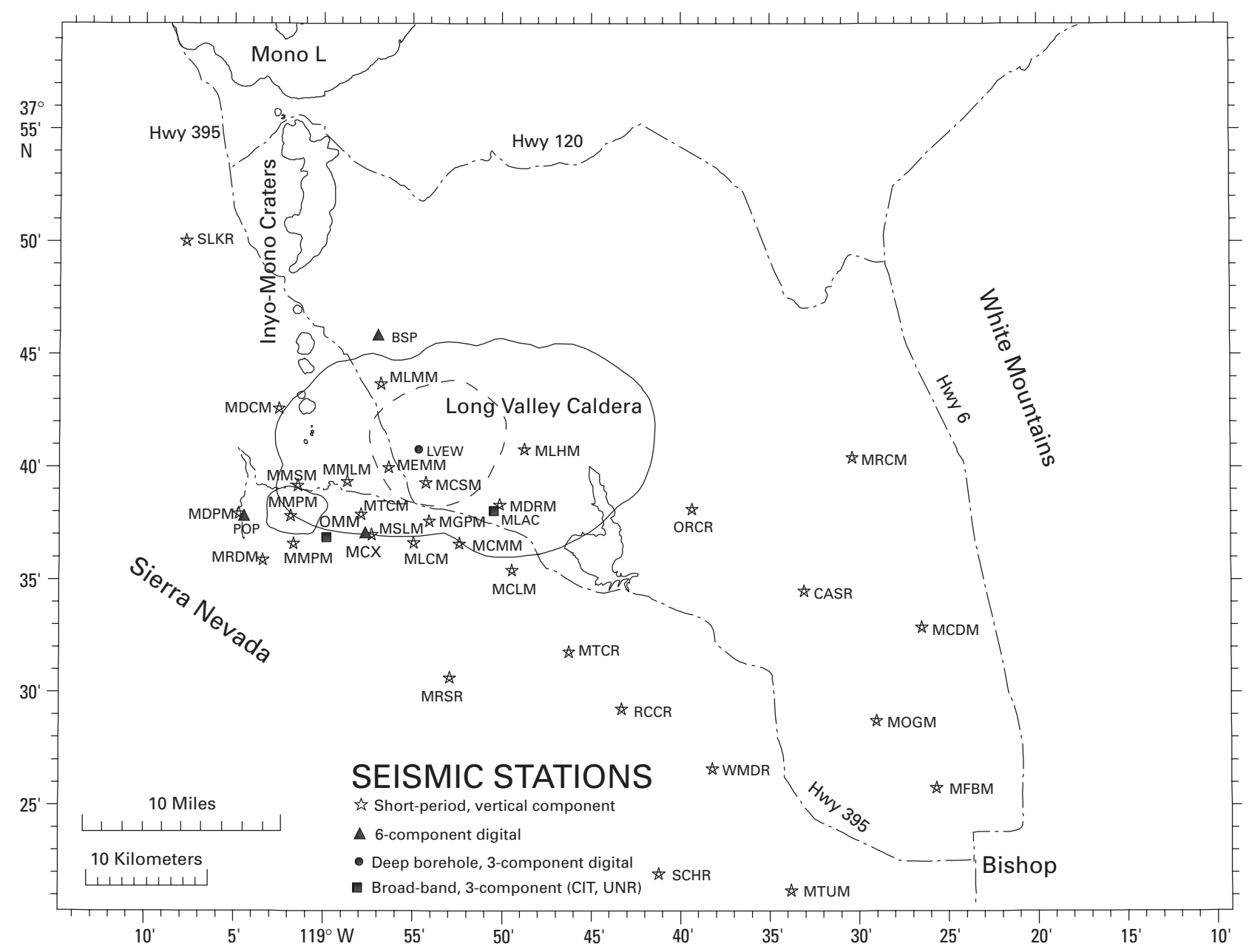

Figure D1.-Map showing seismic stations operating in Long Valley Caldera and vicinity. Stars are stations of the Northern California Seismic Network (NCSN). Triangles are six-component borehole packages colocated with borehole dilatometers. The circle is the deep borehole three-component package installed at a depth of $3 \mathrm{~km}$ (1.8 miles) in the Long Valley exploratory well (LVEW). The square is station MLAC in the Terrascope network operated by the California Institute of Technology. 

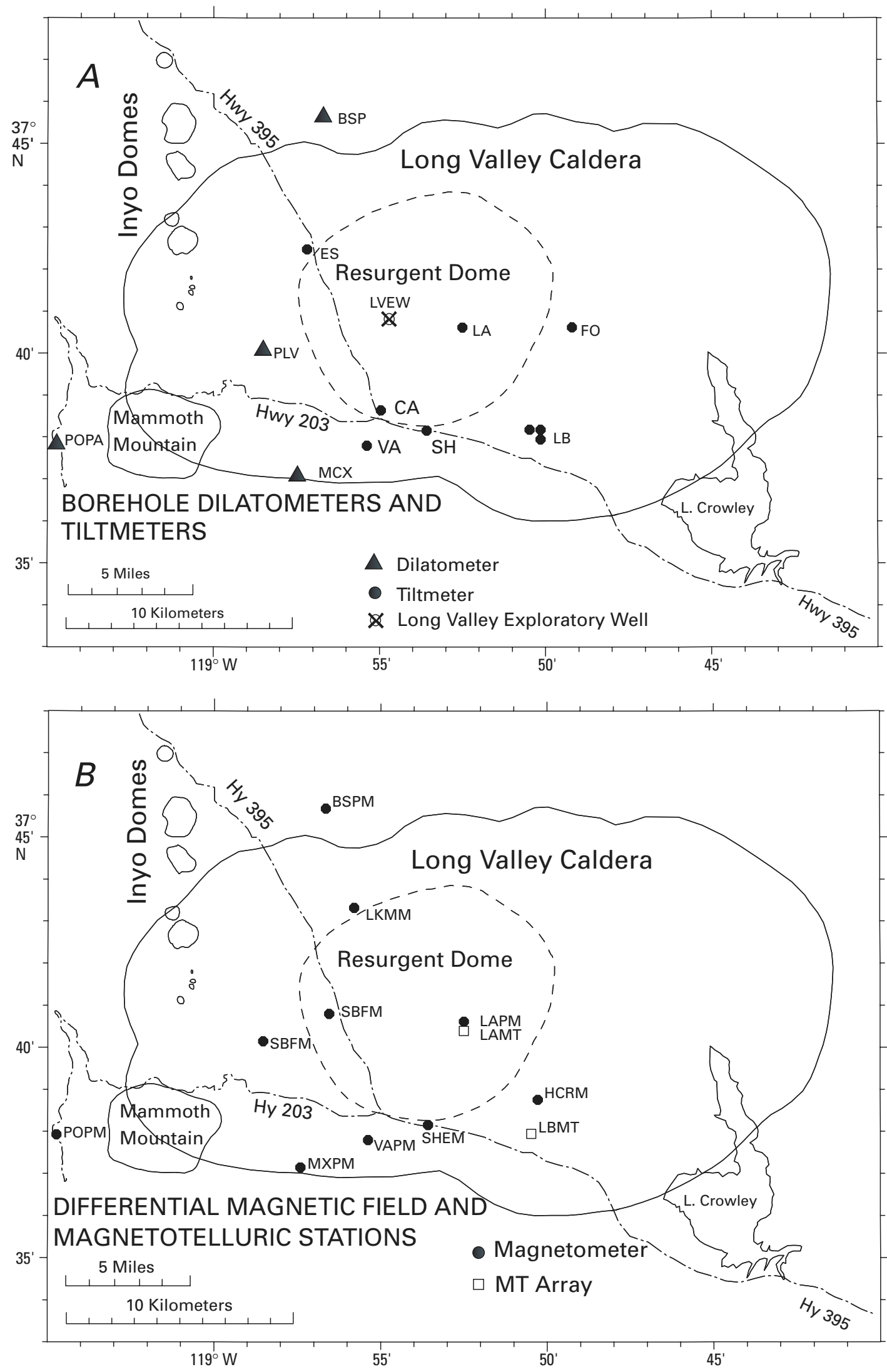

Figure D2.-A, Map of borehole dilatometer (triangles) and tiltmeter (circles) locations. The cluster "LB" represents the long-base Michelson tiltmeter installed and maintained by Roger Bilham of the University of Colorado (Behr, and others, 1992). B, Map of differential magnetometer locations in Long Valley Caldera. The reference magnetometer station, MG, is located $20 \mathrm{~km}$ (12 miles) southeast of the caldera on the Sherwin grade near Highway 395. 
network is less dense to the north of the caldera (see fig. D1). The Earlybird component of this computer system is programmed to initiate pages alerting the LVO SIC and the seismologist on duty in the USGS Menlo Park office of significant increases in the level of seismic activity within LVC/MC. The threshold for initiating a page is nominally set for a single $\mathrm{M} \geq 3$ earthquake and (or) a swarm of 20 or more smaller events per hour. Once a recognized earthquake swarm is under way, these thresholds may temporarily be raised to suppress needless frequently recurring pages.

The real-time capability of the Earthworm system (and its predecessor, the Real-Time-Processing (RTP) system) has been particularly useful in (1) tracking in real-time the spatial/temporal evolution of earthquake swarms within and adjacent to the caldera during episodes of elevated activity; (2) providing high-resolution seismicity maps (for example figs. A3, A5A, and A6) and first-motion focal mechanisms; and (3) providing P-wave arrival time data used in tomographic inversions for P-wave velocity models of the subsurface caldera structure. Hardware/software modules on the Earthworm system provide the capability to view waveforms, spectrograms, and continuous signal levels in the form of real-time seismic amplitude measurements (RSAM amplitudes; see Murray and Endo, 1989) in near real-time for earthquakes occurring within the Long Valley Caldera network and several other sub-networks within NCSN. This capability greatly enhances seismologists ability to recognize signals from unusual seismic sources such as LP or hybrid "volcanic" earthquakes and volcanic tremor.

\section{Borehole Strainmeter (Dilatometer) Network}

Four Sacks-Evertson borehole volumetric strainmeters (dilatometers) installed at depths of $200 \mathrm{~m}$ (650 ft) are operated in the Long Valley Caldera-Mono Craters region in a cooperative effort with the Carnegie Institution of Washington (POPA, PLV, BSP, and MCX in figure D2A). Biaxial borehole tiltmeters are installed with the BSP and MXC dilatometers. These dilatometers are sampled automatically every 10 minutes and the data are transmitted to USGS offices in Menlo Park by the Geostationary Operational Environmental Satellite (GOES). The dilatational strain averaged over the last 60 minutes is automatically computed and updated every 10 minutes by a computer in Menlo Park. The raw online data are then corrected for Earth tides and atmospheric pressure loading, determined from a theoretical Earth-tide model and on-site pressure transducers at each site. These instruments clearly resolve changes in strain to better than $0.02 \mathrm{ppm}$ over several days and $0.01 \mathrm{ppm}$ for periods less than a day. At still shorter periods corresponding to the seismic band (100 sec to $0.1 \mathrm{sec})$, resolution of signals below $0.001 \mathrm{ppm}$ is routine.

\section{Tiltmeter Network}

Data from seven shallow (2 to10 m or 6 to $30 \mathrm{ft}$ deep) borehole tiltmeter sites and a long-base Michelson tiltmeter (fig. D2A) are sampled every 10 minutes and telemetered to USGS offices in Menlo Park at 10 minute intervals by the GEOS satellite. The borehole tiltmeter array is capable of discriminating rapid changes in tilt at the level of 5 to 10 microradians (ppm) occurring within a period of a few days to one week (Mortensen and Hopkins, 1987). The Michelson long-base tiltmeter, which is jointly operated by Roger Bilham at the University of Colorado and the USGS, is an L-shaped, water-tube instrument $0.5 \mathrm{~km}(0.3 \mathrm{mile})$ on a side. It has both greater accuracy and stability than the shallow borehole instruments, and is capable of resolving tilt changes on the order of 0.1 microradian over periods of a week. In principal, it has the capability of resolving tilt changes of 1 microradian over a period of years or more (Behr and others, 1992).

\section{Differential Magnetic Field and Magnetotelluric Network}

Stress changes imposed on a rock induce small changes in the magnetic susceptibility and remanence of the rock, which in turn produces small but measurable variations in the local magnetic field. The local magnetic field in Long Valley Caldera is monitored with absolute, total field magnetometers (Mueller and others, 1991) at 10 sites (figure D2B). Sites BSPM, LKMM, LAPM, SHEM, VAPM, MXPM, PLVM, and POPM were installed as part of a cooperative program with Y. Sasai at the University of Tokyo, Japan. Magnetic field data from these stations are sampled automatically every 10 minutes and transmitted to USGS offices in Menlo Park where they are processed and checked to determine whether changes exceeding the background noise have occurred during the previous 24 hours. To isolate local magnetic field variations, data from adjacent stations are automatically differenced and smoothed with a 3-day smoothing window. The result is monitored daily and plotted weekly. Changes greater than $1 \mathrm{nT}$ at periods greater than one day are considered to be anomalous (a change of $1 \mathrm{nT}$ roughly corresponds to a stress change of several bars). Such short-term changes in Long Valley Caldera have not yet been observed, although they have been documented prior to and during recent eruptions from Mount St. Helens (Washington); Mt. Mihara (Japan); Mt. Ruapehu (New Zealand); and Reunion Island (Johnston, 1989). Mueller and others (1991), however, have documented long-term changes in the differential magnetic field within Long Valley Caldera that correlate with the episode of renewed uplift of the resurgent dome that began in October 1989.

Magnetotelluric sites LAMT and LBMT (fig. D2B) use orthogonal, $0.5-\mathrm{km}$ legs for electric field measurements and fluxgate magnetometers to monitor the electrical resistivity beneath the caldera. These sites were installed as part of a cooperative program with J. Zlotnicki of the Institut de Physique du Globe Paris (IPG) in Paris, France. Data from these instruments are telemetered by GOES satellite to USGS computers in Menlo Park. 

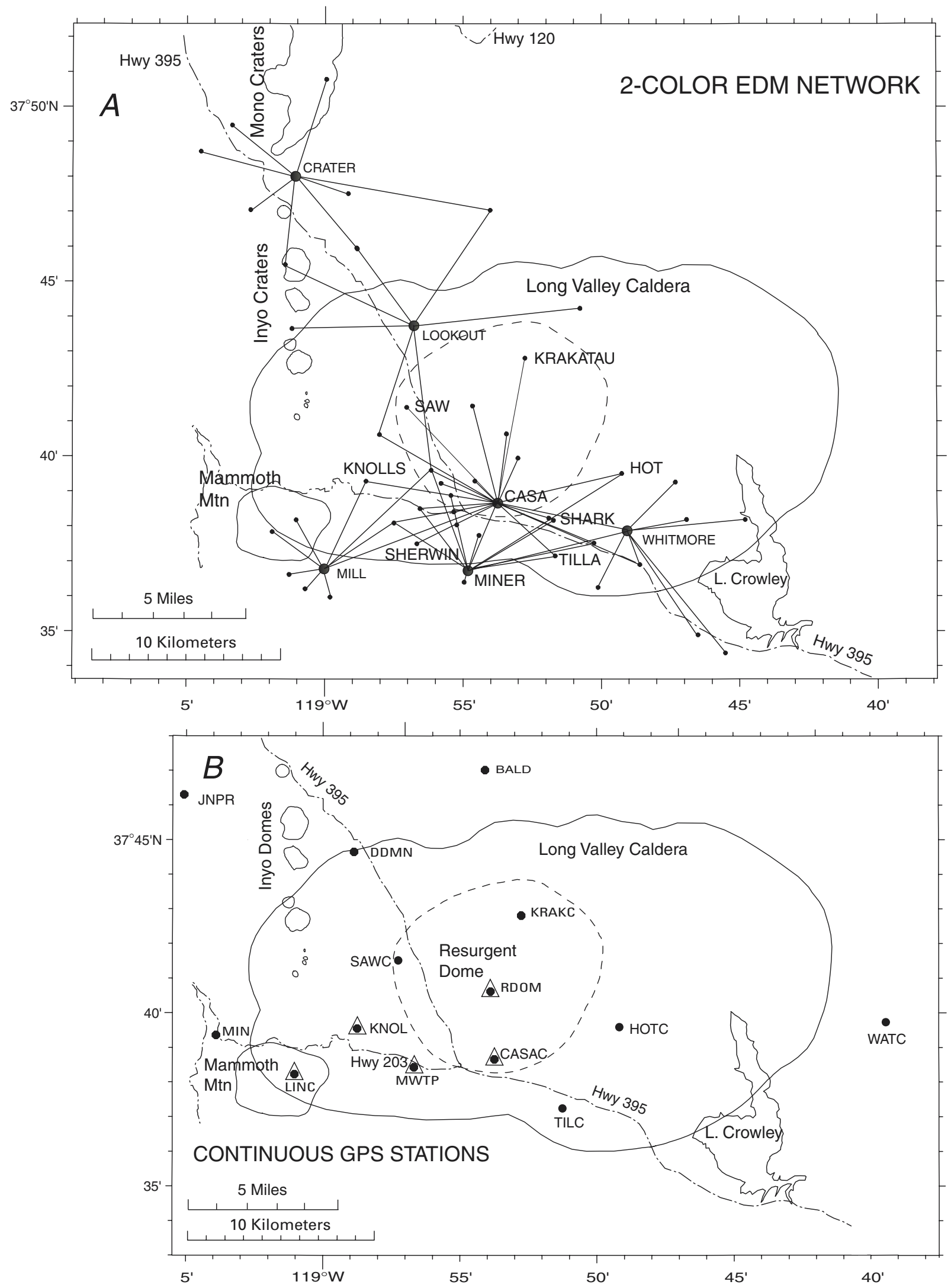

Figure D3.-A, Monuments and baselines in the two-color electronic distance meter (EDM) (geodimeter) network in the Long Valley region. Large dots are instrument sites; small dots are reflector sites. The baselines radiating from the instrument site, CASA, to the labeled reflector sites are measured several times a week, weather permitting. B, Locations of Global Positioning System (GPS) stations operated in a continuous mode. GPS stations operated in real-time mode enclosed in triangles. 


\section{Geodetic Networks}

\section{Two-Color EDM Network}

Distance measurements for eight baselines extending from the monument CASA on the southern part of the resurgent dome (fig. D3A) using a two-color Electronic Distance Meter (EDM) have been collected two to three times a week, weather permitting, since the summer of 1983 . With this measurement frequency, a week or 10 days is the minimum time interval for which meaningful displacements can be resolved under normal circumstances. Approximately 70 other baselines are measured with sampling intervals between one month and one year depending on activity levels and deformation rates. These lines generally are not used in the short-term evaluation of the Color-Code status unless the center of activity shifts away from the central part of the caldera. If necessary, measurements on a single baseline can be repeated as frequently as once every 10 seconds (this will not be an option if evolving activity in the Long Valley region might place the on-site operator at risk).

Based on the analysis of the measurement error, Langbein and Johnson (1997) found two distinct error sources (1) a white noise source due to error in the measurement of the index of refraction of the atmosphere, and (2) a random-walk component due to localized motion of individual monuments. The white-noise error in millimeters $(\mathrm{mm})$ is:

$$
\sigma_{w}=\sqrt{ }\left[0.3^{2}+\left(0.12 \times 10^{-7} \mathrm{~L}\right)^{2}\right]
$$

where $L$ is the length of the line in $\mathrm{mm}$. The random-walk component is:

$$
\sigma_{r w}=\sqrt{ }\left[1.3^{2}+\left(0.18 \times 10^{-7} L\right)^{2}\right]
$$

where $\sigma_{r w}$ has the units of $\mathrm{mm} / \mathrm{Vyr}$. To estimate the 95 percent confidence interval in rate, the above can be combined as:

$$
\sigma_{\text {rate }}=2\left[\left(\sigma_{r w}{ }^{2} / T\right)+\left(\sigma_{w}{ }^{2} 12(N-1) /\left(T^{2} N(N+1)\right)\right]^{1 / 2}\right.
$$

where $N$ is the number of measurements made over the time interval, $T$ years. Thus, for a 10-day interval on a 5 -km-long baseline with three measurements, the 95 percent confidence interval in deformation rate is roughly $100 \mathrm{~mm} / \mathrm{yr}$. In the case of a 200-day interval with 70 observations, however, the 95 percent confidence interval in deformation rate drops to $4.4 \mathrm{~mm} / \mathrm{yr}$ (0.2 inches/year).

These manpower-intensive, two-color EDM measurements will be phased out once the continuous GPS network (see following section) becomes fully operational and after sufficient temporal overlap (6 months to a year) in measurements has accumulated with both systems to insure continuity in the deformation time history within the caldera.

\section{GPS Networks}

\section{Continuous and Real-Time Stations}

Deformation in the region around Long Valley Caldera from 1980 to 1989 was monitored by annual trilateration surveys using Geodolite laser-ranging instruments (Savage, 1988). These annual Geodolite surveys were phased out in 1989 and replaced with an expanded network of monuments surveyed by the Global Positioning System (GPS) (fig. D4). In 1998, the USGS began a 4-year project to update geodetic monitoring in the Long Valley Caldera area with a 16 station permanent GPS network. Four stations (MWTP, LINC, KNOL, RDOM) were installed in 1998, an additional four (CAS2, DEAD, BALD, PMTN) in 1999, two (SAWC, TILC) in the summer of 2000, and an additional four (HOTC, WATC, DECH, and KDAKC) in 2001. Prior to 1998, the USGS operated permanent GPS stations at Minaret (MINS) and at June Lake (JNPR) and the Jet Propulsion Laboratory (JPL) operated stations Krakatoa (KRAK) and CASA. GPS data are collected by NT workstations in Mammoth Lakes and transferred daily to a server at the USGS Cascades Volcano Observatory located in Vancouver, Washington. Twenty fourhour RINEX files for stations installed by the project are available via anonymous FTP. Daily solutions for RINEX files are available at the USGS web site http://quake.wr.usgs.gov/ QUAKES/crustaldef/longv.html

Data from a subset of stations are processed epoch-byepoch in real-time on an NT workstation. The program is available from a commercial source. It offers processing features not available in what is commonly known as real-time kinematic (RTK) solutions. Current real-time processes compute solutions every $5 \mathrm{sec}$, create daily files, and plot results in real-time. A web module is used to transfer plot image files for web browser viewing.

The GPS technique has the following advantages over conventional trilateration or EDM techniques (1) line-of-sight is not required between GPS receiver sites (monuments), (2) measurements can be completed in poor weather, (3) measurements resolve both horizontal and vertical displacements, and (4) data acquisition and analysis processes are easily automated with the use of computers. Real-time GPS or epoch-by-epoch processing gives several $\mathrm{mm}$ accuracy over 24-hour period and cm-level accuracy in near real time.

\section{Regional Geodetic Networks}

The regional geodetic networks involve arrays of monuments that are normally surveyed on an annual basis using leveling, GPS, gravity, and two-color EDM techniques (fig. D4). These regional networks provide long-term definition of the regional deformation field and a regional context for more localized deformation within Long Valley Caldera or along the Mono-Inyo volcanic chain (Marshall, and others, 1997). Because these networks are measured infrequently, they will not normally contribute to the determination of the status for short-term fluctuations in moderate to strong unrest under con- 
dition GREEN. In the case of intense unrest and condition YELLOW (or EVENT RESPONSE), however, the USGS may initiate more frequent surveys of appropriate sections of these regional networks and incorporate the results with the two-color EDM network subject to the above error equations. Typical values for $\sigma_{\mathrm{w}}$ for GPS data are $3 \mathrm{~mm}$ and $10 \mathrm{~mm}$ for horizontal and vertical components, respectively. We expect the randomwalk component to be approximately $2 \mathrm{~mm} / \sqrt{ } \mathrm{yr}$, although other temporally correlated errors may mask this monument noise over time intervals spanning one month to a few years.

\section{Leveling Network}

Leveling lines used to track vertical ground deformation in the Long Valley Caldera- Mono Craters region are shown in Figure D5. The earliest leveling measurements in the Long
Valley region date back to a 1905 survey along Highway 395. Subsequent surveys along this section of the highway were conducted in 1914, 1932, 1957, 1975, 1980, annually from 1982 to 1988, and in 1992, 1995, and 1997 (Castle and others, 1984; Langbein and others, 1995; Savage, 1988). Lines 3 and 6 within the caldera were established in 1975, line 2 in 1982 , lines 4 and 5 in 1983, and the Mary Lake Road line in 1989. All of these lines except the Mary Lake Road line were measured annually from 1983 to 1986 and 1988, and 1992. The Mary Lake Road line was measured in 1989, 1995, and 1997.

The random error in leveling surveys can be approximated by $s=a L^{1 / 2}$ where $s$ is the standard deviation, $a$ is a constant for each order, class, and epoch of leveling, and $L$ is line length in $\mathrm{km}$. (Castle, and others, 1984) estimated $a \approx 6$ for the 1905 and 1914 surveys, and $a \approx 1.4$ for all subsequent surveys through 1983. By extension, $a=1.4$ was used through 1991. Since 1992, the surveys have been of first order and

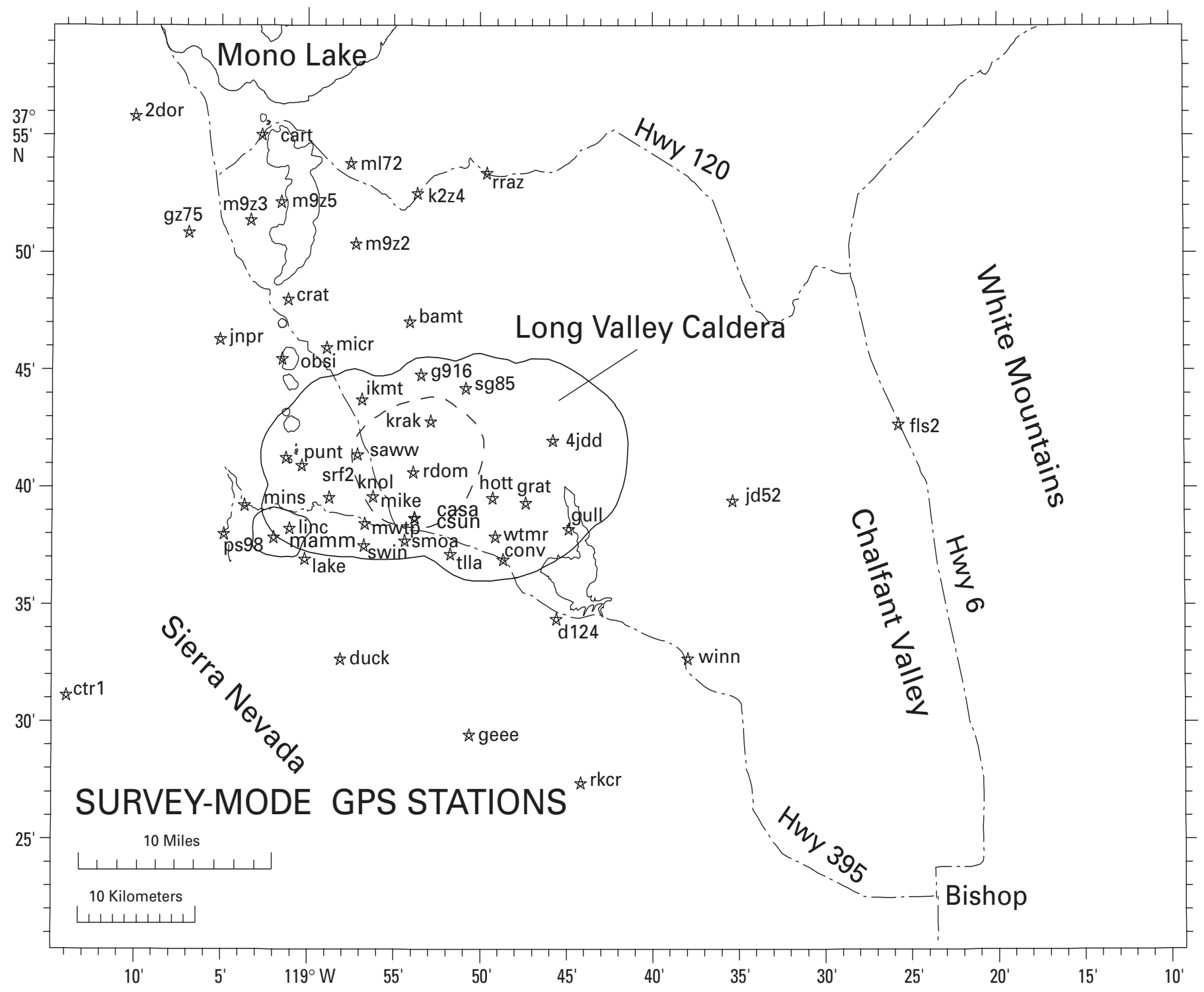

Figure D4.-Map of locations for survey-mode Global Positioning System (GPS) monuments in the Long Valley region. 
with $a=1.0$. Experience shows that these values adequately account for random errors and so can be used to characterize the uncertainty in most leveling surveys, but there is also a possibility of systematic errors. Except for the 1984 survey, which seems to suffer from a serious systematic error (Savage and others, 1987), the leveling results are sufficiently accurate to characterize vertical ground movements throughout the area and in fact are the most accurate information of this type available. However, leveling surveys are time consuming, personnel intensive, and therefore expensive.

The USGS intends to replace the annual leveling surveys by survey-mode GPS measurements following a campaign planned for the summer of 2002 to jointly occupy the network monuments with leveling, GPS, and gravity measurements. Although the GPS results are likely to be less precise than leveling for vertical ground movements, GPS measurements are easier to make, are therefore more cost-effective, and provide information about horizontal as well as vertical ground movements.

\section{Geochemical Monitoring}

\section{$\mathrm{CO}_{2}$-Soil-Gas Concentrations}

The carbon dioxide $\left(\mathrm{CO}_{2}\right)$ gas-concentration monitoring network in the Long Valley Caldera-Mono Craters region, which was established in 1995, currently consists of seven monitoring stations (Figure C6; also see McGee and Gerlach, 1998). Each station consists of a collection chamber buried in the soil, the air from which is pumped to nearby $\mathrm{CO}_{2}$ sensors housed in U.S. Forest Service structures or culverts. Local barometric pressure is also measured at the site HS1.

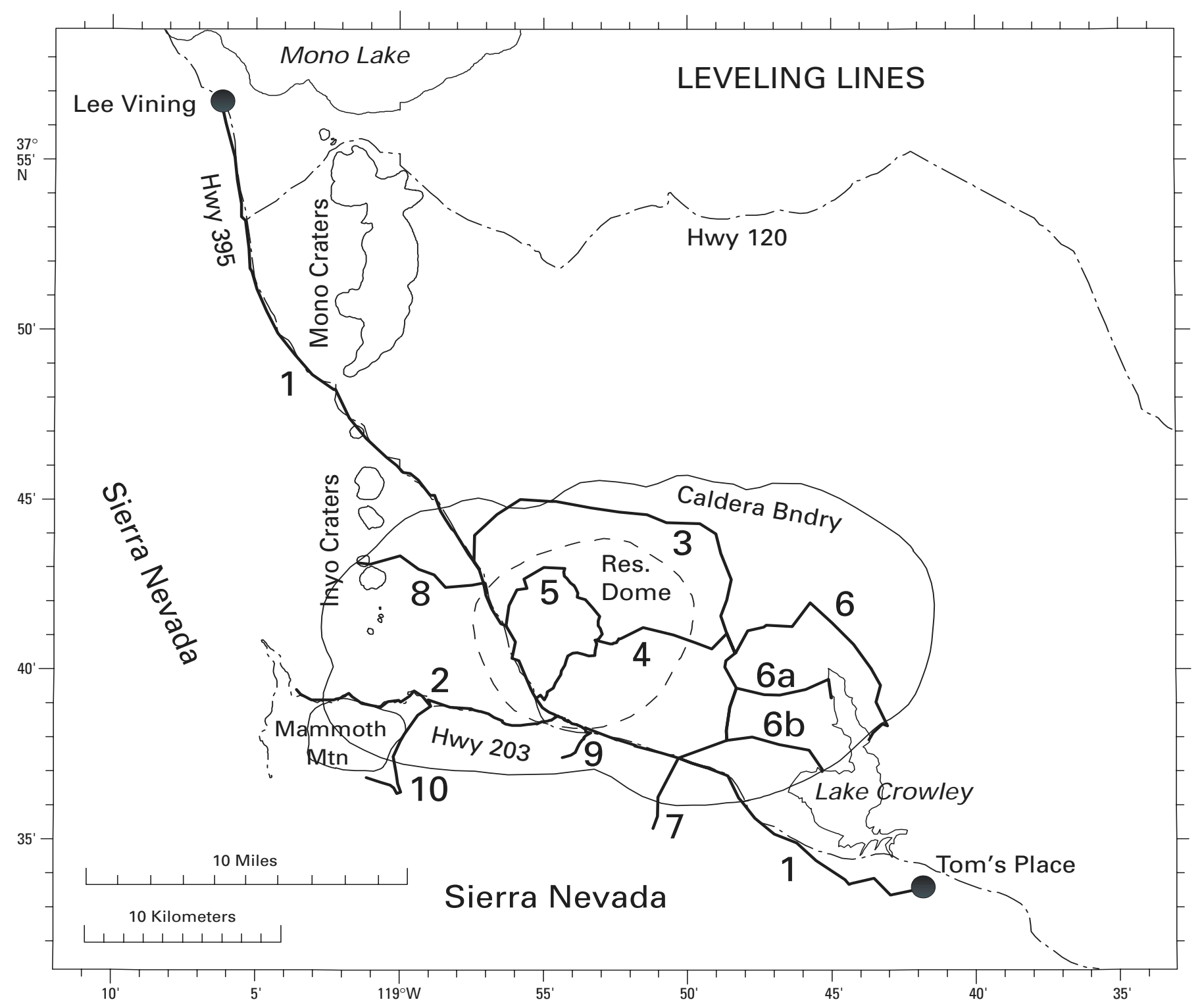

Figure D5.- Map of level lines in the Long Valley Caldera region surveyed to track vertical deformation. Numbers identify individual leveling loops following the convention used by Savage and others (1987). The circles at Lee Vining and Tom's Place indicate reference benchmarks. 
All monitoring sites have backup data loggers that also record ambient temperature. The data are sampled every hour and telemetered every 3 hours to the USGS Cascades Volcano Observatory in Vancouver, Washington, by GOES satellite. Stations HS1 and HS2 are located near the central portion of the tree-kill area near Horseshoe Lake with high $\mathrm{CO}_{2}$ concentrations, whereas HS3 is located in a group campground on the margin of the area of high $\mathrm{CO}_{2}$ concentrations. Stations located away from the Horseshoe Lake tree-kill area include SKI near Chair 19 in the Mammoth Mountain ski area, SRC in Shady Rest Campground adjacent to the U.S. Forest Service Visitors Center in Mammoth Lakes, EQF near the "Earthquake Fault" midway between Mammoth Lakes and the Ski Area, and LSP near Laurel Spring on the southern margin of the caldera.

\section{$\mathrm{CO}_{2}$-Flux Monitoring}

The rate of discharge of $\mathrm{CO}_{2}$ from areas of diffuse gas emission on Mammoth Mountain is monitored both by periodic gas-flux measurements over grids of stations established at several tree-kill areas and continuous flux measurements at a single automated instrument stationed near Horseshoe Lake during the snow-free portion of each year. The grid determinations of total flux at various treekill areas involve some 50 to 100 measurement points and contour-integration techniques applied to the measurements made over a 1 to 3 hour period. Such determinations repeated at daily intervals indicate that the total gas discharge at these areas can vary by as much as $+/-50$ percent in response to changes in atmospheric parameters such as barometric pressure and wind speed. A continuously recording flux instrument has been deployed at the Horseshoe Lake tree-kill area for portions of the past 3 years. Data from this site are transmitted by radio to a base station in Mammoth Lakes were a computer analyzes and stores flux measurements made at hourly intervals. The resultant record can be obtained remotely through telephone-modem connection.

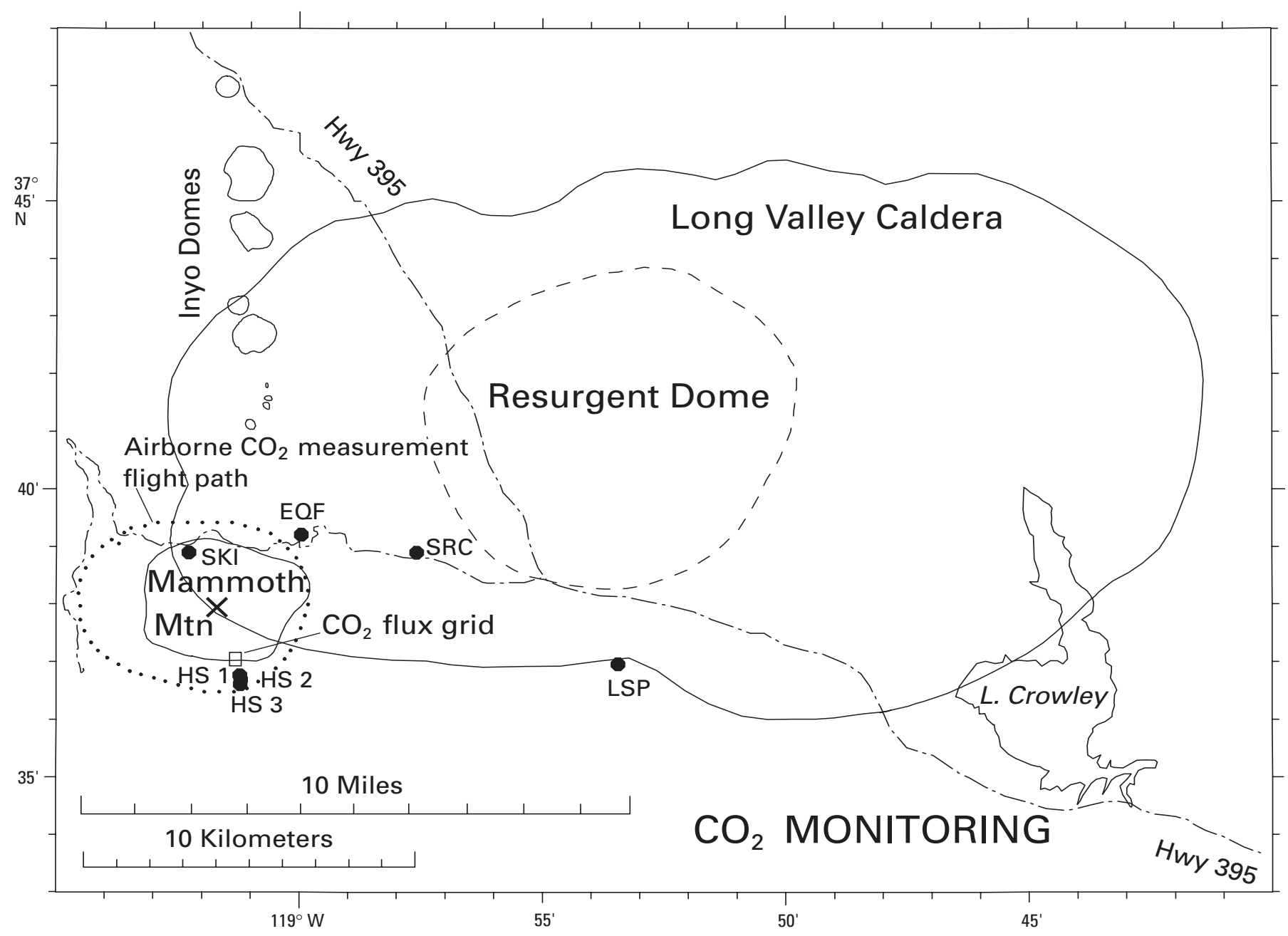

Figure D6.-Map showing stations in the Long Valley region that continuously monitor carbon dioxide $\left(\mathrm{CO}_{2}\right)$ soil-gas concentrations (circles) and a typical flight path for airborne measurements of $\mathrm{CO}_{2}$ flux from Mammoth Mountain (dashed line centered on Mammoth Mountain). Open square indicates location of grid for periodic spot measurements of $\mathrm{CO}_{2}$ flux. 

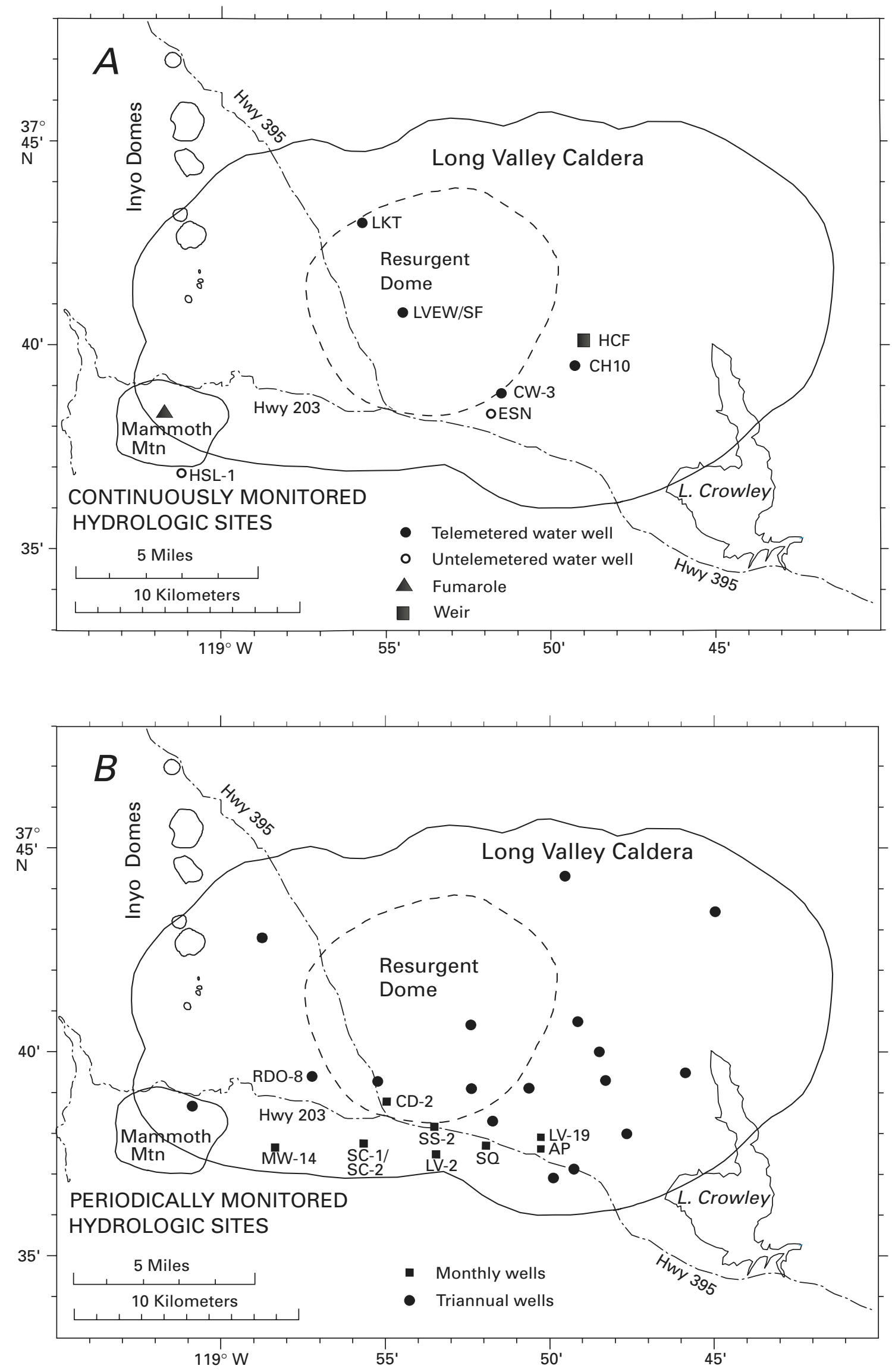

Figure D7.-Map showing locations in the Long Valley region of continuously monitored hydrological sites (A) and shallow water wells that are monitored periodically (B). 


\section{Airborne $\mathrm{CO}_{2}$ Monitoring}

Airborne $\mathrm{CO}_{2}$ surveillance is routinely carried out once or twice a year at Mammoth Mountain to establish baseline $\mathrm{CO}_{2}$ emission rates for comparison in the event of future increases in unrest. The method as applied to Mammoth Mountain is fully documented in Gerlach and others (1999). If necessary, the method can be readily adapted for unrest at other locations in the LVCMC region, such as the resurgent dome or the Mono-Inyo Craters. The Mammoth Mountain airborne surveys are accomplished by flying a series of circular orbits with diameters of 6 to $7 \mathrm{~km}$ centered about the mountain's summit (fig. D6) at altitudes ranging from 2,895 m (9,500 ft) to $3,657 \mathrm{~m}(12,000 \mathrm{ft})$ and with a vertical separation between individual orbits averaging $61 \mathrm{~m}(200 \mathrm{ft})$. The measurements are made with a nondispersive infrared (NDIR) $\mathrm{CO}_{2}$ analyzer and flow control unit interfaced with a laptop computer and chart recorder. The system is mounted in a twin-engine aircraft and configured for open-flow sampling of external air. The analyzer produces average $\mathrm{CO}_{2}$ concentrations at 1 -sec intervals. A pressure transducer produces corresponding 1-sec averages of barometric pressures of external ambient air. Outside air temperature is sampled at 1-sec intervals. Aircraft location during the survey is tracked using a GPS receiver. The concurrent data streams from all instruments are recorded in a Campbell data logger. $\mathrm{CO}_{2}$ emission rates are calculated from these data and wind velocity data. Gas emissions at Mammoth Mountain are presently free of $\mathrm{SO}_{2}$ (sulfur dioxide), but the airborne system can also accommodate correlation-spectrometer (COSPEC) instrumentation for $\mathrm{SO}_{2}$ measurements should they become necessary.

\section{Helium Isotopic Ratio in Fumarole Gas}

The helium isotopic ratio $\left({ }^{3} \mathrm{He} /{ }^{4} \mathrm{He}\right)$ in gas discharged from a fumarole on the north side of Mammoth Mountain has been shown to vary with the degree of crustal unrest in the vicinity of the mountain. Data obtained from periodic sampling of this vent, referred to as Mammoth Mountain Fumarole (MMF), during the years 1982 to 2000 show that a period marked by a significantly increased component of magmatic helium began during the summer of 1989. This increase in the ${ }^{3} \mathrm{He} /{ }^{4} \mathrm{He}$ ratio corresponded with the onset of seismic swarms beneath Mammoth Mountain in May 1989 that appear to have resulted from the emplacement of a magmatic dike. Since 1989, MMF has been sampled several times each year during site visits in which its flow rate and temperature are also determined.

\section{Hydrologic Monitoring}

A network dedicated to hydrologic monitoring in Long Valley Caldera tracks changes in ground-water levels and the discharge of hot springs (Howle and Farrar, 1996). Automated measurements of the free-surface water level in five wells (LKT, CW-3, LVEW, SF, and CH10B; fig. D7A) are recorded at least every 30 minutes and telemetered every 4 hours by GOES satellite to computers in USGS offices in Sacramento, California. Similar measurements are made in two additional wells (HSL-1 and ESN) and recorded by onsite data loggers but not telemetered. Data from these data loggers are recovered during monthly site visits. Water-levels are measured monthly in a network of nine other, mostly shallow wells (CD-2, SC-1, SC-2, AP, LV-2, LV-19, SQ, SS-2, MW-14, RDO-8) at sites throughout the caldera moat (fig. D7B); these measurements provide information on seasonal changes in water-table elevations. Another 20 wells in the caldera region are measured three times a year. The combined discharge of hot springs in Hot Creek gorge is determined monthly from measurements of the differences in chemical flux in the creek at sites both upstream and downstream from the hot springs. At the downstream site (HCF), instruments in a concrete flume continuously track streamflow, temperature, and electrical conductivity. These data are recorded every 4 hours and transmitted by GOES satellite to USGS offices in Sacramento.

The monitoring wells instrumented for automated waterlevel measurements range in depth from about 96 to 2,997 m (315 to 9,800 feet). Ground-water levels are measured using pressure transducers that are either submersed below the water surface or that measure the pressure in a gas-filled tube open below the water surface. Ground-water level data are recorded at least every 30 minutes and at a higher frequency in LKT and CW-3 if the water level changes more than 6 $\mathrm{mm}$ in 30 seconds. Any high-frequency data collected are not telemetered, but are stored on site and retrieved during monthly site visits. Atmospheric pressure is measured at CW3, CH10B, LVEW, LKT, and HSL and recorded every 30 minutes. Telemetered data are automatically processed every 24 hours at midnight and appended to plots of the previous 15 days data posted on a public USGS web page at http://lvo.wr.usgs.gov/HydroStudies.html. Each month, the previous month's data are filtered to remove the effects of atmospheric loading and earth-tide strain from the measured water levels. The measured and filtered data for the past month are plotted and posted on an internal USGS web page at http://eratos.wr.usgs.gov/lv/.

Water levels in each well respond with a unique sensitivity to atmospheric loading, earth tides, and volumeteric crustal strain. The measureable water-level responses in some wells to crustal strain make these wells potentially useful for detecting crustal deformation, although the water-level response to crustal strain is susceptible to complicating factors such as ground-water flow to or from the deformed, saturated rocks tapped by the well. Nevertheless, the wells being monitored with telemetery do show responses to caldera-scale and larger strain events. For three of these wells, LVEW, LKT, and CW-3, the effects of drainage are negligible for variations with periods as much as 14 days. For example, under undrained conditions, the expected water-level change in response to a step volume strain of $0.01 \mathrm{ppm}$ is about $24,5.5$, and $2.5 \mathrm{~mm}$, respectively in LVEW, LKT, and CW-3. Such changes are routinely measured, making these wells sensitive to the same small strain changes detected by the borehole dilatometers (Galloway and others, 1999; Rojstaczer and others, 1985). 
The streamflow data collected at HCF include stage, specific conductance, and water temperature. Data are recorded every 15 minutes and are processed and posted to the Website (http://lvo.wr.usgs.gov/HydroStudies.html) every 24 hours. The processing uses an established stage-discharge relation to convert stage to discharge. Data from this site can be used to determine if significant changes in thermal-water discharge have occurred in Hot Creek Gorge.

\section{Appendix E. Sample Messages Accom- panying Changes in Color Codes}

The LVO SIC will inform by telephone the duty officer of the California Office of Emergency Services (OES) communication center in Sacramento that a specific Color Code is in force according to the procedures outlined previously (see tables 1 and 2; section III). In the case of a condition YELLOW, ORANGE, or RED, the SIC, with concurrence of the Western Regional Geologist, will fax one of the following messages to the Director of OES. OES is responsible for relaying the message to county and city officials within twenty minutes of receipt from the USGS. After appropriate civil officials have been notified, the message will be released to the media and the public.

\section{Condition-YELLOW Message}

The U.S. Geological Survey (USGS) has initiated a field operation centered in Mammoth Lakes to closely monitor the (specify activity: earthquakes swarm activity, ground deformation, etc.) currently centered in (specify place: south moat of Long Valley Caldera, the Mono Craters, etc.) approximately ( $x$ ) miles (direction) from (nearby towns). Activity of this sort is symptomatic of magma (molten rock) movement in the crust beneath volcanic areas throughout the world. Most likely the activity will decay to normal background levels over the next few weeks or months, as has been the case with previous episodes of heightened activity in the Long Valley region. There remains a small possibility, however, that the current activity may escalate and possibly evolve toward a volcanic eruption. In such a case, USGS scientists would expect the earthquake activity and ground deformation to intensify as magma moves upward to shallow depths in the crust. The expanded USGS monitoring efforts will focus on the early identification of any changes in the activity pattern that may be diagnostic of an impending eruption. The USGS will establish direct contact with California Office of Emergency Services (OES) and local civil authorities from the temporary USGS field center in Mammoth Lakes and will keep them informed of significant changes in activity and provide an assessment of its implication for possible volcanic hazards.

\section{Condition-ORANGE Message}

The intense activity (specify type) currently centered in (specify place) indicates that a volume of magma (molten rock) is being injected into the shallow crust with a strong possibility that the magma will reach the surface to produce a volcanic eruption in the coming hours to days. It is not possible to say precisely when magma might reach the surface, nor to specify the precise size, duration, or type of the eruption should one actually develop. Indeed, it is still possible that the magma may yet stop short of the surface and not result in an eruption.

Intensified USGS monitoring efforts from a temporary field center in Mammoth Lakes (or Bridgeport) will focus on the prompt identification of any changes in the activity pattern that may help specify the time and place magma may reach the surface to produce an eruption. The USGS will maintain direct contact with California Office of Emergency Services (OES) and local civil authorities from the temporary USGS field center in and will keep them informed of significant changes in activity and provide an assessment of its implication for possible volcanic hazards.

If an eruption does develop from this activity, it will most likely produce small to moderate volumes of rhyolitic (silica rich, explosive) lava similar the eruptions that occurred 650 years ago at the north end of the Mono Craters and 550 years ago at the Inyo Domes. In this case, any or all of the following may be expected: (1) phreatic (steam blast) eruptions as the magma interacts with shallow ground water, producing explosions that can throw large blocks of rock several hundred yards from the vent (the "eruption" could stop at this point, as it did with the phreatic blasts that formed the Inyo Craters), (2) an explosive magmatic phase during which hot pumice and ash would be ejected several miles into the air producing thick pumice accumulations near the vent, extensive deposits of fine ash hundreds of miles downwind, and destructive pyroclastic flows that may reach distances as great as 3 to 6 miles from the vent, and (3) a final phase that involves the slow extrusion of lava to form steep-sided flows and domes. As with the eruptions 550 and 650 years ago, eruptions may occur from several separate vents in succession, with the vents spaced over a distance as great as 6 miles. Individual eruptions may be separated in time by days to perhaps weeks. Larger, more destructive eruptions following the same basic pattern are possible but less likely.

Also possible, but less likely, is a small to moderate eruption of basaltic (Hawaii-like) lava similar to the eruptions that produced the Red Cones several thousand years ago. In this case, the following may be expected: (1) an initial series of phreatic eruptions as described above for the silicic eruption sequence, (2) the onset of magmatic eruptions with fluid basaltic lava fountaining several hundred yards into the air from a line of vents that may extend several miles. Both 1 and 2 would scatter ash and tephra over the surrounding region and feed the beginnings of slow-moving lava flows, and (3) consolidation of lava fountaining into a few vents feeding lava flows that move downslope at speeds ranging from a few yards per hour to several miles per hour. The resulting lava flows may extend 6 miles or more from the vents depending on the vigor and duration of eruption. 


\section{Condition-RED Messages}

The specific wording for a condition-RED message will depend strongly on the actual nature, size, and location of eruptive activity. A condition-RED message should include the following elements:

- Time of the eruptive activity described in the message.

- Level under condition RED.

- Location of the eruptive activity.

- Nature and size of the eruptive activity.

- Likely impact of the eruptive activity.

- Source of additional/current information about eruption and hazards.

Condition-RED messages will be updated as frequently as needed to describe the ongoing activity and any changes in the anticipated hazardous impacts. Sample condition-RED messages are given below.

\section{Example for Eruption Onset}

A (specify intensity and type as appropriate: for example, minor phreatic, moderate effusive, strong explosive, etc.) eruption began at (specify local time) with the vent(s) centered near (specify place). The U.S. Geological Survey (USGS) has announced a condition RED, LEVEL (specify from table 2) indicating that a (specify intensity: weak, moderate, etc.) eruption is currently underway. Based on its location, type, and current intensity, the eruption can be expected to (specify expected impact on public and built infrastructure, including ash cloud hazards to aircraft, and ash fall hazards downwind). The map illustrates areas likely to be affected by eruptive activity (attach or refer to hazardzonation map and hazard assessment for the vent that is active).
The USGS will closely monitor this eruptive activity and provide frequent updates as conditions evolve. For more information, visit the USGS web site for the Long Valley Observatory at http://lvo.wr.usgs.gov or call (specify telephone number for recorded updates). It is important to recognize that volcanic eruptions can wax and wane in intensity over extended periods. Changes in style and intensity can sometimes occur abruptly with little warning.

\section{Example for Ongoing Eruption}

The following is a U.S. Geological Survey (USGS) update of the eruption at (specify place) as of (specify time). The condition is RED, LEVEL (specify level from table 2).

Specific wording for the remainder of a condition RED update message will depend strongly on the actual nature, size, and location of eruptive activity. In addition to the above, each update message must include at least the following:

- Significant changes in the nature and size of the eruptive activity.

- Changes in the likely impact of the eruptive activity.

- Location of hazard-zonation map and current hazards information (for example, web site URL's, telephone number(s) for recorded messages).

The USGS will continue to closely monitor this eruptive activity and provide frequent updates as conditions evolve. It is important to recognize that volcanic eruptions can vary in intensity over extended periods of time. Changes in the character and intensity of eruptions can sometimes occur abruptly with little warning. 


\title{
Appendix F. Memo Defining the Role of the Long Valley Observatory Scientist-in Charge Under an EVENT RESPONSE
}

\author{
United States Department of the Interior \\ GEOLOGICAL SURVEY \\ Volcano Hazards Team \\ 345 Middlefield Road - Mail Stop 977 \\ Menlo Park, CA 94025 \\ phone: 415-329-4795 FAX: 415-329-5163 \\ e-mail: hill@andreas, wr.usgs.gov
}

September 29, 1999

\begin{abstract}
MEMO
$\begin{array}{ll}\text { To: Chip Groat; Director } & \\ \text { From: } & \text { Dave Hill; Scientist in Charge, Long Valley Observatory }\end{array}$

Through: Bob Tilling: Chief Scientist, Volcano Haxands Tean

Patrick Muffler; Westepn Regional Geolggist

Pat Leaby: Chief Ceolo Rego

Subject: Updating the Long Valley caldera response pl

The existing Long Valley caldera response plan (OFR 91-270), which was published in June 1991 , is still in force. We are currently updating this response plan to incorporate a number of post-1991 developments that have an impact on specific elements in the plan. The most important of these developments include:

1) scientific advances in our understanding of restless volcanic systems based on experience gained through research and monitoring efforts on restless and erupting volcanic systems throughout the world over the past nine years,

2) the four-level color-code notification scheme for monitoring volcanic unrest in the Long Valley-Mono Craters area, which supercedes the alphabetic scheme published in OFR 91-270 and was formally adopted on 12 June 1997, and

3) recent organizational changes within the U.S. Geological Survey.
\end{abstract}

The purpose of this memo is to confirm with you the role of the Scientist-in-Charge (SIC) for the Long Valley Observatory (LVO) during a USGS EVENT RESPONSE to an escalating volcanic crisis in the Long Valley caldera area as spelled out in OFR 91-270 and in light of recent organizational changes within the USGS.

As specified in OFR 91-270, an EVENT RESPONSE entails moving the center for monitoring and communication operations from Menlo Park to our field office in Mammoth Lakes. Under these circumstances, the role of the Scientist-in-Charge for LVO is specified in the first paragraph of page 18 and the fourth paragraph (item [4] ) on page 20 of OFR 91-270.

The following, for your approval, are the updated versions to these two paragraphs proposed for inclusion with the updated Long Valley response plan. Note that the only changes involve replacing "Chief, OEVE (Office of Earthquakes, Volcanoes, and Engineering)" with "Western Regional Geologist" and "Chief Scientist (for Long Valley caldera-Mono Craters monitoring, or LVC/MC)" with "Scientist-in-Charge", respectively. In this context, "Scientist-in-Charge" means Scientist-in-Charge (SIC) of the Long Valley Observatory (LVO).

Paragraph 2, pg 18 of OFR 91-270

When activity at LVC/MC becomes sufficiently intense to prompt the declaration of EVENT RESPONSE conditions by the Western Regional Geologist, the Scientist-in-Charge (SIC) initiates establishment of a field center and ensures that all relevant monitoring, hazards, and support personnel are rapidly mobilized and dispached to that field center. Under these Event Response Conditions, the SIC has full authority to direct all USGS personnel engaged in the response, wherever physically or organizationally located, and to call upon the resources of all USGS units assigned to and necessary for monitoring, hazards assessment, and support activities (see Response and General Operational Procedures below).

Paragraph 4, pg 20 of OFR 91-270 (Item [4] under Response and General Operational Procedures)

[4] Assignment of EVENT RESPONSE Personnel: Either in advance of or upon diclaration of EVENT RESPONSE Conditions, the Western Regional Geologist or the Scientist-in-Charge (of LVO), will make arrangements for the assignment of appropriate personnel and other resources from all USGS units. Once these resources are secured, the SIC has the full authority for assignment of LVC/MC EVENT RESPONSE personnel. Normally, his or her requests for personnel or equipment will be discussed with and relayed through the appropriate supervisor, who must make every effort to supply the resources requested. In the event that a supervisor is not available, the SIC may contact and assign individuals directly. Should the LVC/MC EVENT RESPONSE situation occur simultaneously with heightened activity elsewhere, conflicting demands for personnel and resource will be resolved, if necessary, by the Western Regional Geologist. Once assigned to a LVC/MC EVENT RESPONSE Team, all personnel and equipment fall under the authority of the EVENT RESPONSE structure until released by the SIC or the Volcano Hazards Team Chief Scientist.

Approved

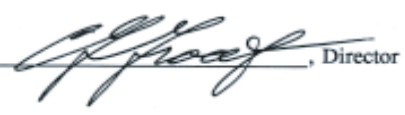

c. Andrea Alpine, Acting Regional Director

Marianne Guffanti, Coordinator, Volcano Hazards Program 
Summary of Color-Code Conditions and associated U.S. Geological Survey (USGS) responses for volcanic unrest in Long Valley Caldera and the Mono-Inyo Craters region.

\begin{tabular}{|c|c|c|c|}
\hline CONDITION & USGS RESPONSE $^{1}$ & ACTIVITY LEVEL & RECURRENCE INTERVALS ${ }^{2}$ \\
\hline \multirow{4}{*}{$\begin{array}{l}\text { GREEN - No } \\
\text { immediate risk }\end{array}$} & \multirow{4}{*}{$\begin{array}{l}\text { Normal operations plus } \\
\text { information calls to } \\
\text { local and other } \\
\text { authorities for weak } \\
\text { through strong unrest as } \\
\text { appropriate }\end{array}$} & Background or quiescence & Most of the time \\
\hline & & Weak Unrest & Days to weeks \\
\hline & & Minor Unrest & Weeks to months \\
\hline & & Moderate-to-Strong Unrest & Months to vears \\
\hline & & & \\
\hline $\begin{array}{l}\text { YELLOW } \\
\text { (WATCH) }\end{array}$ & $\begin{array}{l}\text { Full calldown and } \\
\text { EVENT RESPONSE }\end{array}$ & Intense Unrest & Years to decades \\
\hline $\begin{array}{l}\text { ORANGE } \\
\text { (WARNING) }\end{array}$ & $\begin{array}{l}\text { Full calldown and } \\
\text { EVENT RESPONSE } \\
\text { (if not already in place } \\
\text { under YELLOW) }\end{array}$ & $\begin{array}{l}\text { Accelerating intense unrest: } \\
\text { eruption likely within hours } \\
\text { to days }\end{array}$ & Decades to centuries \\
\hline \multirow{4}{*}{$\begin{array}{l}\text { RED (ERUPTION } \\
\text { IN PROGRESS) }\end{array}$} & \multirow{4}{*}{$\begin{array}{l}\text { Full calldown and } \\
\text { EVENT RESPONSE } \\
\text { (if not already in place } \\
\text { under YELLOW or } \\
\text { ORANGE) } \\
\text { Daily or more frequent } \\
\text { updates on eruption } \\
\text { levels }\end{array}$} & LEVEL 1: Minor eruption & Centuries \\
\hline & & $\begin{array}{l}\text { LEVEL 2: Moderate } \\
\text { explosive eruption }\end{array}$ & Centuries \\
\hline & & $\begin{array}{l}\text { LEVEL 3: Strong explosive } \\
\text { eruption }\end{array}$ & Centuries \\
\hline & & $\begin{array}{l}\text { LEVEL 4: Massive } \\
\text { explosive eruption }\end{array}$ & Centuries to millennia \\
\hline
\end{tabular}

${ }_{2}^{1}$ USGS response for a given condition will include the responses specified for all lower conditions.

${ }^{2}$ Estimated recurrence intervals for a given condition are based primarily on the recurrence of episodes of unrest in Long Valley Caldera since 1980 , the record of $\mathrm{M}>4$ earthquake activity in the region since the 1930's, and the geologic record of volcanic eruptions in the region over the past 5,000 years. 